\title{
Un visage original du Tardiglaciaire en Bretagne : les occupations aziliennes dans l'abri-sous-roche de Kerbizien à Huelgoat
}

An original settlement during the Tardiglacial in Brittany: the rock shelter of Kerbizien in Huelgoat

Grégor Marchand, Jean-Laurent Monnier, François Pustoc'h et Laurent Quesnel

\section{OpenEdition}

Journals

Édition électronique

URL : http://journals.openedition.org/paleo/2761

DOI : $10.4000 /$ paleo.2761

ISSN : $2101-0420$

Éditeur

SAMRA

Édition imprimée

Date de publication : 28 décembre 2014

Pagination : 125-168

ISSN : $1145-3370$

Référence électronique

Grégor Marchand, Jean-Laurent Monnier, François Pustoc'h et Laurent Quesnel, « Un visage original du Tardiglaciaire en Bretagne : les occupations aziliennes dans l'abri-sous-roche de Kerbizien à

Huelgoat », PALEO [En ligne], 25 | 2014, mis en ligne le 20 août 2015, consulté le 07 juillet 2020. URL : http://journals.openedition.org/paleo/2761 ; DOI : https://doi.org/10.4000/paleo.2761

\section{(c) (†) $\ominus$}

PALEO est mis à disposition selon les termes de la licence Creative Commons Attribution - Pas d'Utilisation Commerciale - Pas de Modification 4.0 International 


\title{
Un visage original du Tardiglaciaire en Bretagne : les occupations aziliennes dans l'abri-sous-roche de Kerbizien à Huelgoat
}

\author{
Grégor MARCHAND ${ }^{(1)}$, Jean-Laurent MONNIER(1), \\ François PUSTOC'H ${ }^{(1)}$, Laurent QUESNEL ${ }^{(1)}$
}

\begin{abstract}
Résumé : L'abri-sous-roche de Kerbizien sur la commune de Huelgoat (Finistère) s'ouvre dans un énorme bloc granitique installé en sommet de coteau. II mesure 9,50 m à l'ouverture pour environ 5,50 $\mathrm{m}$ de profondeur, avec une hauteur sous plafond de $2,80 \mathrm{~m}$ depuis le socle rocheux et une surface habitable d'environ $16 \mathrm{~m}^{2}$. Son remplissage sédimentaire a été presque intégralement détruit au début des années 1980, mais un tamisage des déblais et un sondage dans la cavité avaient permis à J.-M. Moullec de décrire avec précision les différentes composantes chronoculturelles présentes, Paléolithique final, Mésolithique et Moyen-Âge. La fouille réalisée en juillet 2011 a permis d'identifier des niveaux en place du Tardiglaciaire (Azilien) au fond de la caverne. Ils formaient une bande de deux mètres de large le long de la paroi et étaient constitués d'un mélange de limons et de sables granitiques issus de l'érosion des parois. La totalité du site a été fouillée, à l'exception d'un bourrelet limoneux au sud-ouest du bloc dont la partie supérieure comprend des occupations aux vestiges indémêlables. Quelques charbons ont été recueillis dans les US 4 et 5 , mais ils sont rares et donc sujets à caution ; une datation par le radiocarbone l'a d'ailleurs confirmé. Le mobilier archéologique recueilli lors de la fouille comprend des roches taillées à destination de l'outillage (principalement silex, mais aussi grès éocène, microquartzite, cataclasite et calcédoine), de petites plaquettes de schiste et trois gros blocs de granite taillés sommairement. Parmi les 1313 objets archéologiques issus de la fouille et du tamisage, $20 \%$ proviennent des unités stratigraphiques tardiglaciaires en place. Pointes à dos courbes, grandes lames très utilisés et chutes de burin composent un assemblage aisément comparable à l'Azilien dans une phase ancienne, très rare dans le nord-ouest de la France. Sa signature fonctionnelle est originale et serait tout à fait compatible avec l'hypothèse d'une station logistique (i.e. halte de chasse) de groupes très mobiles. Leur connaissance des ressources géologiques locales est un élément important à garder en mémoire, qui démontre que les parcours étaient réguliers dans cette partie occidentale de la région, dénuée de silex en position primaire.
\end{abstract}

Mots-clés : abri-sous-roche, Azilien, Bretagne, France, Mésolithique, Tardiglaciaire, technologie lithique.

Abstract: An original settlement during the Tardiglacial in Brittany: the rock shelter of Kerbizien in Huelgoat. The Kerbizien rock shelter on the commune of Huelgoat (Finistere) opens in an enormous granitic block installed in top of slope. It measures $9.50 \mathrm{~m}$ with the opening for approximately $5.50 \mathrm{~m}$ of depth, with a height under ceiling of $2.80 \mathrm{~m}$ from the rock base. The liveable space is approximately $11 \mathrm{~m}^{2}$. Its sedimentary filling was almost completely destroyed at the beginning of the years 1980, but a survey in the cavity allowed J.-M. Moullec to describe with precision various cultural components (Final Palaeolithic, Mesolithic and the middle Ages). The excavation carried out in July 2011 made it possible to identify Tardiglacial levels (Azilian) at the bottom of the cave in a two meters broad band along the wall. This level consisted of a mixture of silts and granitic sands resulting from the erosion of the monolithic block. Some charcoals were collected in the US 4 and 5, but they are quite rare and thus questionable as a radiocarbon date confirmed it. The archaeological materials collected during the excavation are lithic tools (mainly flint, but also Eocene sandstone, microquartzite, cataclasite and chalcedony), small pieces of schist and three large summarily worked granite blocks.

(1) UMR 6566 du CNRS - CREAAH, Laboratoire Archéosciences, Bâtiment 24-25, Université de Rennes 1, CS74205 - FR-35042 Rennes Cedex - gregor.marchand@univ-rennes1.fr 
Among the 1313 lithic pieces, $20 \%$ come from the homogeneous Tardiglacial stratigraphical units. Curved backed points, large blades very used and falls of graver compose an industry easily comparable with Azilian in an old phase. It is very rare in the North-West of France. Its functional signature is original and would be completely compatible with the assumption of a logistical station (i.e. field camp) of very mobile human groups. Their knowledge of the local geological resources is a significant component to be kept in memory, which shows that the courses were regular in this area.

Key-words: Rock shelter, Azilian, Brittany, France, Mesolithic, Tardiglacial, Lithic Technology.

\section{1 - Le Tardiglaciaire dans le nord-ouest de la France}

Une grotte fouillée au XIXe siècle (Roc'h Toul), quelques pointes aziliennes éparses sur le territoire : le Paléolithique final du nord-ouest de la France a longtemps été plongé dans une grande pénombre (Monnier 1980). Tour à tour pouvaient être invoqués des contextes sédimentaires peu développés et donc moins favorables qu'ailleurs à la préservation des niveaux de la fin du Pléistocène, une méconnaissance des industries lithiques afférentes par les acteurs de l'archéologie ou encore l'absence de programme de recherche adapté. En 1999, la fouille préventive sur le site azilien récent des Chaloignes (Mozésur-Louet, Maine-et-Loire), au sud d'Angers, venait exhiber le potentiel que l'on pouvait attendre de certains vallons, même si les sols acides du Massif armoricain n'autorisaient pas la préservation des ossements et limitaient donc les interprétations paléo-économiques (Marchand et al. 2008, 2009, 2011a). La cinquantaine de sites inventoriés par la suite dans le nord-ouest de la France contribua à asseoir davantage ce groupe culturel dans l'espace (Marchand et al. 2004), mais sans aucune datation radiométrique pour organiser les assemblages (fig. 1). Par analogie typologique, on pouvait sans grand risque placer ces sites aziliens dans l'Alleröd, plus particulièrement dans une phase récente à monopointes. Les analyses technologiques des industries lithiques ultérieures, réalisées notamment sur les sites de référence du Camp d'Auvours dans la Sarthe et de la Fosse en Mayenne, ont montré d'autres dynamiques économiques probablement contemporaines du Dryas récent ou du début du Préboréal (Naudinot 2010, 2013). La transition vers le Mésolithique s'enrichit donc de nouvelles étapes, dans un processus bien intégré à ceux des régions voisines, mais les étapes initiales, marquées dans le reste de la France par une phase à bipointes, sont encore à documenter.

Malgré ces limites chronologiques et sédimentaires, cette émersion progressive des connaissances de la fin du Pléistocène sur le Massif armoricain accompagne une prise de conscience de deux contraintes géographiques qui eurent une influence déterminante sur l'organisation économique et les comportements préhistoriques. En premier lieu, l'absence de silex dans les formations géologiques a toujours entraîné dans la Préhistoire régionale un recours aux galets de silex glanés sur les plages ou bien une importation de fort loin, dont le coût s'accroissait à mesure que l'on progressait vers l'ouest de la péninsule. Cette exigence a pesé à toutes les époques sur la dimension des produits obtenus et sur la productivité des blocs, tandis que l'adoption de certaines roches du substrat incita à des adaptations des méthodes de débitage. Les choix des populations impliquées ont eu des effets directs sur les systèmes techniques et révèlent beaucoup de leurs valeurs, de l'organisation du travail ou encore de leurs réseaux sociaux (Marchand 2012, 2014). Quelles furent alors les options adoptées au Tardiglaciaire ? Et que nous disent-elles des sociétés de l'époque?

En second lieu, la dimension océanique pèse sur ces régions, même si elle reste difficile à prendre en compte au Paléolithique supérieur à cause de la submersion de la bande littorale lors de la transgression marine. Avec des niveaux marins inférieurs de plus de soixante mètres sous l'actuel durant l'Alleröd, les littoraux tardiglaciaires étaient éloignés de 10 à $15 \mathrm{~km}$ des côtes actuelles. La péninsule armoricaine se dessinait déjà, fermant au sud un immense estuaire qui drainait notamment le Rhin, la Seine, la Somme et la Tamise, et qui est connue comme la « Paléo-Manche ». On est en droit de supposer que ses rivages étaient des espaces convoités, car l'ethnographie a justement montré toute la prodigalité de certaines économies de prédations maritimes (Yesner 1980 ; Kelly 2007). Pour la Bretagne, l'acquisition préférentielle de galets côtiers pour fabriquer les outillages en pierre fait apparaître en négatif cette zone aujourd'hui submergée, comme un rappel permanent de son importance. Autre conséquence d'une implantation en péninsule, les interactions avec des communautés voisines sont nécessairement plus réduites que dans une zone continentale, engendrant ainsi de possibles spécificités stylistiques.

La fouille d'un niveau azilien ancien au fond de l'abri-sousroche de Kerbizien, sur la commune de Huelgoat (Finistère), à l'ouest de la péninsule armoricaine, participe de ce renouvellement des connaissances. Elle apporte une signature fonctionnelle fort originale qui provoque des échos dans les réflexions paléo-économiques actuellement développées dans la région.

\section{2 - L'abri-sous-roche de Kerbizien}

\section{1 - Une cavité dans les chaos granitiques de Huelgoat}

L'abri-sous-roche de Kerbizien est installé dans la partie orientale du massif de granite de Huelgoat (Finistère) bien 


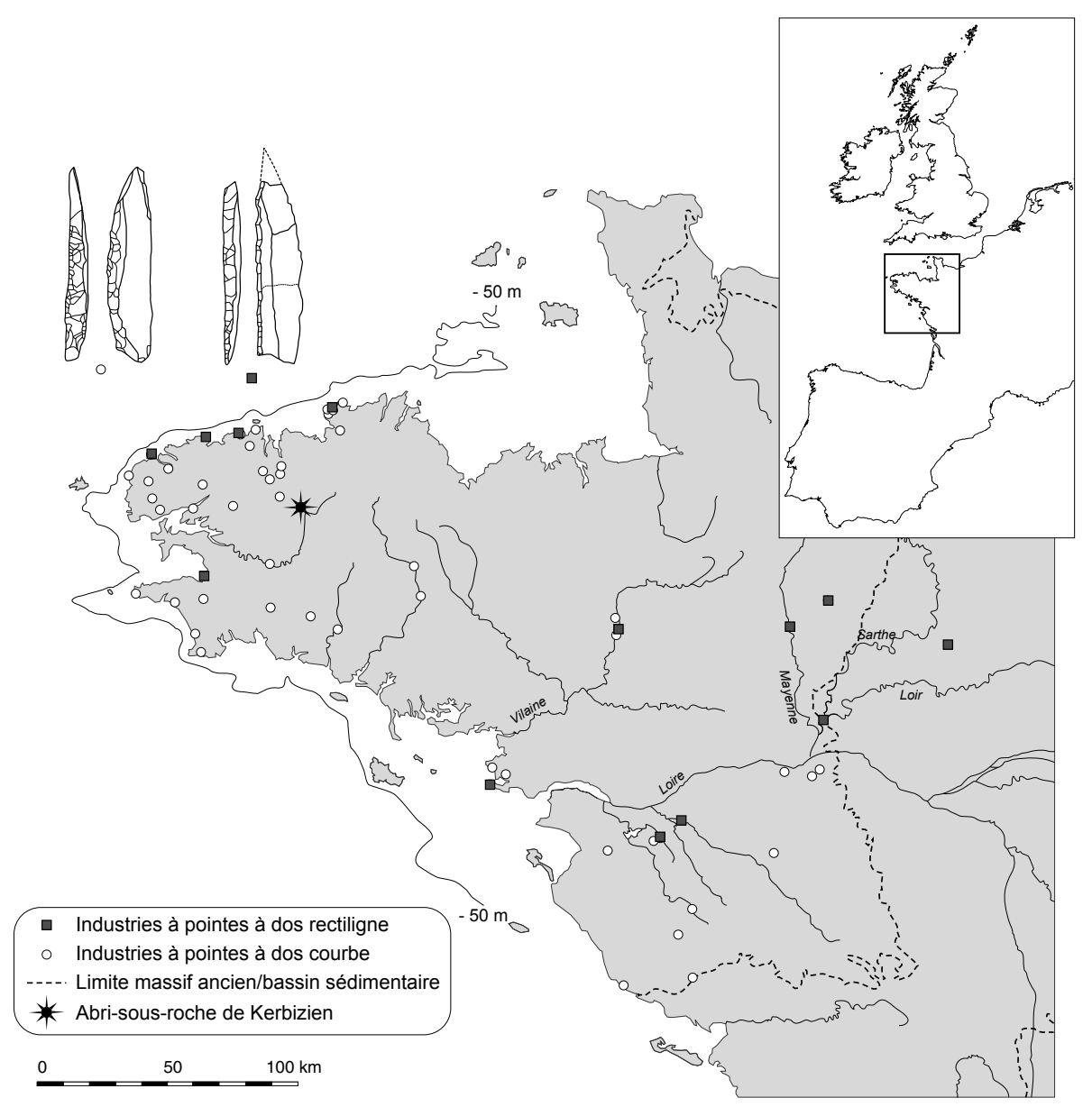

Figure 1 - Répartition des sites aziliens (pointes à dos courbe) et post-aziliens (pointes à dos rectiligne) sur le Massif armoricain. L'abri de Kerbizien est signalé par une étoile noire (DAO : G. Marchand).

Figure 1 - Location of the azilian sites (Curve Backed Points) and postazilian sites (Straight Backed Points) on the Armorican Massif. The black star corresponds to the Kerbizien rock shelter (CAD: G. Marchand). connu pour les chaos que son érosion engendre lorsque les arènes ont été érodées. Ils ont représenté une entrave à la circulation humaine sur les pentes et surtout au fond des vallées, où les rivières courent sous les amas gigantesques de boules de granite. Ils constituaient assurément des abris favorables, hélas très dégradés par l'action des carriers des $\mathrm{XIX}^{\circ}$ et $\mathrm{XX} \mathrm{X}^{\circ}$ siècles. Cette partie orientale des Monts d'Arrée est une zone élevée (entre 200 et $380 \mathrm{~m}$ ) et le climat océanique lui confère aujourd'hui une très forte humidité ; la pluviométrie annuelle y est de $1400 \mathrm{~mm}$ contre $700 \mathrm{~mm}$ sur le littoral nord. La courbe bathymétrique des $-50 \mathrm{~m}$ sur les cartes marines est à $45 \mathrm{~km}$ au nord, $75 \mathrm{~km}$ vers le sud et $80 \mathrm{~km}$ à l'ouest : le littoral septentrional est donc le plus proche, même si l'abri-sousroche de Kerbizien s'inscrit en amont dans le bassin versant de l'Aulne, fleuve principal du Centre-Bretagne qui coule vers l'ouest. Les chasseurs de la Préhistoire récente ont donc investi une zone collinéenne aux caractères très originaux, élevée, humide et encombrée de blocs granitiques énormes. Évaluée à l'aune de la configuration géographique de la Bretagne, elle est très éloignée de l'océan, mais aussi des gisements de roches taillables, tant les galets de silex côtiers que les roches locales (grès éocènes, cataclasites, ultramylonites, phtanites, calcédoines, microquartzites).

Le site de Kerbizien se trouve à $1850 \mathrm{~m}$ au nord-ouest de l'église de Huelgoat (Finistère), sur le versant sud-ouest d'une colline de $231 \mathrm{~m}$ d'altitude, à hauteur de la courbe des 190 m NGF (fig. 2). Le site borde un petit thalweg très peu imprimé qui naît à cet endroit et qui n'apparaît pas clairement sur les cartes de l'IGN non plus que sur les photographies aériennes. D'axe nord - sud, il est trop pentu et trop court $(180 \mathrm{~m}$ ) pour recueillir un cours d'eau pérenne, mais il offre un couloir de circulation des plus naturels vers le « ruisseau des carrières » qui court en contrebas (altitude de 180 m NGF). Ouvert vers l'ouest avec un surplomb plus petit au sud-ouest, l'abri de Kerbizien est particulièrement impressionnant par son aspect monolithique (fig. 3, 4 et 5). La cavité est creusée aux dépens d'un énorme bloc de granite haut de 6,77 $\mathrm{m}$ depuis le sol actuel. Ce bloc est long de 19,40 m (axe nord-sud) pour 18,20 m de large (axe estouest) ; il sert aujourd'hui de limite parcellaire, inséré dans un gros talus de pierre. L'abri-sous-roche mesure 9,50 m à l'ouverture pour environ $5,50 \mathrm{~m}$ de profondeur (fig. 6,7 et 8). II ne s'agit évidemment pas d'une cavité karstique soumise à des phénomènes de sous-tirage et le sommet du remplissage de l'abri est plat, de même que le socle rocheux, sans dénivelé marqué entre l'intérieur et l'extérieur. À l'entrée, la hauteur sous plafond est aujourd'hui de 2,80 m depuis le socle rocheux. La paroi ne s'incline nettement que vers le fond, ce qui lui assure une bonne habitabilité : à un mètre du fond, le plafond est encore à 1,40 m. À l'Azilien, il en allait sensiblement de même, le niveau de circulation surmontant de seulement 
$20 \mathrm{~cm}$ le substrat rocheux. Quatre gros blocs d'environ deux mètres de longueur chacun occupent le nord de la cavité (blocs 1, 2, 3 et 6) ; ils amputent d'environ $11 \mathrm{~m}^{2}$ la surface totale. II ne reste qu'un faible espace entre leur sommet et le plafond (par exemple $12 \mathrm{~cm}$ au-dessus du bloc 2 ou $35 \mathrm{~cm}$ au-dessus du bloc 6 ). Malgré ces rochers qui condamnent l'occupation de la partie nord de l'abri, un individu debout dispose encore de $16 \mathrm{~m}^{2}$ de couverture rocheuse au centre de l'abri et devant les blocs du nord, tandis que $4 \mathrm{~m}^{2}$ supplémentaires s'offrent encore à lui vers le fond, s'il accepte cependant d'être légèrement courbé.

Au sud de l'abri immédiatement devant le surplomb, deux gros blocs posés à plat occupent l'espace sur une douzaine de mètres carrés environ. Le plus important (bloc 4) est long de 3,50 m pour $2,50 \mathrm{~m}$ de large et $1,00 \mathrm{~m}$ d'épaisseur depuis le sol actuel, avec une face supérieure plane qui en fait un espace très confortable pour s'y installer devant l'abri. On imagine sans peine une zone de travail qui prodigue une meilleure restitution calorique que le sol nu. II a été débité à son extrémité nord, comme en témoigne sa brisure nette, les traces de débitage très érodées et la fosse creusée à cet endroit pour bien le dégager. II est difficile d'en restituer précisément la forme originelle mais il ne pouvait pas dépasser deux mètres de longueur supplémentaire car il n'atteignait pas les carrés de la bande $L$ et il ne bloquait donc pas l'entrée de la cavité. Des traces plus récentes de débitage (trois encoches pour des coins de bois) sont également présentes en partie ouest du bloc, mais l'arrachement du rocher n'a pas eu lieu. Le bloc 5 est de même longueur que le précédent, mais il est large d'un mètre seulement. Engagé à moitié sous le surplomb, il rend à cet endroit la surface inhabitable, contrairement au précédent. A l'ouest du bloc 4, l'épandage d'une partie du remplissage de l'abri-sous-roche au cours des années 1980 forme un bourrelet de déblais très perceptible.

Un espace d'environ $4 \mathrm{~m}^{2}$ est également protégé et aisément accessible au sud du bloc monolithique de l'abri, à hauteur des bandes $\mathrm{F}$ et $\mathrm{G}$, quoiqu'il ne dépasse pas un mètre sous plafond et qu'il soit très étroit (un peu plus d'un mètre). Le terrain à cet endroit est plus élevé qu'ailleurs, car il n'a pas été bouleversé par les travaux. Cette petite éminence correspond à un bourrelet lœssique qui s'est accumulé au sud du bloc principal, probablement lorsque soufflaient des vents du nord de l'ère glaciaire. Ces sédiments éoliens ont été bloqués à environ cinq mètres au sud par un autre bloc granitique de plus de $10 \mathrm{~m}$ de long, peu élevé au-dessus du sol actuel (fig. 6). Malgré son étroitesse, cette zone abritée fut le siège d'occupations

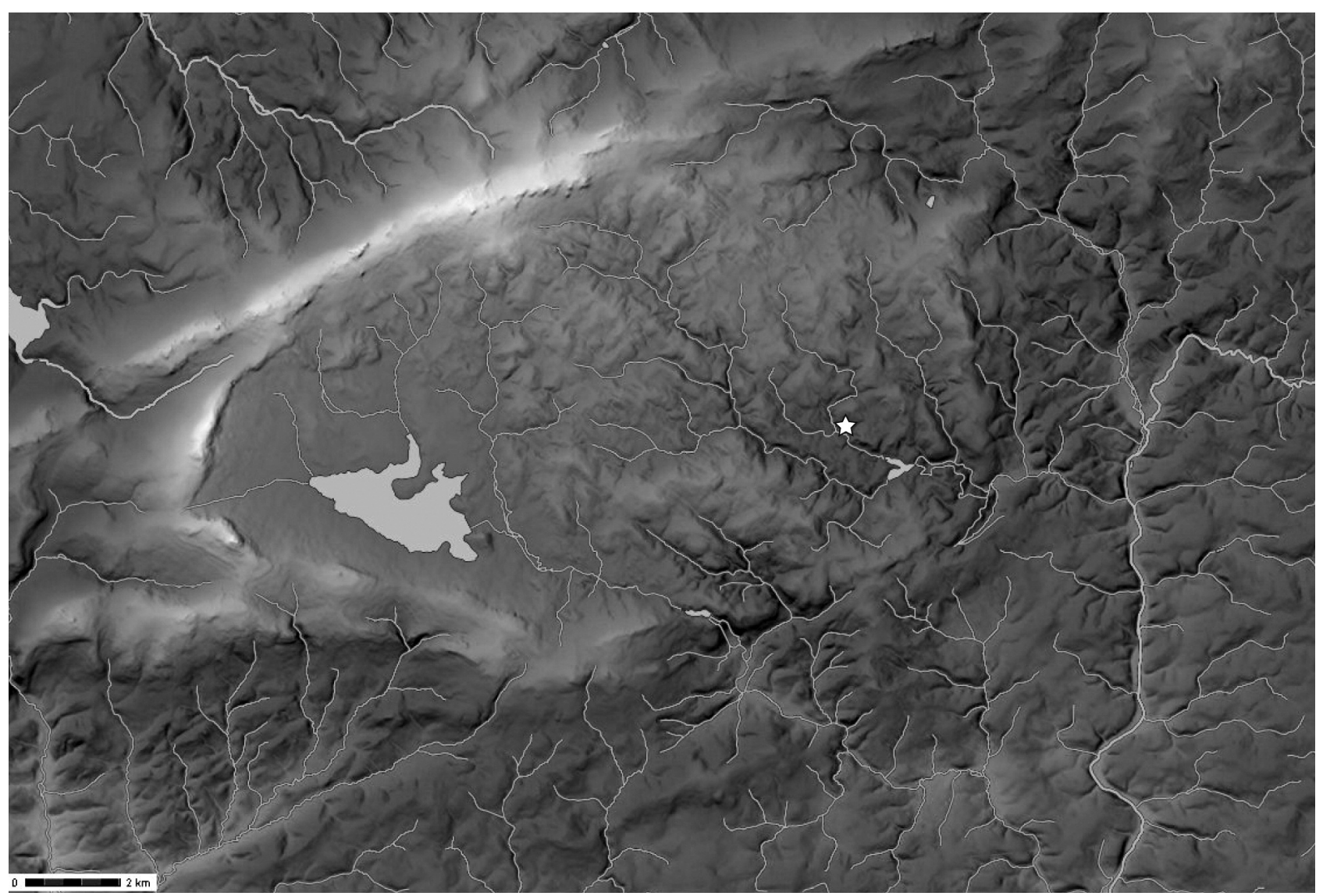

Figure 2 - Position de l'abri de Kerbizien à l'est des Monts d'Arrée (étoile blanche) (fonds de carte : IGN géoportail).

Figure 2 - Location of the Kerbizien rock shelter in the eastern Arrée Mountains (map: IGN géoportail). 


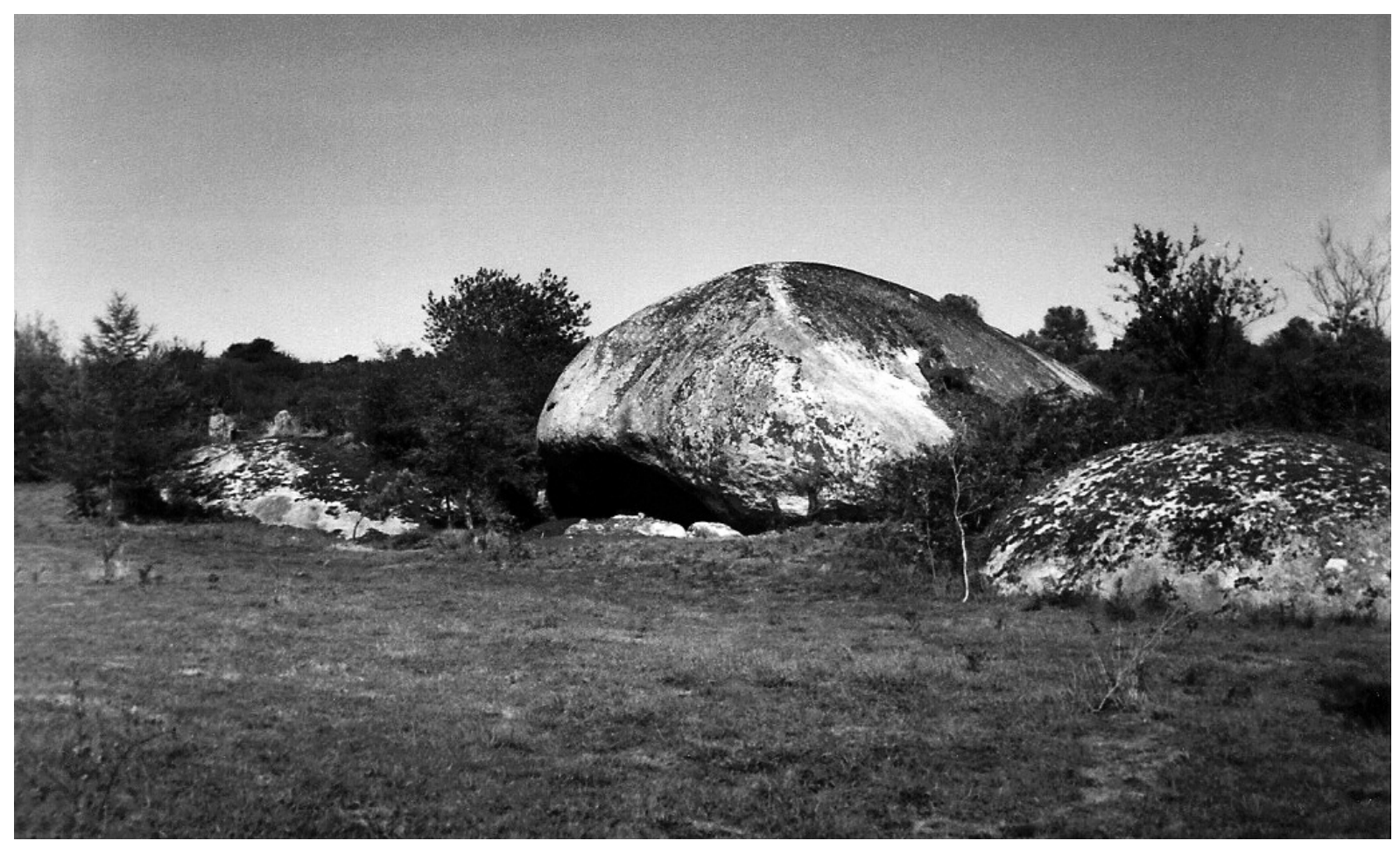

Figure 3 - Vue de l'abri-sous-roche de Kerbizien (Huelgoat, Finistère) depuis le sud-ouest au début des années 1980, avant la destruction partielle de son remplissage et le développement des arbres (cliché originel de A.-M. Mazurier, travaillé par F. Bertin).

Figure 3 - The Kerbizien rock shelter during the years 1980 before the partial destruction of the prehistoric layers (Picture: A.-M. Mazurier, reworked by F. Bertin).

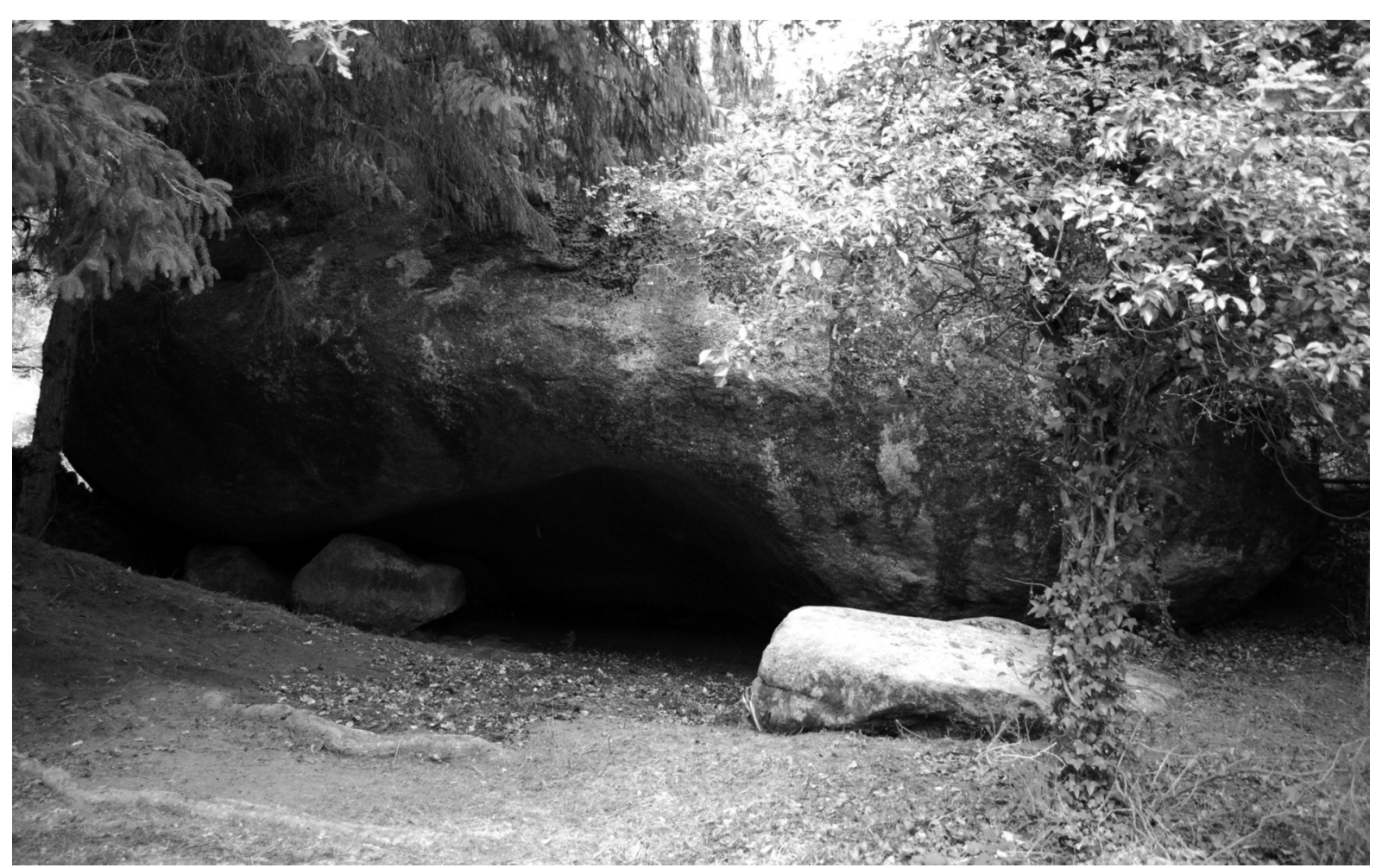

Figure 4 - Vue de l'abri-sous-roche de Kerbizien depuis l'ouest à l'issue du rebouchage en juillet 2011 (cliché G. Marchand).

Figure 4 - The Kerbizien rock shelter viewed from the west after the 2011 excavation (Picture: G. Marchand). 


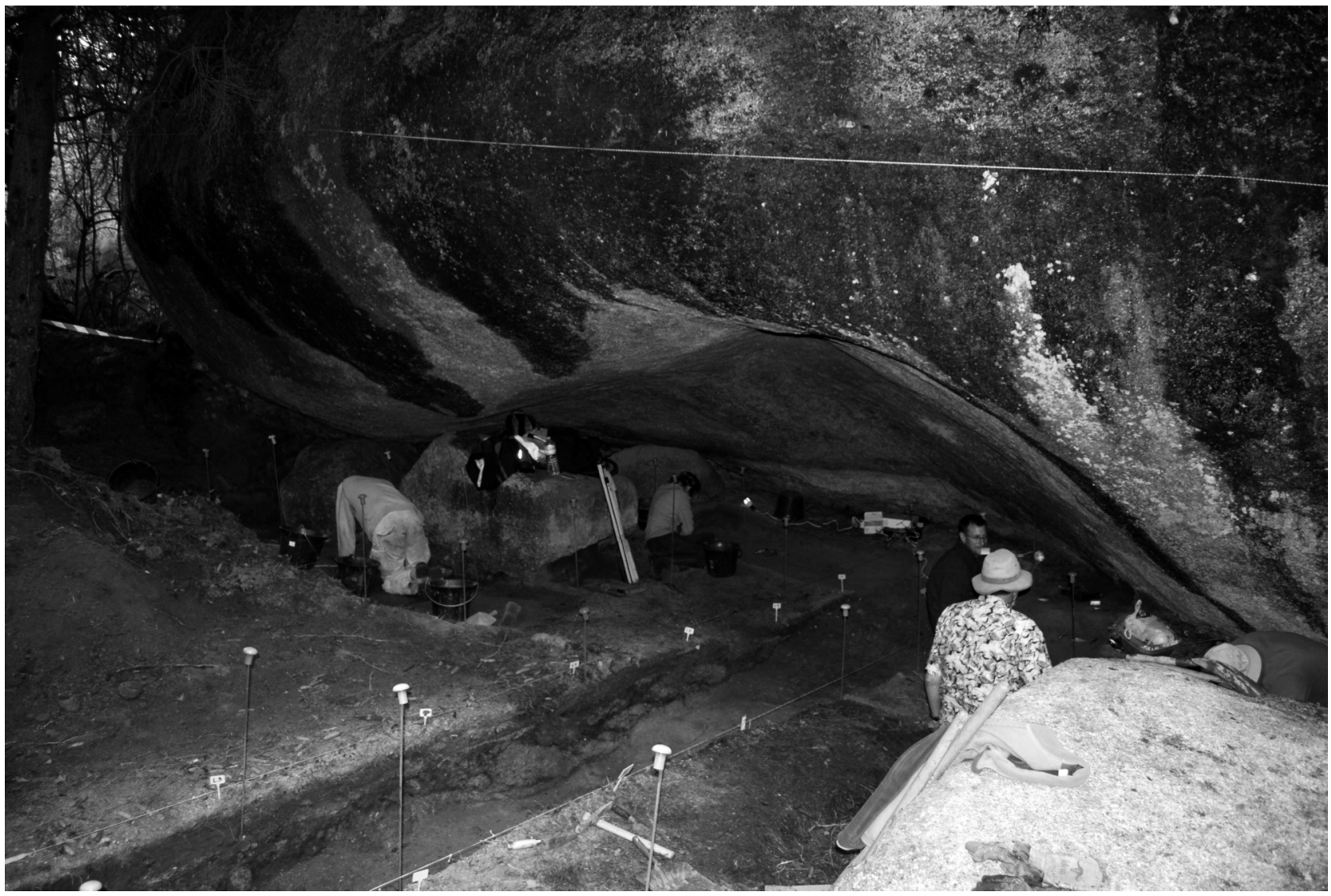

Figure 5 - La caverne de Kerbizien en cours de fouille vue depuis le sud-ouest. Les niveaux lœssiques altérés apparaissent nettement dans la coupe nord de la tranchée $L$ par leur couleur jaune marbrée de veines de rouille. Leur troncature radicale par le bulldozer est également manifeste en sommet (cliché : G. Marchand).

Figure 5 - The Kerbizien rock shelter viewed from the southwest. The loess altered levels appear significantly in the north of the section. The radical truncation of these levels by the mechanical scrapping is also evident in the top of the trench (Picture: G. Marchand).

aziliennes et mésolithiques hélas mêlées dans le sol actuel, avec un mobilier lithique relativement peu dense toutefois.

Le très beau volume habitable de cette cavité et sa nature monolithique en font un lieu d'habitat assez exceptionnel à l'échelle locale (fig. 8) : nos nombreuses visites dans les chaos alentours - certes tous très amputés par les carriers ne nous en ont pas révélé de similaire. Sa position élevée dans le paysage et son ouverture à l'ouest furent aussi probablement des paramètres importants dans les choix d'implantation, tandis que l'éloignement du cours d'eau devait être une contrainte qui visiblement a été contournée.

\section{2 - Destruction et sauvetage partiel dans les années 1980}

Kerbizien est entré dans la sphère de la connaissance archéologique grâce à Jean-Michel Moullec, qui est intervenu au début des années 1980 pour stopper la destruction du remplissage de la cavité. Le remplissage de l'abri avait été largement entamé au bulldozer et son contenu répandu sur le terrain environnant afin d'aplanir l'ensemble et de bien dégager le surplomb dans une optique paysagère. J.-M. Moullec remarqua dans les déblais du jardin une forte abondance de matériel lithique taillé, pour l'essentiel d'âge mésolithique, de même que de nombreuses scories. Un sondage de sauvetage fut réalisé par ce chercheur en 1984 après avis favorable du Service régional de l'archéologie, puis une nouvelle campagne de tamisage des déblais en 1985 (Moullec 1984, 1985). À cette occasion, dans un petit carré de $50 \mathrm{~cm}$ de côté implanté le long de la paroi du fond (à hauteur de nos carrés L3 et K3), il a pu détecter un niveau arénacé visiblement intact et il suggéra à l'époque de considérer le gisement comme partiellement préservé, sans que cette recommandation ne percole particulièrement dans la communauté archéologique où le remplissage fut considéré comme irrémédiablement détruit. Ces rapports très complets n'ont jamais été exploités en publication. À l'instar de l'abri-sous-roche de Pont-Glas à PlounéourMénez (Finistère ; Le Goffic 1990 ; Marchand et Le Goffic 2009 ; Marchand et al. 2011b), Kerbizien est devenu le parangon des habitats mésolithiques en abri-sous-roche en Bretagne (Gouletquer et al. 1996, 1997), tout en étant un 


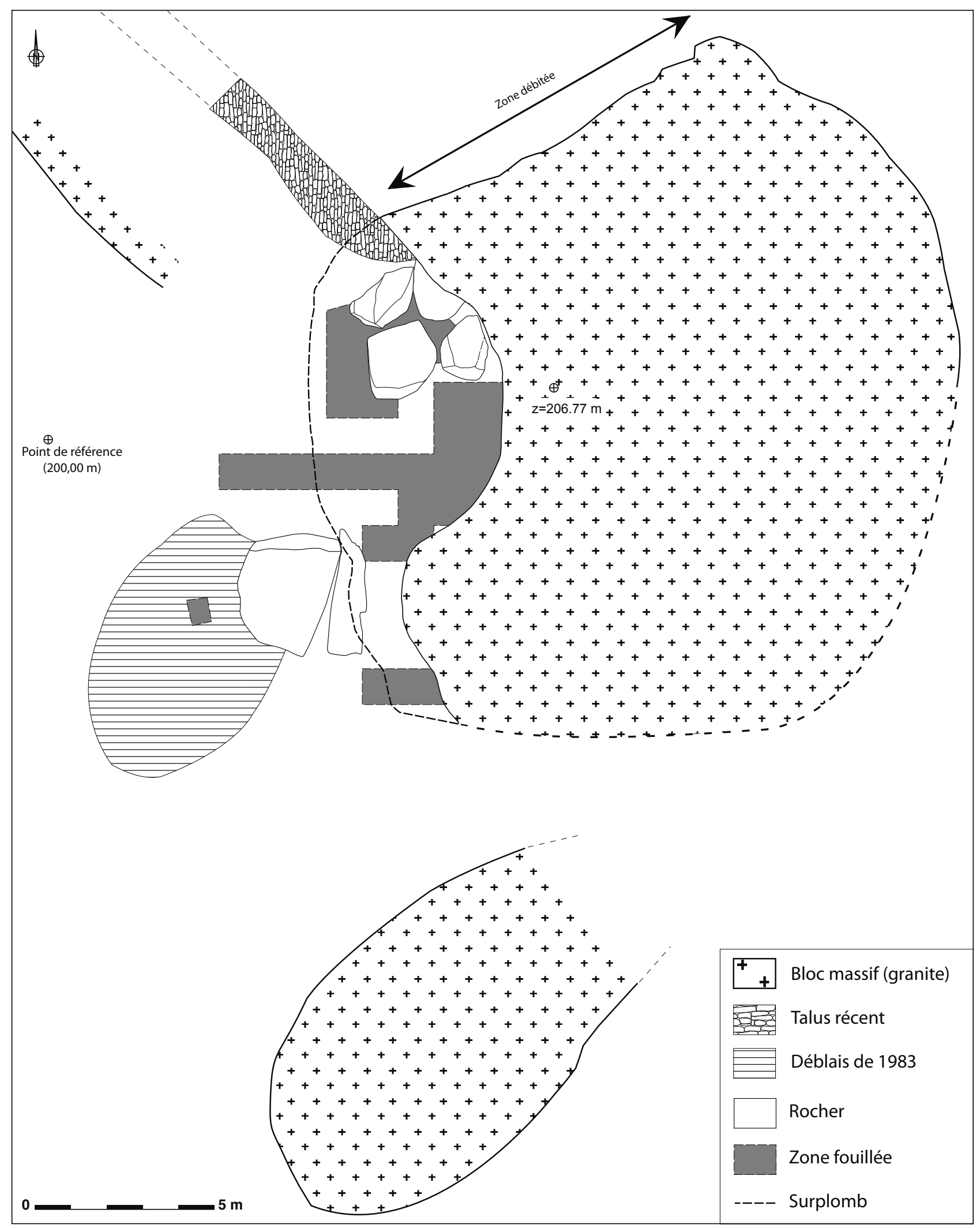

Figure 6 - Plan général du site de Kerbizien en 2011, avec l'emplacement des zones fouillées sous les surplombs (Relevé et DAO : G. Marchand).

Figure 6 - General map of the Kerbizien rock shelter (Drawings and CAD: G. Marchand). 


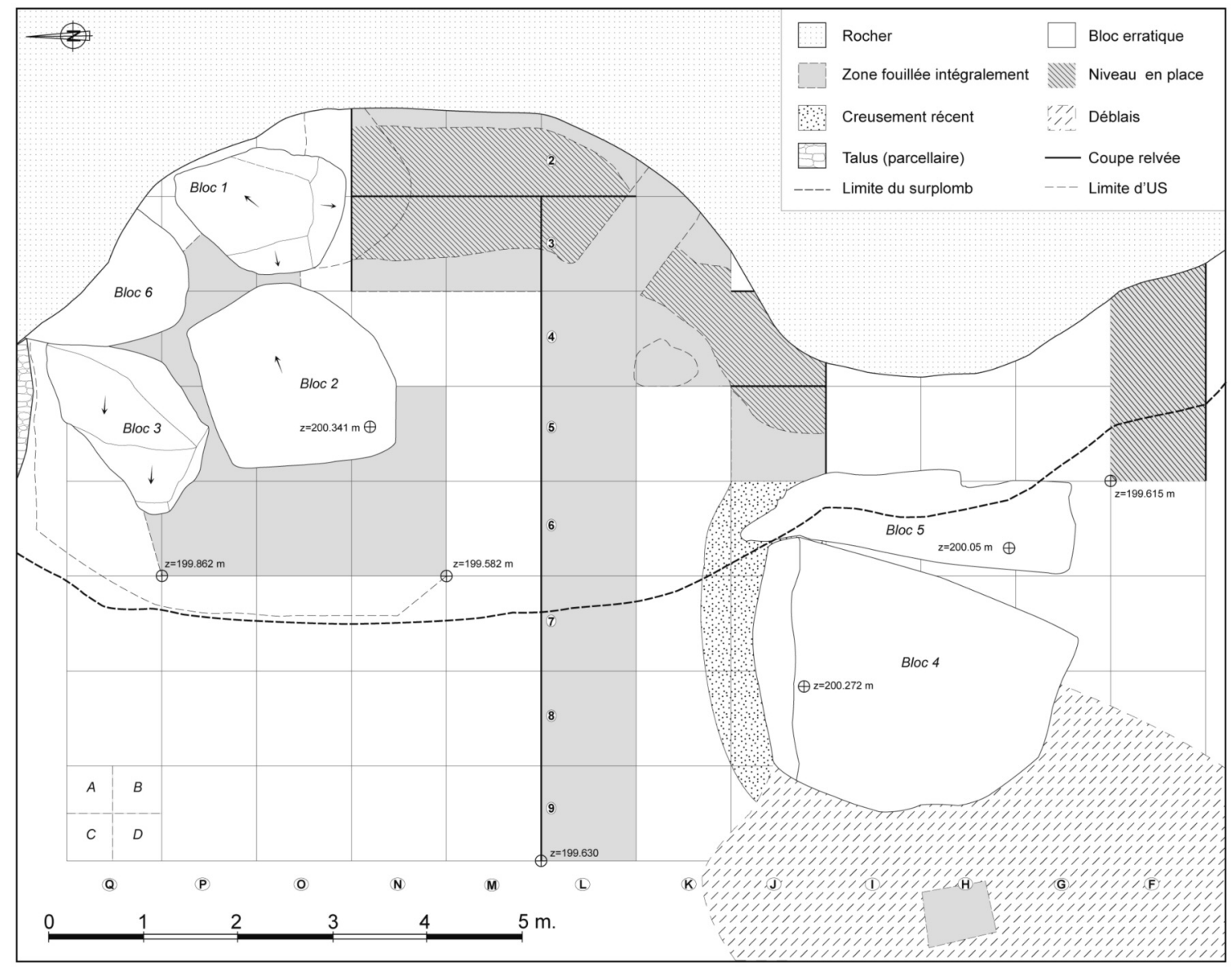

Figure 7 - Plan de la fouille de Kerbizien avec indication des niveaux aziliens en place dans la cavité et sous le surplomb sud du bloc (Relevé et DAO : G. Marchand).

Figure 7 - Map of the excavation of Kerbizien showing the preserved Azilian level inside the rock shelter and by the south of the block (Drawings and CAD: G. Marchand).

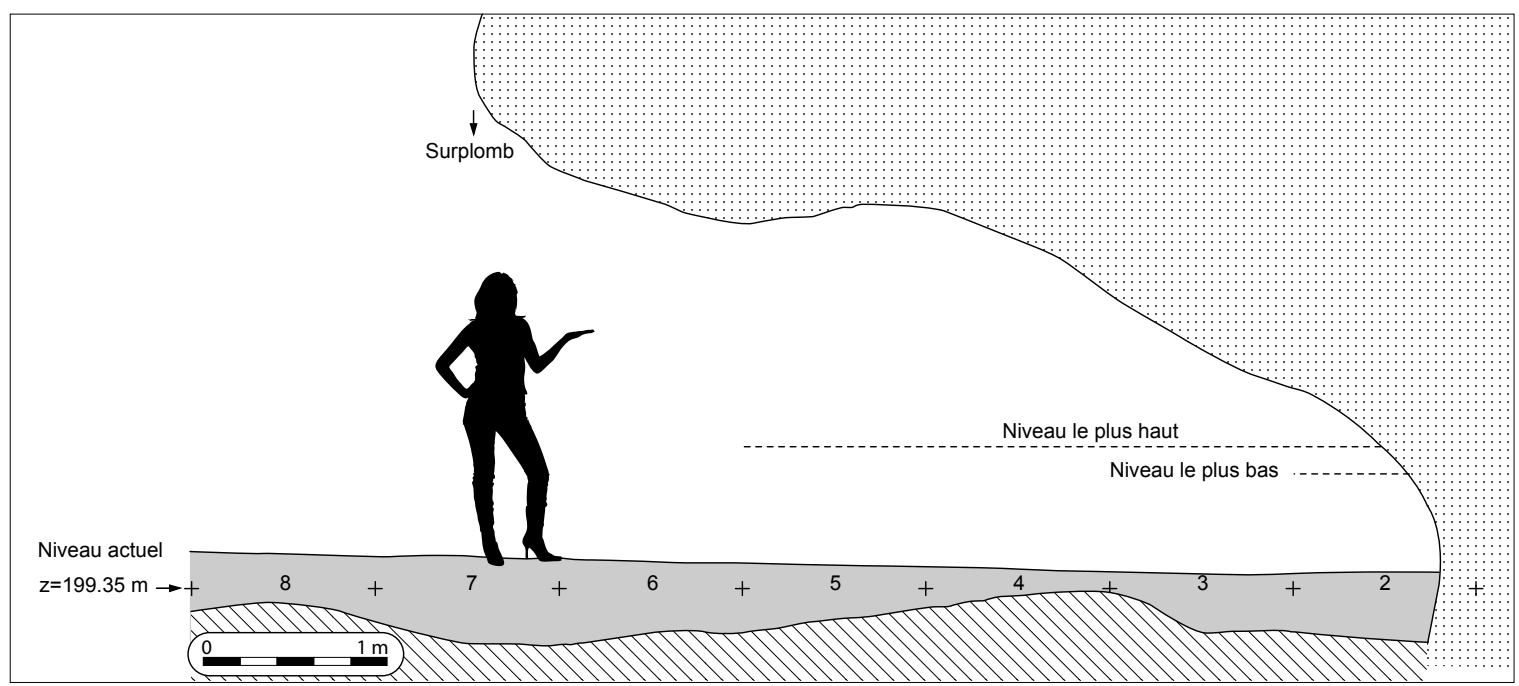

Profil à l'interface L/M (en coupe nord de la bande L)

Figure 8 - Profil de l'abri-sous-roche à l'interface des bandes L et M (coupe nord) (Relevé et Dao : G. Marchand).

Figure 8 - Profile of the Kerbizien rock shelter (between the bands L and M / north section) (Drawings and CAD: G. Marchand). 
peu oublié des travaux récents, ce que l'on ne peut que regretter à la vue du mobilier déjà recueilli.

Dans les deux rapports de sondages réalisés par J.-M. Moullec en 1984 et 1985, il était signalé en tout 2940 pièces lithiques:

- en 1984, 1248 pièces dans les tas de déblais partiellement tamisés et 660 recueillis par le propriétaire de la parcelle (J.-J. Mazurier) ;

- en 1985, 1032 pièces supplémentaires dans les tas de déblais ou dans les terres remaniées de l'abri, dont 46 dans le petit sondage réalisé dans la banquette du fond.

Le large panel des roches métamorphiques et sédimentaires du Massif armoricain était identifié. Le rapport de J.-M. Moullec note $15 \%$ de calcédoine (aujourd'hui nommée calcédoine du Clos) et $9 \%$ de microquartzite de la Forest-Landerneau. Le microgranite (cataclasite de Mikaël) et le phtanite sont aussi signalés. Le reste du mobilier est en silex. Dans les nombreuses planches de J.-M. Moullec, plusieurs composantes chronoculturelles étaient évidentes :

- le Paléolithique final (Azilien), sous la forme de très nombreuses pointes aziliennes, de grattoirs sur bout de lame et de débitage laminaire à partir de deux plans de frappe opposés ;

- le premier Mésolithique (groupe de Bertheaume, daté aujourd'hui de l'intervalle 8200-7500 avant notre ère), avec des triangles scalènes étroits et de nombreuses lamelles à dos étroites ;

- le second Mésolithique (Téviecien, daté de la fin du $7^{\circ}$ et du $6^{e}$ millénaire avant notre ère), plus discret mais marqué par les trapèzes symétriques ;
- une période historique, pendant laquelle l'habitat a servi d'atelier métallurgique (nombreuses scories et tessons).

Nous n'avons pu récupérer qu'un lot de 755 pièces lithiques conservées par A.-M. Mazurier, qui correspond probablement aux ramassages de son mari, augmentés au fil des glanes et au cours des années (le reste du mobilier est pour l'instant impossible à localiser). On note parmi les 52 armatures, 10 fragments de pointes à dos courbes, 7 triangles scalènes étroits et 3 trapèzes symétriques. Les premières sont exclusivement en silex gris et sont identiques aux pièces aziliennes recueillies en fouille, tandis que les autres armatures mésolithiques ont été réalisées également en cataclasite, en microquartzite de la Forest-Landerneau, en calcédoine du Clos, en grès éocène et en phtanite (par ordre d'importance) (tabl. 1).

\section{3 - Fouille en 2011 d'un niveau azilien résiduel}

\section{1 - Implantation de la fouille}

La dimension tardiglaciaire des assemblages de Kerbizien n'avait pas été bien perçue dans les travaux précédents et c'est dans le cadre d'un programme de recherche sur le fonctionnement des économies mésolithiques que l'abri a été abordé. L'exigence de doter de petites stations le corpus d'habitats déjà connus semblait impérative à satisfaire, pour contraster avec les vastes sites de plein air fouillés jusqu'à présents dans la région. Elle nous avait incités à fouiller intégralement l'abri de Pont-Glas en 2007 et 2008 (Marchand et Le Goffic 2009 ; Marchand et al. 2011b), avant de porter l'attention sur Kerbizien en juillet 2011. II s'agissait d'établir un bilan stratigraphique, objectif qui s'est orienté vers la fouille totale des remplissages lorsque l'importance de leur dégradation est apparue.

\begin{tabular}{|l|c|c|c|c|}
\hline \multicolumn{1}{|c|}{ Matière } & Débitage et outillage commun & Armature & $\begin{array}{c}\text { Total } \\
\text { (N) }\end{array}$ & Total (\%) \\
\hline Silex & 456 & 38 & 494 & 65,4 \\
\hline Ultramylonite de Mikaël & 88 & 1 & 89 & 11,8 \\
\hline Calcédoine du Clos & 68 & 2 & 70 & 9,3 \\
\hline $\begin{array}{l}\text { Microquartzite de la Forest- } \\
\text { Landerneau }\end{array}$ & 60 & 5 & 65 & 8,6 \\
\hline Grès écocène & 22 & 6 & 28 & 3,7 \\
\hline Phtanite & 9 & 0 & 9 & 1,2 \\
\hline Total & $\mathbf{7 0 3}$ & $\mathbf{5 2}$ & $\mathbf{7 5 5}$ & $\mathbf{1 0 0}$ \\
\hline
\end{tabular}

Tableau 1 - Décompte des pièces de surface (collection Mazurier 2011).

Table 1 - Scoring of the pieces found out of the stratigraphy by Mazurier. 

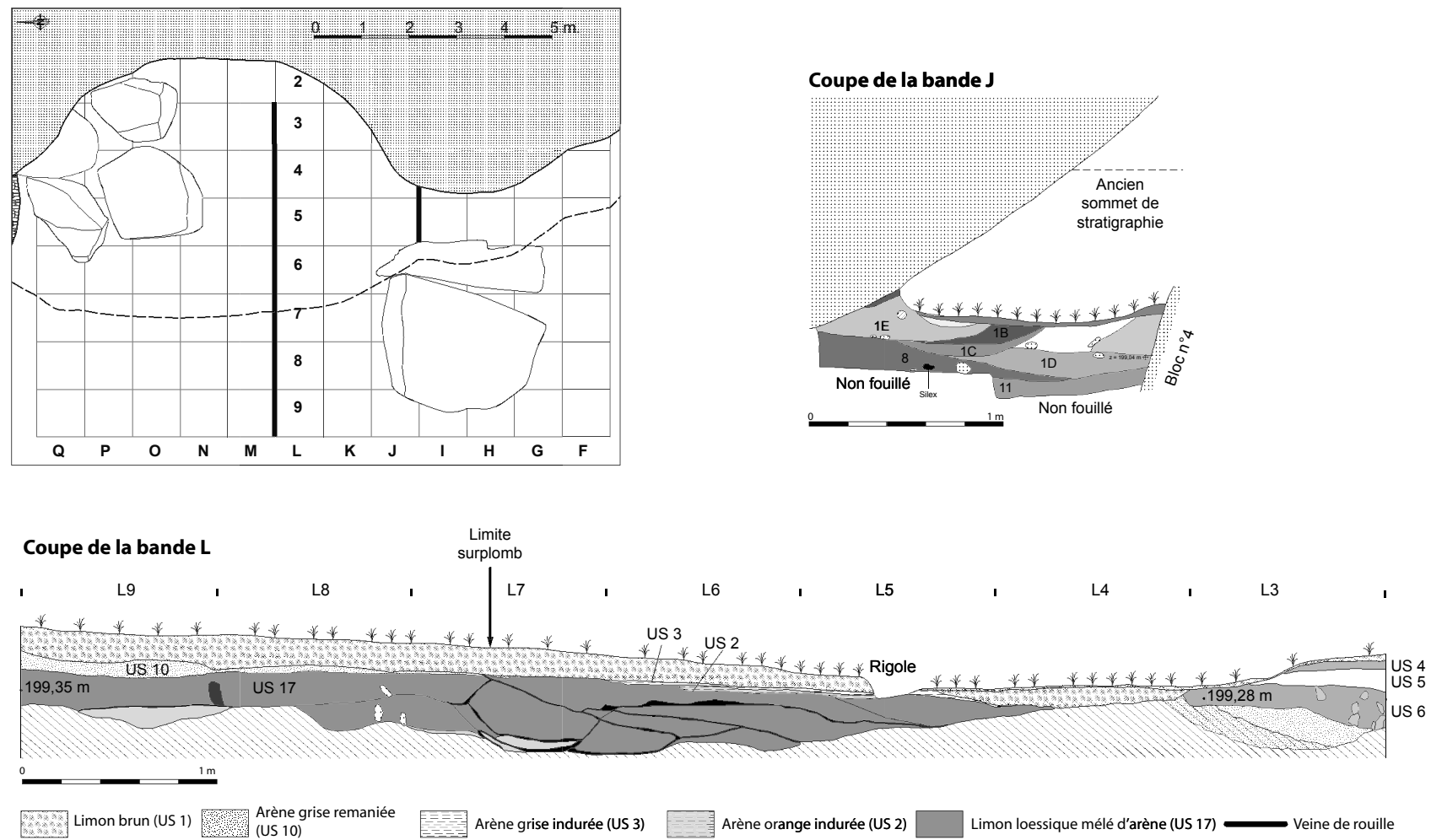

Figure 9 - Coupes sagittales dans l'abri de Kerbizien. En bas : coupe nord de la bande L, avec des limons lossiques mêlés d'arène granitique, marbrés de veines de rouille installées dans le réseau racinaire, avec une troncature majeure au bulldozer. En haut : coupe sud des carrés $\mathrm{J} 4$ et J5, dans l'angle sud-ouest de la caverne, dans une zone de ruissèlements le long de la paroi. Les industries aziliennes en place se trouvaient dans l'US 8 et au sommet de l'US 11 (Relevé : G. Marchand ; DAO : L. Quesnel).

Figure 9 - Stratigraphic sections in the Kerbizien rock shelter. Bottom: north section of the $L$ band, with loess silt mixed with granitic sand. Top: section of the squares $\mathrm{J} 4$ and $\mathrm{J} 5$ in the southwest corner of the cave, in an area of water running along the rock. The Azilian industries were in the 8 and 11 stratigraphic units (Drawings and CAD: L. Quesnel and G. Marchand).

Le carroyage métrique implanté couvrait la totalité du surplomb, ainsi qu'une bande de trois mètres de large devant. Les bandes signalées par des lettres vont de $Q$ à $F$, du nord au sud ; les bandes marquées par des chiffres vont de 2 à 9 , d'est en ouest. Une tranchée sagittale (du fond vers l'extérieur) a d'abord été réalisée dans la bande $L$, sur huit mètres de long (fig. 9 et 10). La partie sud-ouest du bloc, avec son petit surplomb, a été également testée dans la bande $F$ sur $2 \mathrm{~m}$ de long (carrés F4 et F5 ; fig. 11). Même si les niveaux pléistocènes et holocènes mesurent près de 1,20 m d'épaisseur, seule leur partie supérieure comprend des vestiges lithiques sur environ $0,30 \mathrm{~m}$.

L'essentiel des dépôts archéologiques a été enlevé dans toute la cavité au milieu des années 1980, comme nos fouilles l'ont montré. Nous fûmes heureusement nettement plus chanceux dans une bande de deux mètres de large tout le long de la paroi du fond, où le mince niveau de feuilles et de poussières (la litière - US 1) recouvrait directement deux unités stratigraphiques aziliennes bien en place (US 4 et 5). II convenait bien évidemment de se défier de la partie en contact avec la paroi où l'activité intense des fouisseurs entrainait un remaniement des sédiments de haut en bas. L'absence d'intérêt paleoethnographique sur une aussi petite surface nous a donc incités à réaliser une fouille par $1 / 4$ de mètre carré et par US. La totalité des terres a été tamisée à l'eau dans des tonneaux sur le site ou dans le ruisseau en contrebas, l'eau utilisée provenant de ce ruisseau par seaux successifs. Nous avons utilisé des tamis de maille $2 \mathrm{~mm}$ (tamis de 12 des maçons). Le grand nombre d'esquilles recueillies est la rançon de cette méthode.

En conséquence, à l'issue de ces deux semaines de travail intensif, on peut considérer que l'abri-sous-roche de Kerbizien ne contient plus de niveaux archéologiques, qu'ils soient en place ou non d'ailleurs. Seule la partie sud, au sud des blocs 4 et 5 et en plein-air, recèle encore des vestiges, mais avec une répartition peu dense et des mélanges évidents entre occupations dans l'horizon supérieur du sol actuel. II semblerait tout à fait alléchant de réaliser au moins une tranchée à la pelle mécanique en travers du vallon, dans le prolongement de notre bande $L$. On y trouverait certes les vestiges lithiques issus de la stratigraphie détruite de l'abri, mais surtout d'autres niveaux limoneux qui auraient peut-être enregistré des occupations depuis le Paléolithique. Ce projet n'est évidemment pas d'actualité, en raison du jardin de la propriété actuelle. 


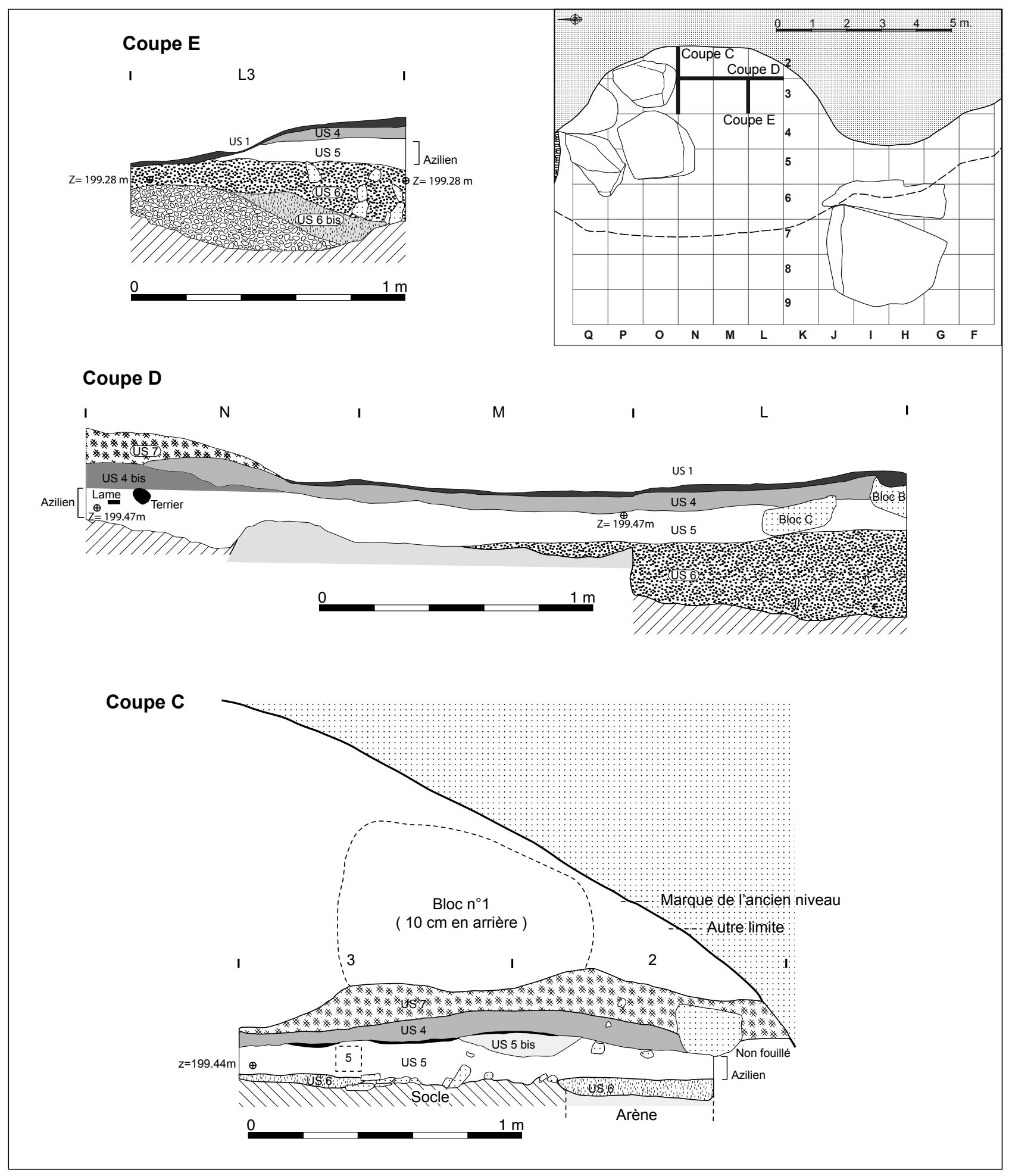

Figure 10 - Relevés stratigraphiques établis dans le bourrelet azilien en place au fond de la caverne. Les industries aziliennes en place se trouvaient dans les US 4, 5 et au sommet de l'US 6 (Relevé : G. Marchand; DAO : L. Quesnel).

Figure 10 - Stratigraphic records made in the Azilian bead up at the bottom of the cave. The azilian industries were up in the 4, 5 and 6 US (summit) (Drawings: G. Marchand; CAD : L. Quesnel). 


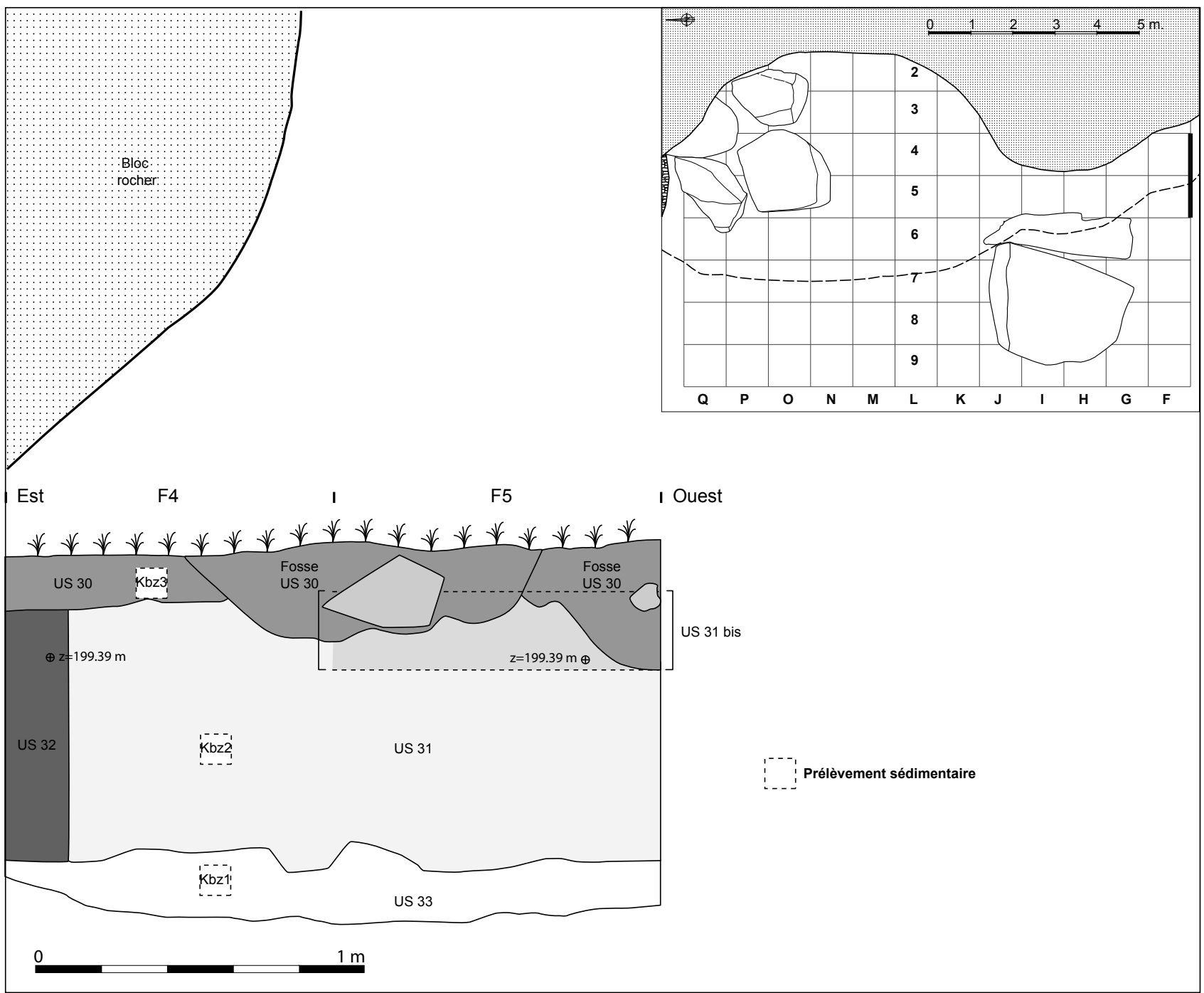

Figure 11 - Relevé stratigraphique de la coupe sud du sondage de la bande F (F4 et F5) (Relevé : G. Marchand ; DAO : L. Quesnel).

Figure 11 - Stratigraphic record of the southern section of the F band (F4 and F5) (Drawings: G. Marchand; CAD : L. Quesnel).

\section{2 - Description des unités stratigraphiques}

Le granite de Huelgoat est une roche à grains moyens et gros, de teinte gris clair à gris bleu foncé, à mégacristaux de feldspath potassique et à cordiérite automorphe. Comme nous l'avons observé, les gros blocs s'érodent en pelures d'oignon, avec de nettes faces d'arrachement opposées aux surfaces exposées à l'air. L'acidité des sols qui naissent sur un tel substrat est évidemment à rappeler, qui n'a permis que la préservation des restes minéraux et des charbons. Cette arène granitique issue de l'érosion est la source principale d'accroissement du remplissage de la cavité. À l'extérieur, elle vient s'enrichir des poussières et dépôts végétaux à l'Holocène et de limons lœssiques au Pléistocène.
Deux lignes horizontales bien nettes superposées et espacées de $18 \mathrm{~cm}$ sur toutes les parois de la cavité nous signalent deux états successifs de destruction de cette stratigraphie, épaisse d'un mètre en moyenne à son maximum. Personne ne peut assurer qu'elle était de belle qualité et exempte de perturbations, mais l'abondance et la variété fonctionnelle du mobilier lithique recueilli permettent d'évoquer des habitats mésolithiques très importants, bien différents d'ailleurs de ceux enregistrés sur la petite station de Pont-Glas. La succession des unités stratigraphiques dans l'abri-sous-roche est donc gravement tronquée et l'on ne peut que décrire sa partie basale, accessible immédiatement sous une mince litière de feuilles et de poussières (les déblais ont été étalés hors de l'abri). A l'intérieur de la caverne, un bourrelet constitué principalement d'arène granitique n'avait pas été 
bouleversé (US 4, 5 et 6) et il constitue l'heureuse surprise de l'opération, objet de cet article. II se prolonge dans ce que l'on nommera ici « l'angle de l'abri » (carrés J4 et J5), très affecté par la circulation de l'eau qui ruisselle sur la paroi, mais indéniablement en place et stratifié. Dans cette cavité, les US 13 et 32 correspondent à une bande d'une vingtaine de centimètres de large qui court le long de la paroi. Enrichies en matière organique par les ruissellements et les terriers innombrables creusés depuis la nuit des temps, ce sont des zones mélangées où le mobilier de toutes périodes abonde.

Devant l'abri principal, la succession des couches est affectée par un très léger pendage de l'extérieur vers l'intérieur de l'abri (fig. 9 et 10). II existe aussi une très légère inclinaison du nord au sud, qui correspond à la pente de la colline, mais il convient de remarquer que les blocs 4 et 5 bloquent les sédiments et ont empêché les dépôts sédimentaires pléistocènes et holocènes de glisser. Si une telle configuration a pu maintenir en place les sédiments au cours des siècles, elle n'a pas été efficace contre les assauts d'un engin mécanique... La quasi-totalité du remplissage archéologique a été emportée... Un niveau très tassé par les travaux des années 1980 et marqué par des feux nombreux (US 1) surmonte un limon loessique (US 17), que nous avons fouillé jusqu'au rocher sur toute la longueur de la tranchée, sur une profondeur moyenne de $0,40 \mathrm{~m}$, sans aucune découverte archéologique. Ce très beau niveau pléistocène en place est donc non daté avec précision. II montre une association complexe de limons éoliens (lœss) et d'arènes granitiques, avec de grandes lignes de rouille liées aux migrations de fer le long des racines. Épais d'une vingtaine de centimètres, il repose sans transition sur le rocher, ce qui laisse penser à une mise à nu avant le dépôt des lœss et donc un possible lessivage des niveaux archéologiques antérieurs. Cette action pourrait expliquer l'absence de vestiges du Paléolithique avant le dépôt des limons éoliens. II y avait donc la possibilité d'un enregistrement d'occupation archéologique dans cette US 17, mais nos travaux n'en ont pas montré l'existence.

$\mathrm{Au}$ sud du bloc monolithique (bande $\mathrm{G}$ et $\mathrm{F}$ ) les dépôts sédimentaires n'ont pas été décapités par les travaux et l'on observe l'établissement d'un sol (au sens pédologique) sur un limon lœssique enrichi d'arène granitique (fig. 11). Épais de $1.20 \mathrm{~m}$, ils sont aussi vierges de vestiges que l'avant de l'abri, confirmant l'absence d'habitation au Pléniglaciaire dans cet abri. On observe de bas en haut :

- un niveau très induré de limon et d'arène granitique, de teinte jaune (US 33 - Prélèvement Kbz1) ;

- un limon jaune-orangé très fin, épais de 0,80 m (US 31 Prélèvement Kbz 2);

- un limon organique brun correspondant à l'horizon A du sol actuel (US 30 - Prélèvement Kbz 3).

L'effet de paroi à cet endroit a reçu le nom d'US 32.

Pour conclure, parmi les zones en place, qui nous intéressent évidemment davantage, on peut distinguer :

- le fond de l'abri (carrés N2, N3, M2, M3, L2 et L3) ;
- une zone de « gouttière » à l'angle de l'abri, extrêmement riche en mobilier (dont des pointes aziliennes - carrés J4 et J5) ;

- la zone au sud du bloc (carrés de la bande F).

\section{3 - Les niveaux aziliens}

\subsection{1 - La banquette du fond de l'abri}

Une banquette d'arène granitique avait été préservée au fond de l'abri et son exploration a été facilitée par un contrôle stratigraphique permanent dans la coupe du petit sondage de J.-M. Moullec, puis par plusieurs coupes frontales et sagittales lors de nos décapages à la truelle. La banquette en place était couverte soit d'une litière de feuilles mal décomposées et de poussières (US 1), soit de déblais de terriers dans les carrés N2 et N3 (US 7). L'US 4 est apparue après un rapide et aisé décapage (fig. 12). Cette arène orange très compacte était épaisse de $5 \mathrm{~cm}$ dans les carrés $L$ et $M$; elle s'épaississait jusqu'à $10 \mathrm{~cm}$ en $\mathrm{N}$. Bien évidemment, on ne peut dire de combien elle a été décapitée dans les années 1980. Le niveau inférieur (US 5) montrait également une matrice arénacée largement dominante, avec une teinte brune un peu plus prononcée que la précédente, sur une épaisseur de $10 \mathrm{~cm}$. Un cailloutis un peu plus épais matérialise la base du niveau ; on note également un piétinement du rocher en N3 B. L'US 5 est comme l'US 4 un niveau très compact. Une industrie lithique exclusivement azilienne a été découverte dans l'US 4 et dans l'US 5, soit sur une épaisseur totale de $15 \mathrm{~cm}$.

Des blocs de granite aux dimensions décimétriques sont apparus dans ces deux US, un dont la base était dans l'US 4 (N2-3), d'autres étaient plutôt posés à la base de l'US 5 (carrés M 2, M3, N2 et N3), trois autres encore particulièrement remarquables - étaient posées à mihauteur de l'US 5 dans les carrés K3, L3 et L2 (fig. 13 et 14). Ces derniers ont été dénommés $A, B$ et $C$ (fig. 15). Le bloc $B$ avait déjà été découvert par J.-M. Moullec dans son sondage et laissé fort opportunément en place. Leur manipulation par les humains ne fait pas doute : non seulement ils reposaient face d'arrachement sur le sol ce qui implique qu'ils furent retournés, mais ils portent aussi de nettes traces de débitage. Aucun percuteur n'a été découvert à proximité. Quatre autres blocs granitiques de 10 à $25 \mathrm{~cm}$ de long gisaient à $30 \mathrm{~cm}$ au sud (carré K3), hélas immergés dans l'US 13 (effet de paroi). Ils n'étaient pas débités cette fois.

Le mobilier archéologique recueilli comprend des roches taillées à destination de l'outillage (silex, grès éocène, microquartzite de la Forest-Landerneau et calcédoine du Clos), mais aussi de petites plaquettes de schiste et des fragments millimétriques de schiste.

Quelques charbons ont été recueillis dans les US 4 et 5 , mais ils sont rares et donc sujets à caution. D'après Nancy Marcoux, anthracologue à l'université de Rennes 1, ces charbons présentent d'ailleurs au microscope une allure assez fraîche et donc récente. Un fragment de brindille de noisetier, récupéré dans l'US 5 carré L2, sous-carré $D$ (soit à hauteur des blocs de granite), a néanmoins été envoyé 


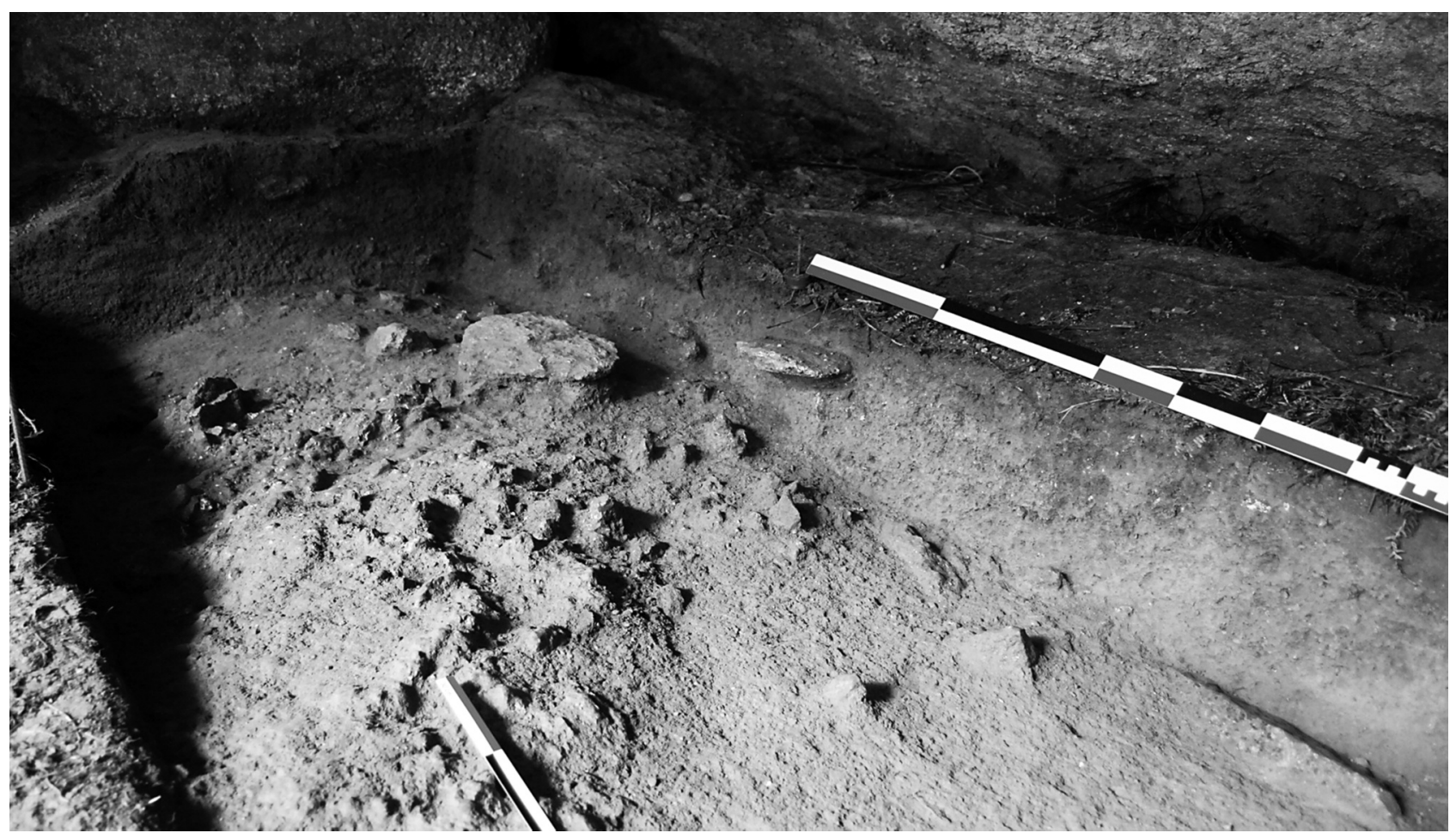

Figure 12 - Base du niveau azilien en place dans les carrés M3 et N 3 (cliché : G. Marchand).

Figure 12 - Bottom of the Azilian level in the M3 and N3 squares (picture: G. Marchand).

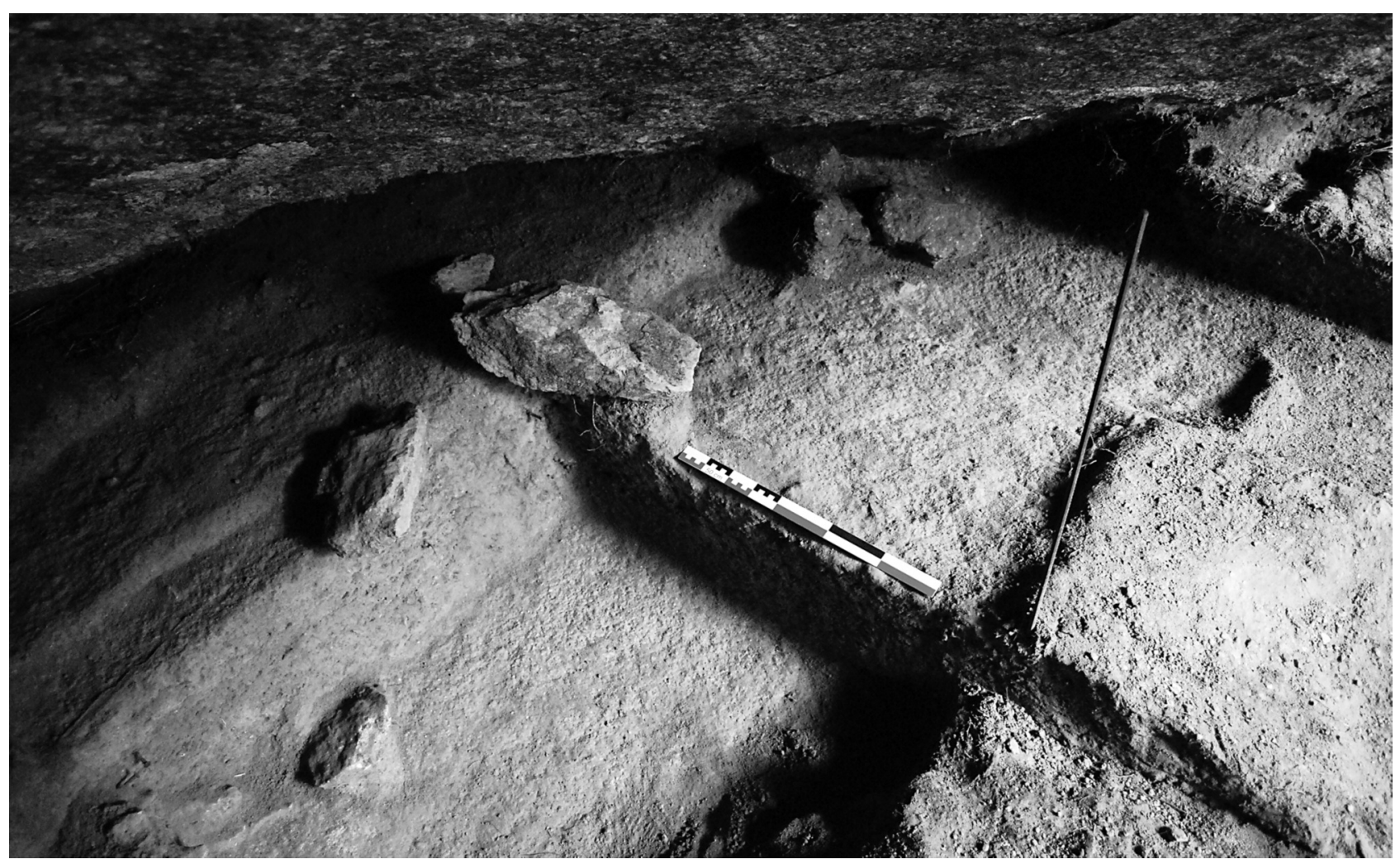

Figure 13 - Partie sud de l'abri, niveau azilien en place. Le carré $L 3$ a été surcreusé et apparait au premier plan. Les blocs de granite taillés $A, B$ et $C$ sont encore en place, au-dessus de ce sondage profond (cliché : $G$. Marchand).

Figure 13 - Southern part of the rock shelter. The A, B and C granite blocks are visible on the upper part of the deep survey (picture: G. Marchand). 

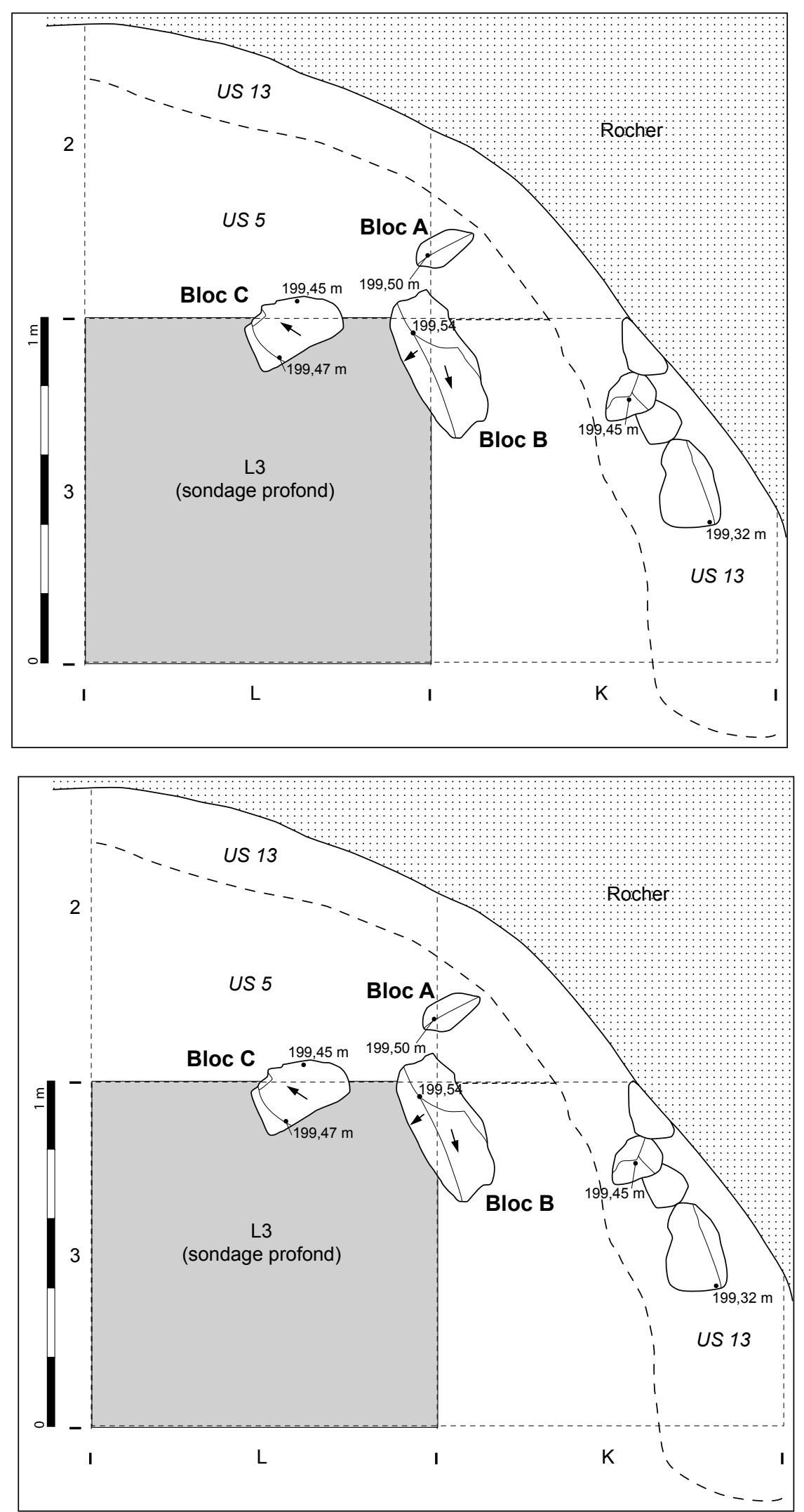

Figure 14 - Plan de la base du niveau d'occupation azilien, dans les carrés N2, N3, M2 et M3

(DAO : L. Quesnel).

Figure 14 - Plan of the bottom of the Azilian layer in the N2, N3, M2 and M3 squares (CAD : L. Quesnel).

Figure 15 - Plan de la base du niveau d'occupation azilien, dans les carrés $L 2$, $L 3, K 2$ et $K 3$, avec les trois blocs granitiques taillés $A, B$ et $C$ (DAO : $L$. Quesnel).

Figure 15 - Plan of the bottom of the Azilian layer in the L2, L3, K2 and $K 3$ squares, with the granite blocks $A, B$ and C (CAD: L. Quesnel). 
pour datation par la méthode du radiocarbone à BetaAnalytic. Le résultat obtenu est de $5220 \pm 40 \mathrm{BP}$ (Beta306 993), soit une datation à 1 sigma entre 4040 et 3980 avant notre ère. Cette valeur est bien trop récente par rapport à nos attentes et surtout elle ne correspond pas à une occupation du Néolithique moyen prépondérante dans le mobilier archéologique, même dans les niveaux bouleversés. On signalera quand même une bitroncature trapézoïdale de grandes dimensions en silex (K3A-US13), interprétable comme une flèche tranchante de cette époque. La proximité de l'effet de paroi qui a dû contaminer la zone est probablement en cause dans cette datation décevante, les micro-charbons migrant au gré des déplacements des animaux fouisseurs et de la circulation des eaux.

La couche azilienne reposait sur une couche également arénacée orange à jaune citron, nettement moins compacte, ou plus rarement sur le rocher (carré M3 ; souscarré $A, C$ et D). L'US 6 a livré en N2 D une poche de limon éolien, preuve que le niveau d'arène ne correspond pas au rocher désagrégé en place, mais plutôt à l'accumulation des grains chutant des parois, qui sont venus se mêler aux limons. Cette US n'a livré des vestiges lithiques que dans sa partie supérieure, sans traces d'occupation antérieure. Elle apparaît comme plus épaisse à proximité de la paroi du fond, ce qui nous semble ressortir d'un processus érosif. Lorsque les occupants aziliens arrivèrent dans cette caverne - pour ce que l'on peut en juger dans sa partie la plus profonde - ils s'installèrent donc soit sur un sable arénacé grossier, soit plus rarement sur le rocher. La bande 2 n'était pas directement adaptée à l'occupation humaine, sinon pour un couchage, à cause de l'inclinaison de la paroi ; le mobilier archéologique découvert a pu y être déposé au gré des " coups de pied " ou des abandons de déchets, en périphérie des zones d'activités.

\subsection{2 - L'angle de l'abri (J4-J5)}

La fouille de l'angle de l'abri nous a donné bien du fil à retordre car c'est une zone où les ruissellements des pluies (fort abondantes localement en juillet 2011) se concentrent naturellement, à cause du bombement du rocher. Elle impose bien des contorsions à cause du plafond bas et n'a été véritablement comprise que par ses coupes stratigraphiques, en fin d'exploration. L'inclinaison de la paroi et la circulation des eaux rendent malaisée l'occupation, d'où évidemment sa préservation relative lors des bouleversements drastiques des années 1980. C'est pourtant là que la densité de mobilier lithique est la plus forte, notamment celle des pointes aziliennes. Les unités stratigraphiques sont inclinées du nord-est vers le sudouest, c'est-à-dire de l'intérieur vers l'extérieur de l'abri et vers le bloc 5. C'est donc une zone de « vidange » dans la logique spatiale propre à cette cavité. La stratigraphie comprend de bas en haut (fig. 9, en haut) :

- l'arène vierge (US 15) ;

- l'arène 11 vierge de vestige à l'exception de son sommet (mais de très rares pièces) ;

- une arène noire, surchargée de matière organique, qui contient les silex aziliens (US 8), de $15 \mathrm{~cm}$ d'épaisseur au maximum et biseautée vers l'extérieur ; son induration est probablement due au concrétionnement du fer,

- une série de couches sableuses (1B, 1C, 1D) recoupées par un petit chenal d'écoulement ( $1 \mathrm{~F}$ et $1 \mathrm{G}$ ) dans le carré $\mathrm{F} 5$, qui se résume à une seule US (1E) vers l'intérieur dans le carré F4.

La corrélation directe est aisée entre ces dernières et la banquette préservée au fond de l'abri (US 11 = US 6 ; US 8 = US 5 ; US 1D = US 4).

\subsection{3 - La tranchée $F$}

Les niveaux préhistoriques sont également préservés dans la partie sud-est du bloc monolithique, mais au sein d'un sol actuel bien développé. On distingue de bas en haut depuis le rocher (fig. 11):

- un niveau très induré de limons et de sables granitiques, de teinte jaune (US 33) ;

- un limon jaune-orangé très fin, sur une épaisseur de 0,80 m ; - un limon organique de couleur brune (horizon A du sol actuel).

Le long de la paroi et sur une largeur de 0,20 m environ existait une bande de limon mêlée à de l'arène, de teinte brune, qui correspond à une zone très perturbées par les fouisseurs et les infiltrations. Deux creusements successifs ont perturbé l'horizon humique supérieur. Les vestiges mésolithiques (notamment deux trapèzes) viennent de la fosse du carré F5 (sous-carré D). Les pointes aziliennes ont été découvertes au sommet du limon éolien de l'US 31. II ne semble pas judicieux de conclure que les lœss (d'ordinaire datés du Pléniglaciaire) se sont déposés en même temps que les pointes aziliennes (d'ordinaire datées de l'Alleröd), mais plutôt qu'il y a eu une remobilisation de ces lœss à la fin du Pléistocène et à l'Holocène.

\section{4 - Interprétation sédimentologique}

Cinq prélèvements de 10 sur $10 \mathrm{~cm}$ pour une profondeur de $5 \mathrm{~cm}$ ont été effectués dans les coupes à des fins d'analyses granulométriques. Elles ont été réalisées à l'université de Rennes 1 par deux d'entre-nous (JLM et FP). Dans la tranchée $F$, les trois prélèvements réalisés dans les trois unités sédimentaires montrent à la base un lœss mêlé de sable arénacé sur $20-25 \mathrm{~cm}$ d'épaisseur (US 33 tabl. 2), qui se charge progressivement en sable arénacé et en matière organique (US 31) jusqu'à l'horizon humique supérieur très riche en matières organiques et nettement moins bien classé (US 30) (fig. 16 à 18).

Dans la tranchée de la bande $L$, un prélèvement avait été réalisé dans l'US 17 (Kbz4), hors des veines d'oxydes de fer qui marbraient ces limons jaunes. L'analyse sédimentologique révèle un lœss contenant de rares graviers. Au fond de l'abri dans le carré N3, l'US 5 qui emballe les vestiges aziliens montre à l'inverse un faible apport limoneux et une constitution par fragmentation progressive des rochers alentours. L'examen morphoscopique révèle que la totalité des quartz sont nonusés et proviennent d'un tel apport (tabl. 3). 


\begin{tabular}{|c|c|}
\hline Nom & Description \\
\hline $\begin{array}{l}\text { Kbz1 } \\
\text { (US 33) }\end{array}$ & $\begin{array}{l}\text { Sédiment à texture limoneuse, couleur : humide 10YR5.5/6 (brun jaune) - sec 10YR6/5 (brun jaune clair) - présence } \\
\text { de sable et graviers (altération granitique) - assez bon classement autour de } 35 \text { microns et bonne symétrie de la } \\
\text { courbe }\end{array}$ \\
\hline $\begin{array}{l}\text { Kbz2 } \\
\text { (US 31) }\end{array}$ & $\begin{array}{l}\text { Sédiment à texture limoneuse, davantage de graviers - couleur : humide 7.5YR4.5/4 (brun) - sec : 10YR5/3 .5 (brun } \\
\text { à brun-jaune) - un peu moins bien classé. Très riche en matière organique }\end{array}$ \\
\hline $\begin{array}{l}\text { Kbz3 } \\
\text { (US 30) }\end{array}$ & $\begin{array}{l}\text { Sédiment à texture limoneuse, présence de graviers (idem à Kbz2) - Couleur : humide 10YR3.5/6 (brun jaune } \\
\text { sombre) - sec : } 7.5 Y R 4.5 / 3 \text { (brun) - moins bien classé que les précédents - beaucoup de matière organique }\end{array}$ \\
\hline $\begin{array}{l}\text { Kbz4 } \\
\text { (US 17) }\end{array}$ & $\begin{array}{l}\text { Sédiment à texture limoneuse, très peu de graviers et sable - couleur : humide : } 7.5 \text { YR4.5/6 (brun soutenu) - sec } \\
\text { 10YR6/4 (brun jaune vif) - assez bon classement }\end{array}$ \\
\hline $\begin{array}{l}\text { Kbz5 } \\
\text { (US 5) }\end{array}$ & $\begin{array}{l}\text { Sédiment à texture sablo-limoneuse, beaucoup de graviers (arène granitique) - couleur : humide : 10YR5/6 (brun } \\
\text { jaune) - sec : } 10 \text { YR5.5/4 (brun jaune vif) - assez bon classement - courbe de } 50 \text { à } 20000 \text { microns : médiocre } \\
\text { classement }(\mathrm{Hq}=3, \mathrm{Md}=1600 \text { microns) et forte asymétrie }(\mathrm{Asq}=3,3),\end{array}$ \\
\hline
\end{tabular}

Tableau 2 - Analyse sédimantologique de cinq échantillons (J.-L. Monnier et F. Pustoc'h).

Table 2 - Sedimentological analysis of five samples (J.-L. Monnier et F. Pustoc'h).

\begin{tabular}{|c|c|c|c|c|c|c|c|c|c|c|c|c|c|c|c|}
\hline Échantillon & $\begin{array}{c}\% \\
\text { L\&A }\end{array}$ & $\begin{array}{l}\% \\
\mathrm{~S}\end{array}$ & $\begin{array}{l}\% \\
\text { G }\end{array}$ & $\begin{array}{c}\text { \%text } \\
\text { A }\end{array}$ & $\begin{array}{c}\text { \%text } \\
\text { L }\end{array}$ & $\begin{array}{c}\text { \%text } \\
\mathrm{s}\end{array}$ & $\begin{array}{l}\text { Q25 } \\
(\mu)\end{array}$ & $\begin{array}{l}\text { Q50 } \\
(\mu)\end{array}$ & $\begin{array}{l}\text { Q75 } \\
(\mu)\end{array}$ & $\begin{array}{l}\text { Q25 } \\
(\alpha)\end{array}$ & $\begin{array}{l}\text { Q50 } \\
(\alpha)\end{array}$ & $\begin{array}{l}\text { Q75 } \\
\text { (a) }\end{array}$ & $\mathrm{Hq}$ & Asq & $\begin{array}{l}\text { NU } \\
\%\end{array}$ \\
\hline Kbz1 & 64,0 & 27,3 & 8,7 & 2,9 & 68,4 & 28,7 & 18,04 & 34,80 & 53,31 & 17,44 & 14,58 & 12,73 & 2,3 & $+0,5$ & 100 \\
\hline Kbz2 & 57,7 & 28,0 & 14,3 & 3,2 & 61,7 & 35,1 & 16,47 & 36,41 & 62,28 & 17,83 & 14,39 & 12,06 & 2,9 & $+0,6$ & 100 \\
\hline Kbz3 & 62,3 & 22,5 & 15,2 & 4,7 & 76,7 & 18,6 & 10,51 & 24,58 & 42,96 & 19,78 & 16,09 & 13,67 & 3,1 & $+0,6$ & 100 \\
\hline Kbz4 & 88,2 & 10,5 & 1,3 & 4,0 & 75,3 & 20,7 & 13,70 & 29,59 & 46,38 & 18,63 & 15,29 & 13,34 & 2,6 & $+0,7$ & 100 \\
\hline Kbz5 & 16,1 & 50,6 & 33,3 & 2,2 & 56,6 & 41,2 & 22,43 & 42,73 & 65,92 & 16,49 & 13,69 & 11,81 & 2,3 & $+0,5$ & 100 \\
\hline
\end{tabular}

Tableau 3 - Morphoscopie : test effectué sur les fractions 500-400 microns : NU à $100 \%$.

Table 3 - Morphoscopy : test on the 5 samples (500-400 microns : NU à 100\%).

À cause de la troncature majeure des dépôts holocènes, on insistera donc sur la découverte de dépôts lœssiques devant l'abri et surtout au sud du rocher, sous la forme d'un léger bourrelet. Cette position concorderait évidemment avec un apport éolien depuis les rivages de la Manche au nord, par dessus les Monts d'Arrée. Hormis les aspects purement archéologiques, la mise en évidence d'un témoin de la couverture lœssique érodée est intéressante, en ce qu'il témoigne de l'extension vers le sud des apports lœssiques datant du Pléniglaciaire supérieur weichsélien (MIS 2). L'étude sédimentologique de la composition des tumulus de l'Âge du Bronze armoricain avait déjà abordé cette question sur la frange nord de la Bretagne (Briard et Monnier 1976), dans des zones où les placages lœssiques ne sont pas cartographiés. Le mécanisme de ces apports durant les phases les plus froides du dernier glaciaire sont désormais mieux connus (Lefort, Monnier, Danukalova à paraître). On trouve un tel nappage aux alentours, par exemple le long d'un chemin d'exploitation qui conduit au village de Kerbizien, à $130 \mathrm{~m}$ au sud-est de l'abri.

Il y a eu une probable vidange des niveaux archéologiques et une mise à nu du rocher avant le dépôt des lœss, car on observe une superposition directe sans transition. À cette époque, l'abri de Kerbizien n'a pas fait l'objet d'occupation humaine. Ce sont des niveaux de sables arénacés remaniés à l'intérieur de l'abri et un sol actuel constitué au sommet de lœss remaniés au sud-ouest du bloc qui 


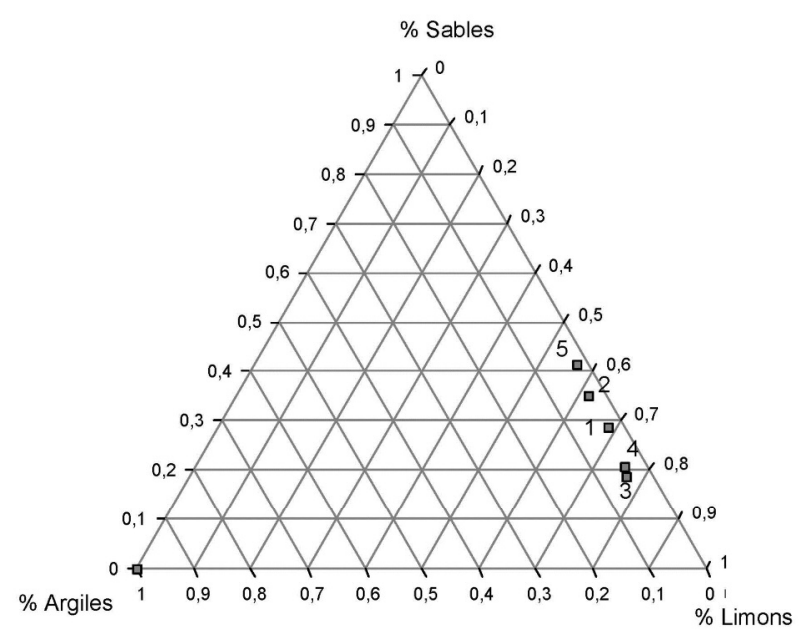

Figure 16 - Premier diagramme des textures des 5 échantillons. Figure 16 - First diagram textures of 5 samples.

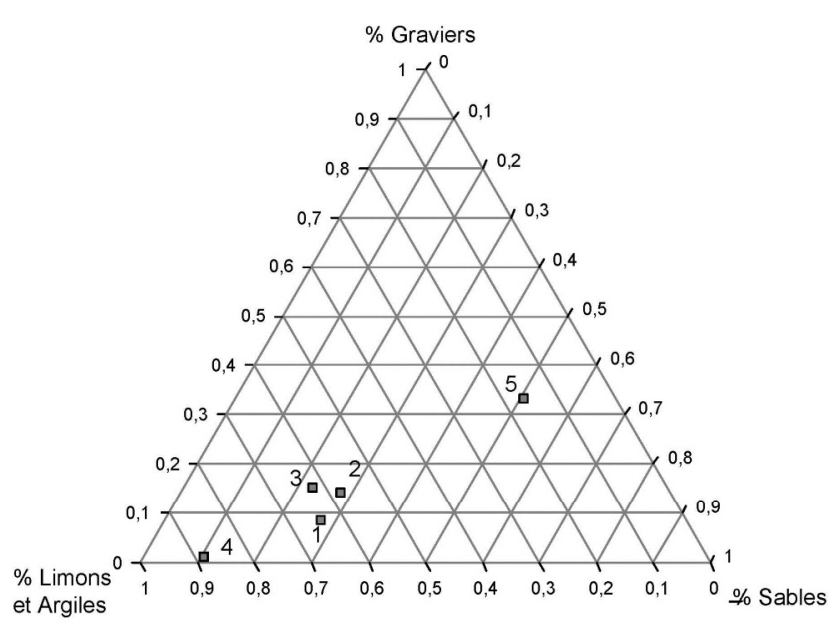

Figure 17 - Second diagramme des textures des 5 échantillons.

Figure 17 - Second diagram textures of 5 samples.

Projection des ind. sur le plan factoriel $\left(\begin{array}{ll}1 \times 2 & 2\end{array}\right)$

Observations avec la somme des cosinus carrés $>=0,00$

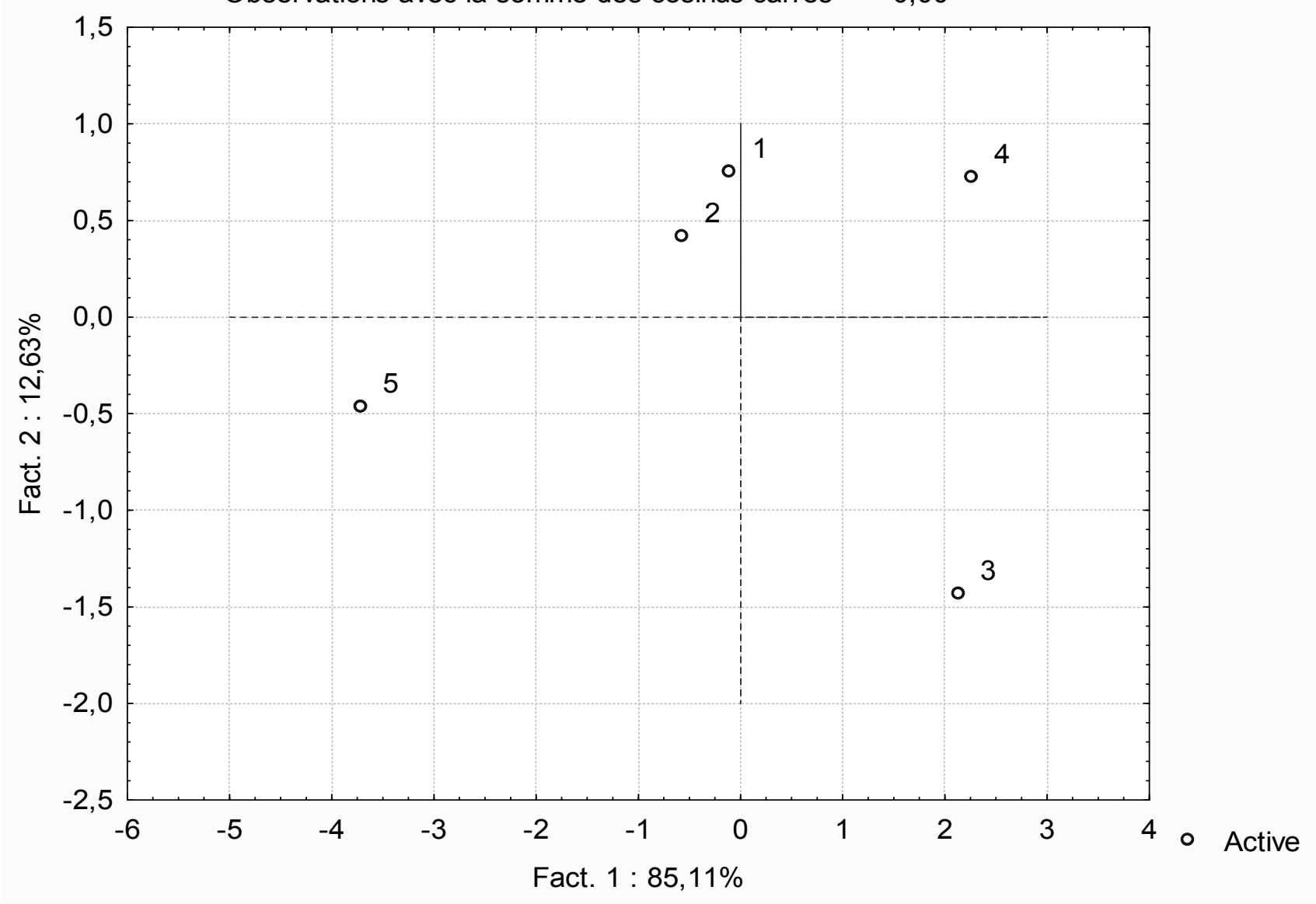

Figure 18 - ACP : variables $=\%<50$ microns, \%sables, \%graviers, \%argile, Q25, Q50, Q75.

Figure 18 - ACP : variables $=\%<50$ microns, \%sand, \%gravel, \%clay, Q25, Q50, Q75. 
enregistrèrent la première installation azilienne soit à la fin du Bölling, soit au début de l'Alleröd. La troncature mécanique majeure des années 1980 empêche de décrire plus avant l'histoire sédimentaire du site dans la cavité. Par ailleurs, dans la partie sud, il n'y a pas eu de recouvrement sédimentaire important, les apports de la désagrégation du rocher ne suffisant pas à produire une matrice susceptible d'emballer distinctement les vestiges du Mésolithique et du Paléolithique final.

\section{5 - Répartition spatiale des objets archéologiques}

La fouille a été réalisée par unité stratigraphique et par quart de mètre carré. II n'y a pas eu à regretter ce choix de fouille, qui permet une meilleure connexion entre le tamisage et le relevé des pièces à l'œil, puisque les niveaux en place étaient peu étendus. La densité de mobilier était très différente suivant les zones (fig. 19 à 24). Parmi les carrés aziliens en place, c'est indéniablement l'angle de l'abri (J4-J5) qui remporte la palme de la densité, avec 83 pièces (esquilles comprises) en J5. L'amputation du sommet de la banquette du fond a probablement fait disparaître maints objets archéologiques, mais l'inclinaison du plafond n'a jamais dû en faire une zone très confortable. II ne s'agit pas non plus d'une zone de déchets préférentielle car nous observons de faibles densités dans les US 4 et $5: 12$ pièces en M2, 8 en M3, 16 en N2 et 26 en N3. Les carrés F4 et F5 montrent des concentrations nettement plus importantes, respectivement 132 et 208, mais il s'agit d'occupations cumulées dans un sol actuel, apparemment sans rabotage superficiel.

Si l'on restreint ces considérations aux seules pièces aziliennes, la partie sud de l'abri (qualifiée aussi d'angle) livre encore les concentrations maximales : il ne s'agissait pourtant que de zones périphériques à l'habitat, qui plus est très humides pour le carré $\mathrm{J} 5$, mais qui se trouvaient le long de l'axe naturel de circulation entre la caverne et l'extérieur. On notera seulement comme élément pertinent dans ces plans de répartition le regroupement des grandes lames utilisées en fond d'abri. La découverte de petites plaquettes de schiste dans les niveaux aziliens a été une information stimulante pour établir les parcours des hommes et des femmes de la fin du Paléolithique. Les trois plus grandes viennent du même endroit que les lames, plus précisément dans le carré N2 ; il y en a une autre de plus de $50 \mathrm{~mm}$ en J5. En revanche, les petits fragments sont répartis un peu partout dans les carrés en place, ce qui est bien difficile à interpréter : certes, le fractionnement de ces objets est aisé, mais pour que ces petits éléments se retrouvent partout, il faut bien imaginer que les objets en schiste ont été déplacés dans l'habitat.

La répartition des scories étudiées par $\mathrm{N}$. Jouanet-Aldous peut être décrite comme totalement inverse de celle des restes aziliens (ce qui est rassurant...), avec une augmentation à mesure que l'on s'éloigne de la caverne en direction de l'ouest et une présence dans les carrés F4 et F5 au sud-ouest de l'abri principal. Cette dispersion est difficile à interpréter, dans la mesure où les niveaux médiévaux correspondants ( $\mathrm{VII}{ }^{e}$ au IX $\mathrm{X}^{\mathrm{e}}$ siècle après $\mathrm{J} . \mathrm{C}$.) ont été totalement détruits et éparpillés devant l'abri. II n'est pas certain d'ailleurs que ces activités sidérurgiques aient évité l'abri-sous-roche et il a été trouvé de nombreuses scories également dans le tas de déblais devant le bloc 4 , des déblais issus du remplissage de la cavité.

\section{4 - Étude de l'outillage lithique}

\section{1 - Aspects généraux de l'assemblage lithique}

L'industrie lithique taillée récoltée pendant l'opération de juillet 2011 compte 1313 éléments, dont la moitié provient de l'intérieur de l'abri au niveau de la banquette, $20 \%$ de la partie sud de l'abri, le reste ayant été recueilli dans les zones perturbées de l'abri (bandes 4 à 9) ou les interstices (fig. 25). Une part de ce mobilier provient des US supérieures ( $22 \%$ - US $1,7,30$ ) ou des effets de parois (13\% - US 13 et 32 ) ; une autre part des multiples unités remaniées (24\%). II reste $20 \%$ du mobilier qui est issu des unités stratigraphiques en place dans l'abri, auxquels on peut ajouter l'US 31 de la bande $F$ (partie sud), qui compte à elle-seule $21 \%$ des pièces lithiques en place, avec de fortes réserves ici puisqu'elles gisaient dans le sol actuel.

II s'agit d'une série lithique affectée par les chocs thermiques dans une mesure normale pour un site régional $(23 \%)$ et ce taux diminue nettement si l'on ne considère que les US aziliennes en place (14,5\%). Le silex est la matière dominante $(72 \%)$, suivie par le microquartzite de la ForestLanderneau (8\%), la calcédoine du Clos $(7 \%)$ et l'ultramylonite de Mikaël ( $5 \%)$. Les grès éocènes sont plus rares (3\%) de même que les phtanites (1\%) (fig. 26). Ces proportions diffèrent notablement de l'inventaire réalisé par J.-M. Moullec : dans la série qu'il avait recueilli par tamisage des déblais, le silex n'atteignait que $65 \%$ des objets, les roches régionales étant les mêmes que dans notre série mais en plus grande proportions. On peut l'expliquer aisément par le fait que les fouilles de 2011 ont affecté de manière préférentielle des niveaux du Paléolithique final dans lesquels le silex domine davantage (fig. 27), tandis que les récoltes antérieures prenaient mieux en compte le Mésolithique connu régionalement pour le grand usage qui y était fait des roches du socle armoricain (Marchand 2012). D'ailleurs, dans l'abri de Pont-Glas aux occupations exclusivement mésolithiques, ces matériaux comptaient pour la moitié des industries. II est évident que les roches régionales sont moins aptes aux réalisations laminaires (Marchand et Tsobgou Ahoupe 2007) et qu'elles ont donc été davantage négligées à l'Azilien.

De manière générale, nos observations à la loupe binoculaire complétées par celles de J. Jacquier (Université de Rennes 1) révèlent une conservation médiocre des traces d'usage, si l'on excepte les traces d'impact sur les armatures ou les plus évidents esquillements des bords. 


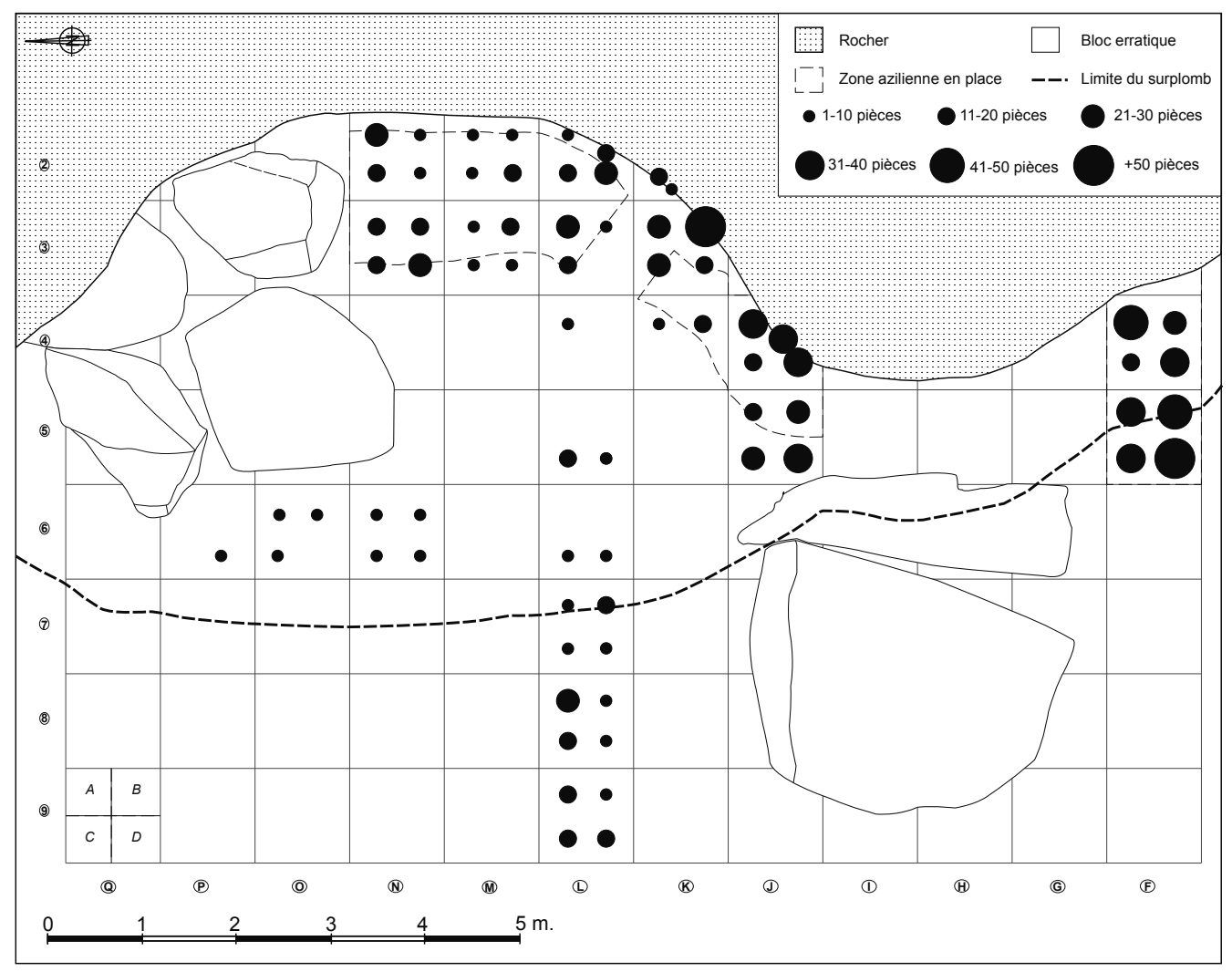

Figure 19 - Répartition des vestiges lithiques taillés, toutes unités stratigraphiques confondues (DAO : $G$. Marchand).

Figure 19 - Location of the knapped lithic remains from all the stratigraphic origins (CAD: G. Marchand).

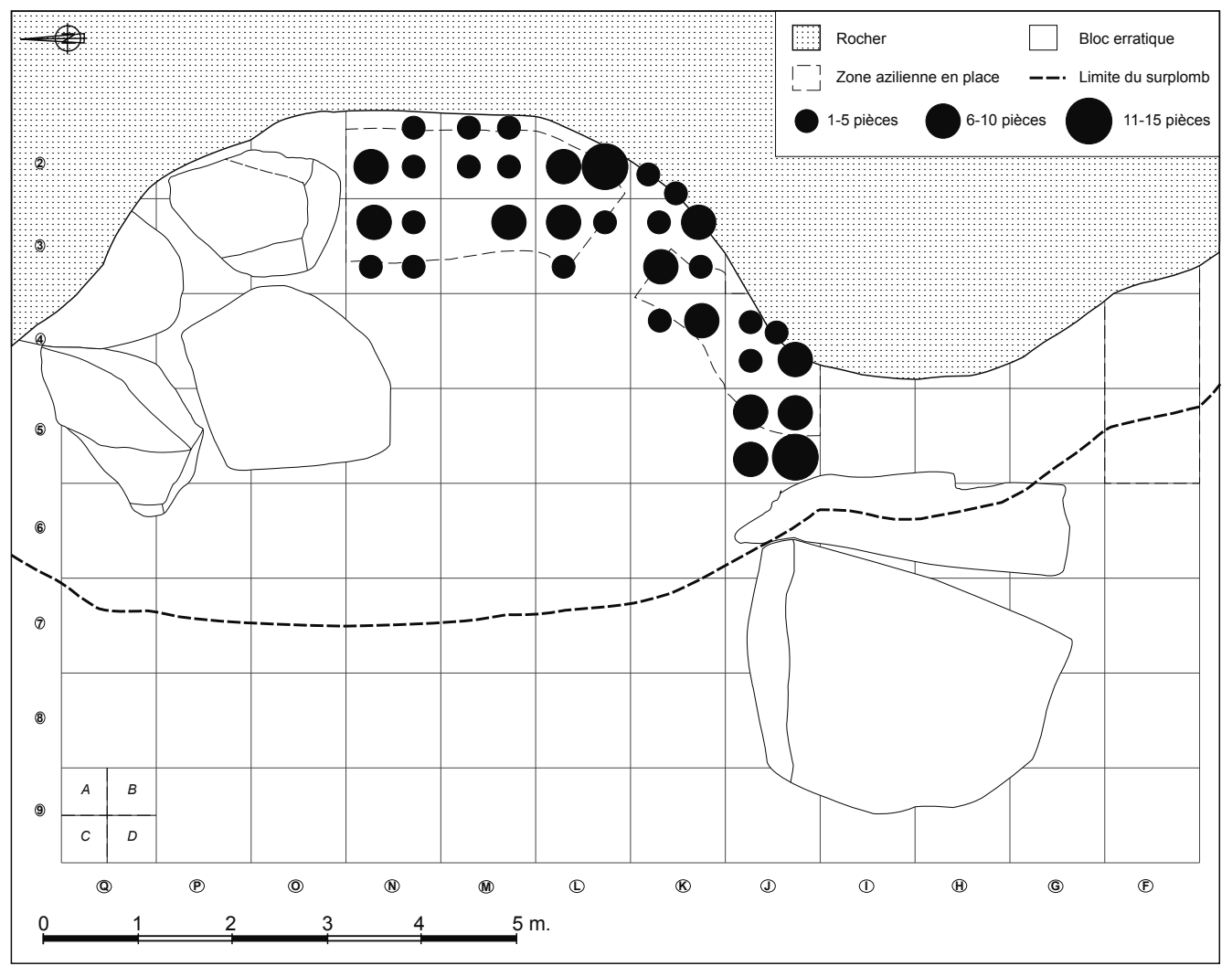

Figure 20 - Répartition des vestiges lithiques taillés dans la caverne et dans les couches aziliennes en place (DAO : G. Marchand).

Figure 20 - Location of the knapped lithic remains in the Azilian levels of the rock shelter (CAD: G. Marchand). 


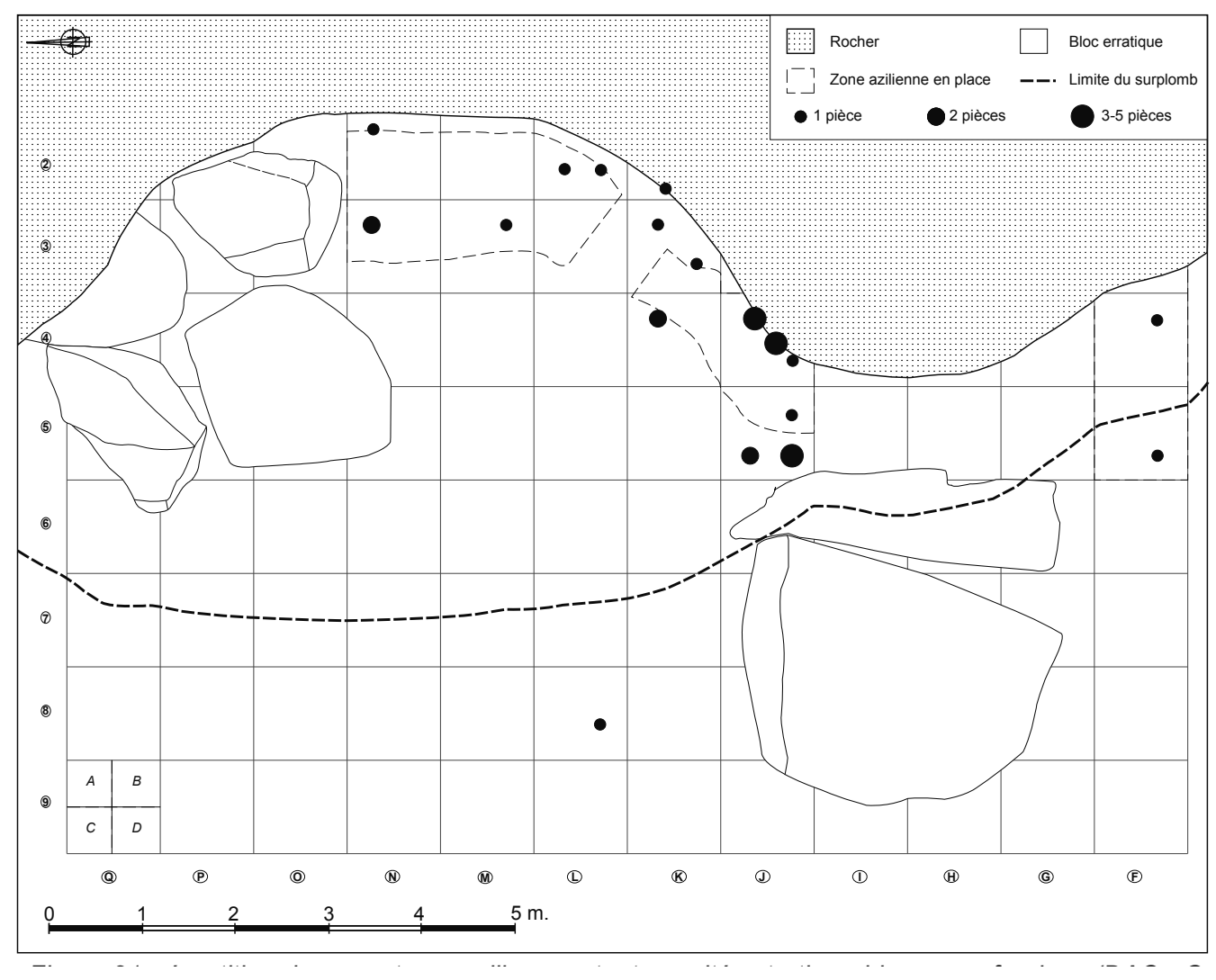

Figure 21 - Répartition des armatures aziliennes, toutes unités stratigraphiques confondues (DAO : G. Marchand).

Figure 21 - Location of the Azilian points from all the stratigraphic units (CAD: G. Marchand).

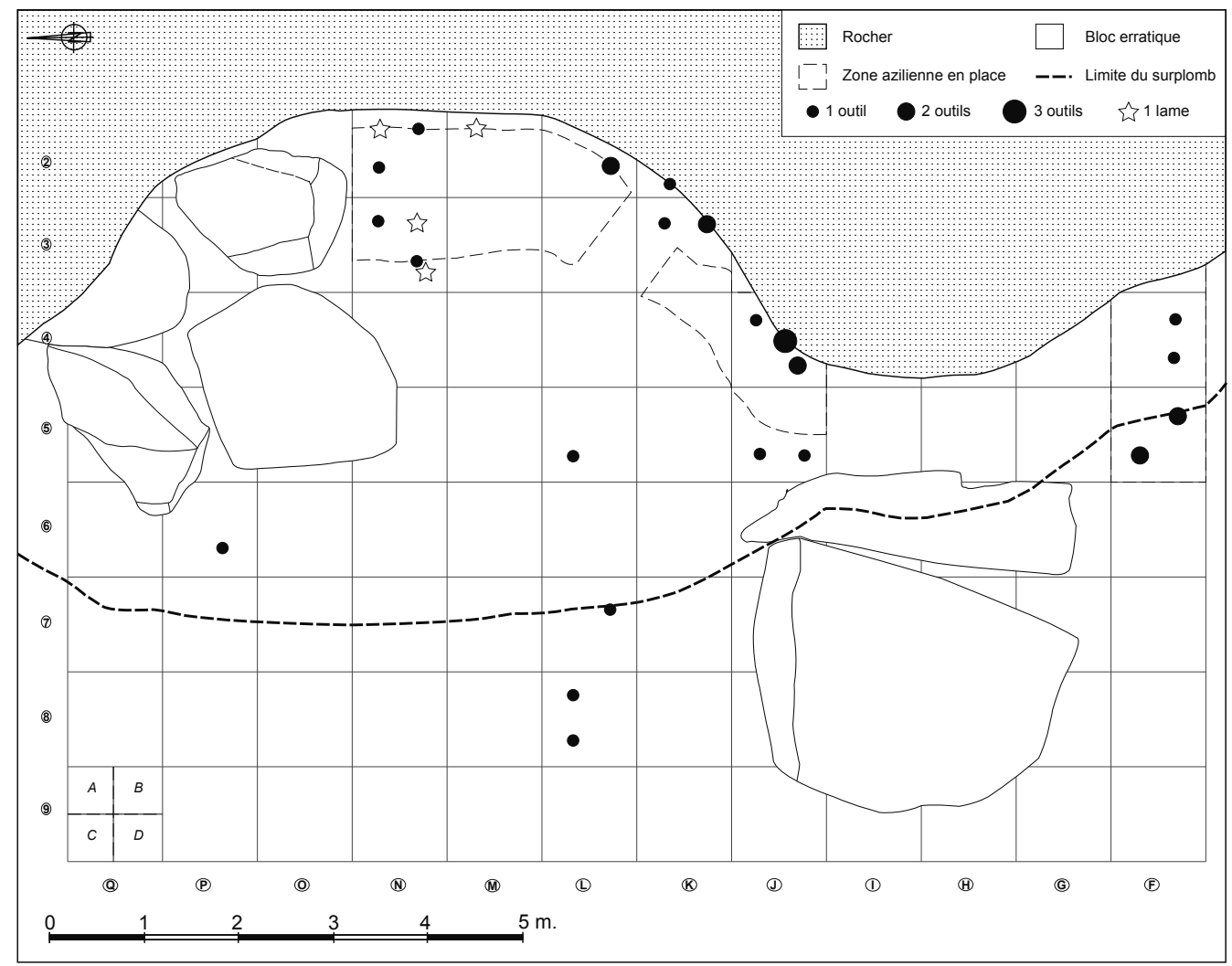

Figure 22 - Répartition des outils aménagées et des grandes lames utilisées, toutes unités stratigraphiques confondues (DAO: G. Marchand).

Figure 22 - Location of the retouched tools and the used blades from all the stratigraphic units (CAD: G. Marchand). 


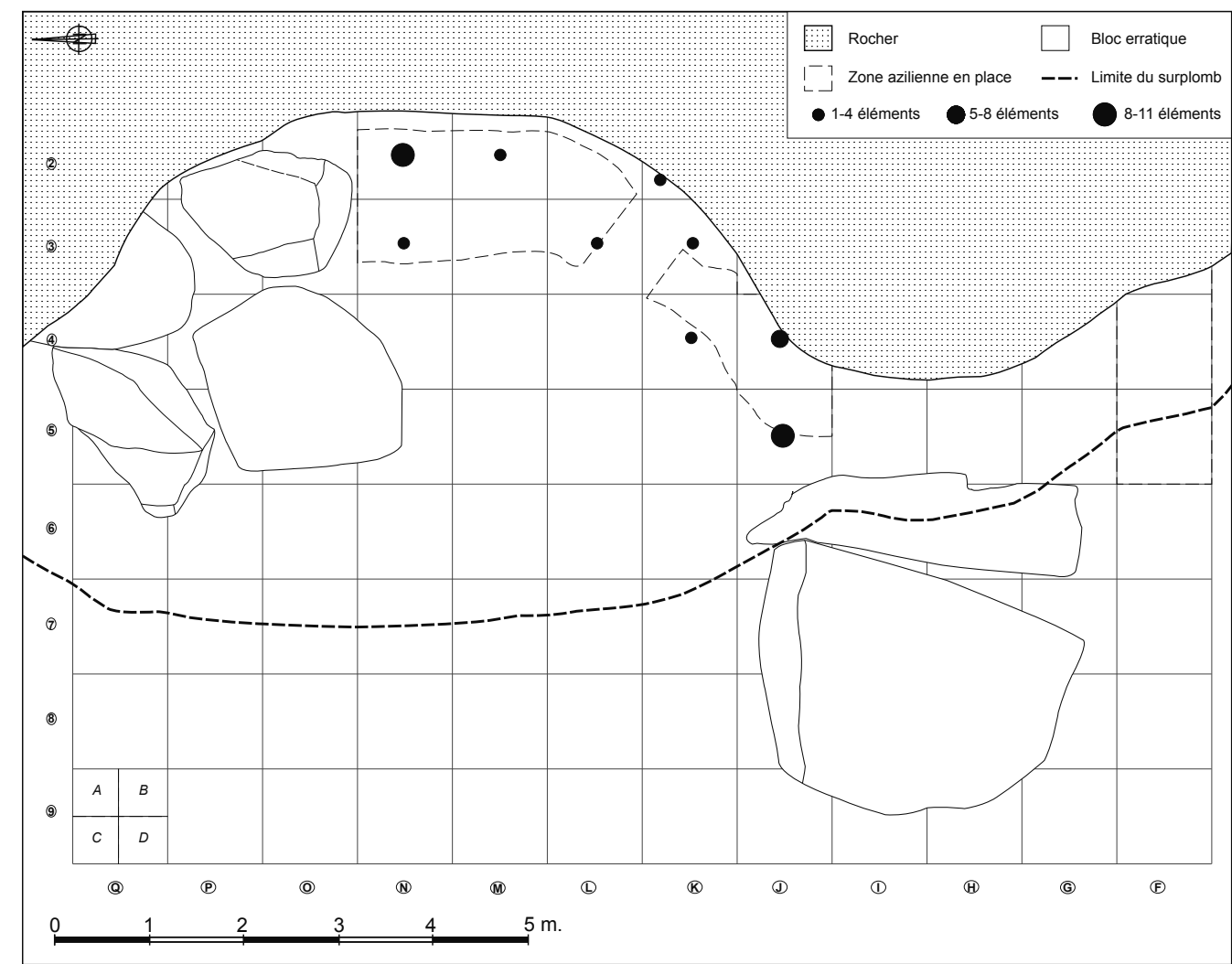

Figure 23 - Répartition par mètres carrés des plaquettes de schiste de dimensions supérieures à $10 \mathrm{~mm}$ dans les unités stratigraphiques aziliennes (4, 5, 6, 8 et 11) (DAO : G. Marchand).

Figure 23 - Location by square meters of the schist plates bigger than $10 \mathrm{~mm}$ in the Azilian levels (stratigraphic units: 4, 5, 6, 8 et 11) (CAD: G. Marchand).

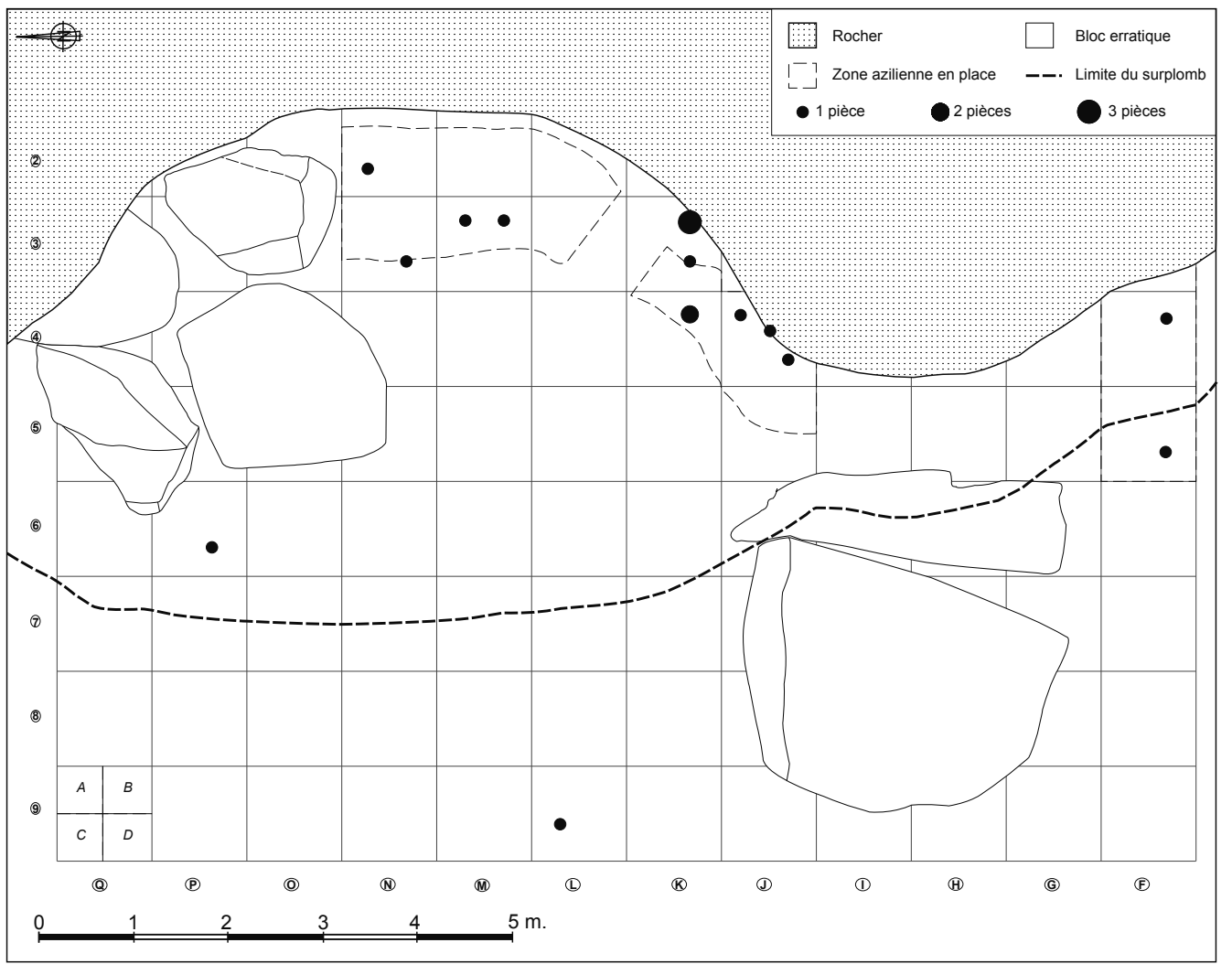

Figure 24 - Répartition des chutes de burin, toutes unités stratigraphiques confondues (DAO : G. Marchand).

Figure 24 - Location of the burin spalls from all the stratigraphic units (CAD: G. Marchand). 


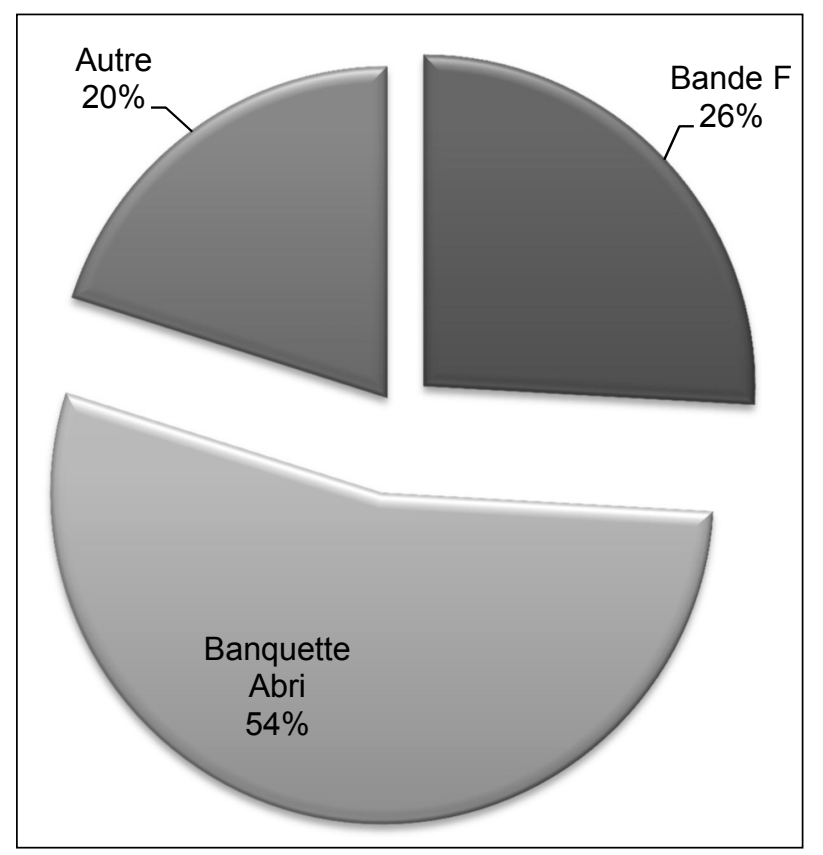

Figure 25 - Répartition des 1313 pièces lithiques taillées recueillies dans les principales zones de l'abri en juillet 2011.

Figure 25 - Origins of the 1313 lithic pieces found in the rock shelter during the 2011 excavation.

\section{2 - Matériel des unités stratigraphiques aziliennes}

\subsection{1 - Caractères généraux}

L'industrie lithique taillée récoltée dans les unités stratigraphiques homogènes de l'intérieur de l'abri (US 4, 5 , 6,8 et 11) est forte de 314 éléments, dont 21 armatures, 9 outils aménagés, 19 outils a posteriori et 137 esquilles. II s'agit de pièces peu affectées par le feu : toutes matières confondues, il y a $13,4 \%$ de pièces brûlées ou chauffées et seulement $7,5 \%$ pour les seuls silex. C'est également une série peu patinée, puisqu'on compte $6,1 \%$ de silex affectés et $2,4 \%$ de pièces portant un simple voile (cette indication est peu intéressante pour les autres roches dont l'altération de surface est moins perceptible). Ces pièces lithiques n'ont pas souffert de remaniement particulier et leur fractionnement est " normal », avec même des lames de très belles dimensions selon les standards régionaux.

\subsection{2 - Les matières premières de l'Azilien}

Le premier enseignement important de cette série exceptionnelle concerne l'usage de roches locales dès l'Azilien ancien en Centre-Finistère, ce qui a des implications évidentes sur nos conceptions du degré de mobilité des êtres humains de l'époque (fig. 26). Ces systèmes techniques d'essence pourtant laminaires ont absorbé une faible part de roches pourtant peu favorables à ces réalisations, il est vrai pour la fabrication d'éclats.

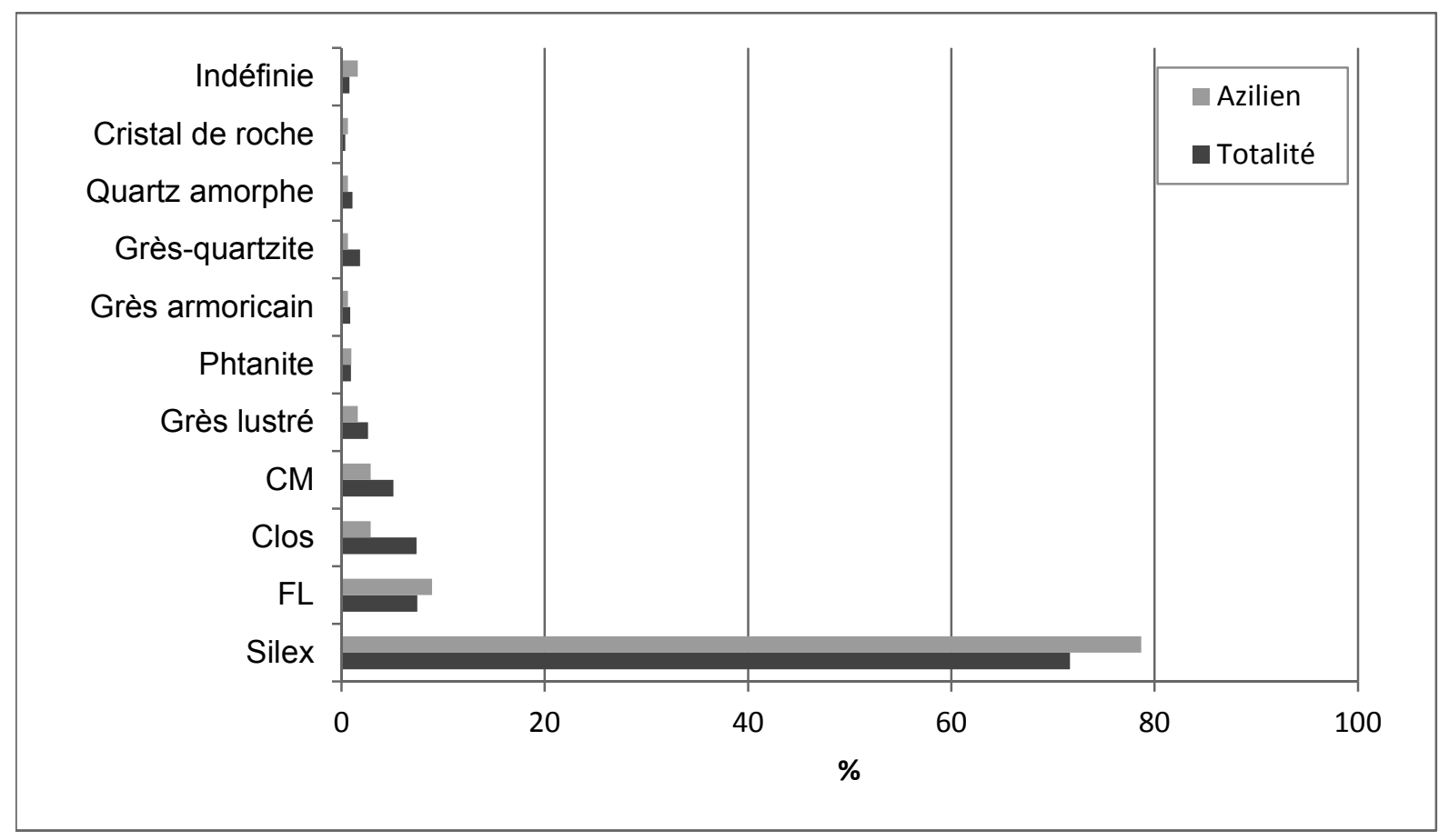

Figure 26 - Principales matières premières travaillées dans la totalité de la collection recueillie en fouille $(N=1313)$ et dans les niveaux aziliens en place $(N=314)$.

Figure 26 - Main raw materials of all the assemblages $(N=1313)$ and in the azilian level $(N=314)$. 


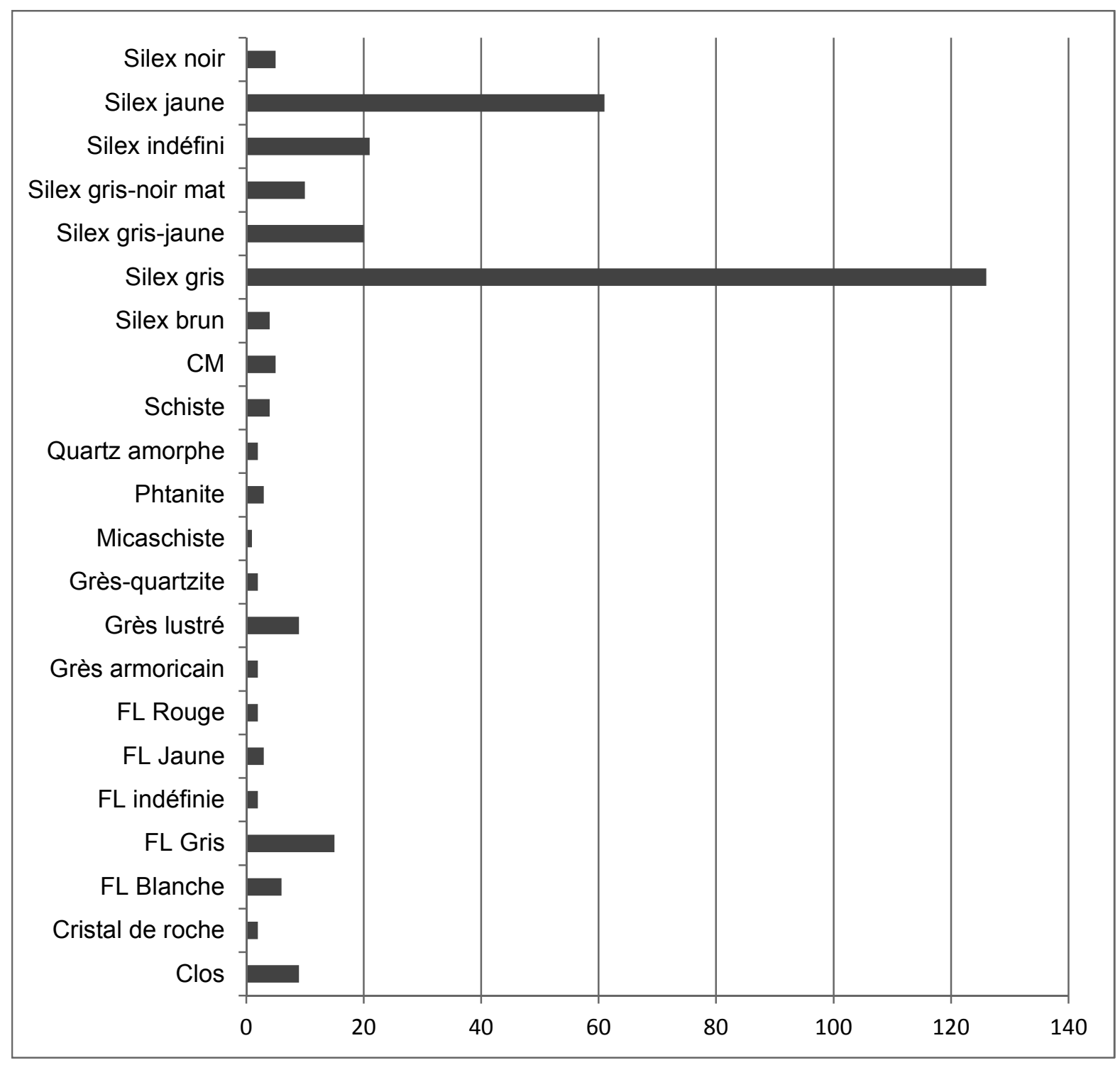

Figure 27 - Principales matières premières travaillées dans les niveaux aziliens en place $(N=314)$.

Figure 27 - Main raw materials in the azilian level $(N=314)$.

Les silex comptent pour $79 \%$ des pièces recueillies, avec plusieurs variétés (tabl. 4, 5 et 6 ). Le débitage laminaire s'est exprimé au mieux sur ces roches. La position de cet abri-sous-roche très éloignée de tous les lieux potentiels d'approvisionnement est probablement à l'origine du faible nombre de cortex observable et donc de notre difficulté à définir le caractère importé ou non des silex. Les variétés grises (gris-moyen) et gris-jaunes représentent $60 \%$ de ces types de roche dans l'Azilien, de même qu'ils dominent sans conteste dans les séries remaniées de l'abri quelles que soient les périodes (fig. 27). Leurs cortex sont assurément roulés et nous indiquent une glane sur les plages de la Paléo-Manche. Les silex jaunes qui forment 25 $\%$ du corpus sont aussi issus de galets marins pour la plupart. Les plages actuelles où l'on peut rencontrer de tels galets sont aujourd'hui situées à $37 \mathrm{~km}$ au nord, mais avec des niveaux marins inférieurs d'au moins $60 \mathrm{~m}$, il faudrait aller au moins à $10 \mathrm{~km}$ au large des côtes actuelles pour atteindre des cordons littoraux. Les gisements crétacés de la Manche sont encore plus éloignés et ils n'étaient pas directement accessibles au Tardiglaciaire (Monnier 1980). Parmi les silex originaux, relativement rares, on note une variété de teinte noire, d'aspect sec et à la surface mate, qui est arrivée sous forme de blocs assez volumineux (roulés ou non-roulés ?) et qui a fait l'objet d'une production d'éclats. Au sein de ces dix éléments recueillis dans les niveaux en place, on remarque une grande tablette de ravivage qui témoigne d'un débitage de lamelle suivant un rythme semi-tournant, avec une abrasion fine de la corniche. Un silex jaune translucide montre de longs 


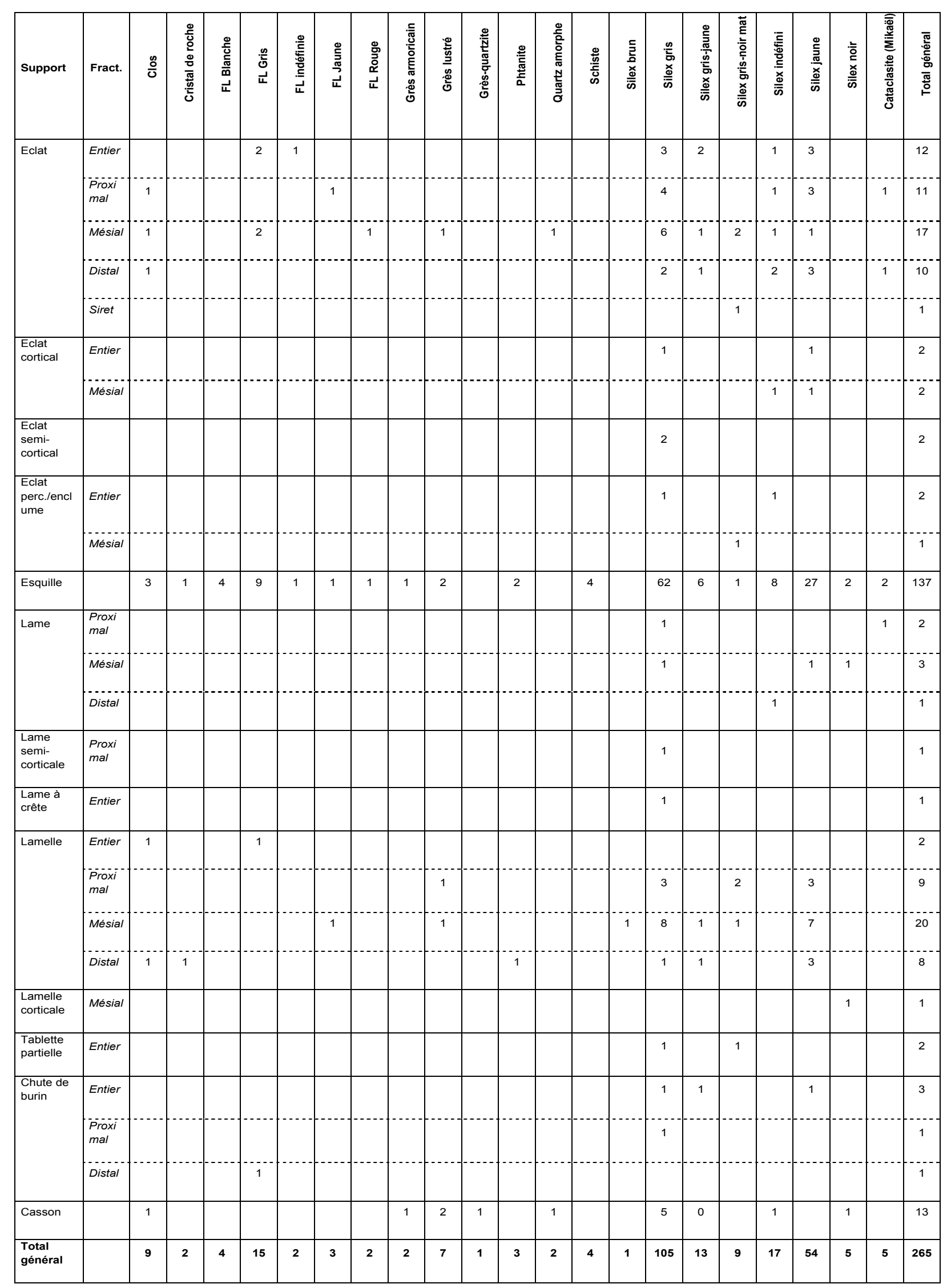

Tableau 4 - Classement des produits bruts de débitage par matières premières issues des unités stratigraphiques aziliennes en place et homogènes (US 4, 5, 6, 8 et 11).

Table 4 - Classification of the unretouched blanks by raw material. Pieces found exclusively in the homogeneous azilian levels (US 4, 5 , 6,8 et 11). 


\begin{tabular}{|c|c|c|c|c|c|c|c|c|c|}
\hline Type & Fraction & 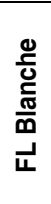 & 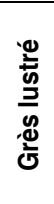 & 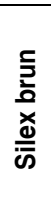 & $\begin{array}{l}\stackrel{\infty}{\vdots} \\
\times \\
\text { 心 }\end{array}$ & 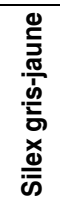 & 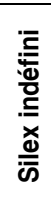 & 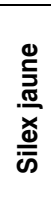 & 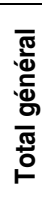 \\
\hline \multirow[t]{2}{*}{ Armature indéfinie } & Fragment & 1 & & & 1 & & 2 & 1 & 4 \\
\hline & Krukowski & & & & 1 & & & & 1 \\
\hline Bipointe azilienne & Entier & & & & 1 & 1 & & & 2 \\
\hline \multirow[t]{2}{*}{ Monopointe azilienne } & Entier & & & & & 1 & & & 1 \\
\hline & Fragment & & 1 & & 1 & & & & 2 \\
\hline Pièce à dos courbe & Fragment & & & 1 & 5 & & & 1 & 7 \\
\hline $\begin{array}{l}\text { Pièce à dos } \\
\text { rectiligne }\end{array}$ & Fragment & & & & 3 & & & & 3 \\
\hline Total général & & 1 & 1 & 1 & 12 & 2 & 2 & 2 & 21 \\
\hline
\end{tabular}

Tableau 5 - Armatures issues des unités stratigraphiques aziliennes en place et homogènes (US 4, 5, 6, 8 et 11).

Table 5 - Arrowheads from the homogeneous azilian levels (US 4, 5, 6, 8 et 11).

\begin{tabular}{|c|c|c|c|c|c|c|c|c|c|c|c|}
\hline Support & Type d'outil & 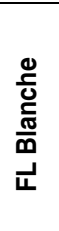 & 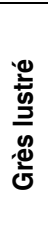 & 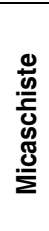 & 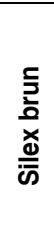 & 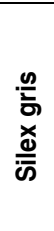 & 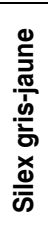 & 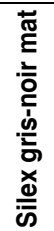 & 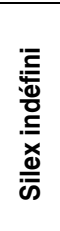 & 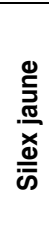 & 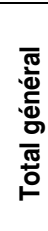 \\
\hline \multirow[t]{5}{*}{ Éclat } & $\begin{array}{l}\text { Bord abattu total } \\
\text { rectiligne }\end{array}$ & & & & & & & & & 1 & 1 \\
\hline & Retouche diverse & & & & & & & 1 & & & 1 \\
\hline & Fil ébréché continu & & & & 1 & & & & & 2 & 3 \\
\hline & Fil ébréché discontinu & 1 & 1 & & & 1 & 1 & & & 1 & 5 \\
\hline & Pièce esquillée & & & & & & & & 1 & & 1 \\
\hline Galet & Galet fendu et abrasé & & & 1 & & & & & & & 1 \\
\hline \multirow[t]{2}{*}{ Indéfini } & Retouche diverse & & & & & 1 & & & & & 1 \\
\hline & Pièce esquillée & & & & & & & & 1 & & 1 \\
\hline \multirow[t]{3}{*}{ Lame } & Retouche diverse & & & & & 2 & 2 & & & & 4 \\
\hline & Fil ébréché continu & & & & & & 1 & & & 1 & 2 \\
\hline & Retouches partielles & & & & & 1 & & & & & 1 \\
\hline Lame à crête & Burin & & & & & 1 & & & & & 1 \\
\hline \multirow[t]{4}{*}{ Lamelle } & Coche & & & & & 1 & & & & & 1 \\
\hline & Fil ébréché discontinu & & & & 1 & 2 & & & & & 3 \\
\hline & Fil ébréché continu & & & & & & & & & 1 & \\
\hline & Retouches continues & & & & & 1 & & & & & 1 \\
\hline $\begin{array}{l}\text { Total } \\
\text { général }\end{array}$ & & 1 & 1 & 1 & 2 & 10 & 4 & 1 & 2 & 6 & 28 \\
\hline
\end{tabular}

Tableau 6 - Types d'outils trouvés dans les unités stratigraphiques aziliennes en place (US 4, 5, 6, 8 et 11).

Table 6 - Tool types found in the homogeneous azilian levels (US 4, 5, 6, 8 et 11). 
filaments blancs groupés parfois en faisceaux identifiés comme des spicules de spongiaire ; la présence également de bryozoaires laisse penser à une formation en milieu marin. II porte un cortex non roulé, peu épais, sans zone sub-corticale, qui signale une collecte dans un bassin sédimentaire encore à détecter. Les plus proches gisements d'argiles à silex d'âge secondaire sont à plus de $280 \mathrm{~km}$ en droite ligne depuis l'est dans la Sarthe. Cette roche très caractéristique de ces niveaux aziliens a servi sous la forme de lames et d'éclats.

Le microquartzite de la Forest-Landerneau (contracté ici en $\mathrm{FL}$ ) est une roche à l'aspect saccharoïde, constituée de grains de quartz de dimensions en apparence identiques, sans ciment décelable. Présente en fort bancs sur la commune éponyme, à l'est de Brest dans la vallée de l'Elorn à $40 \mathrm{~km}$ à l'ouest du site, elle existerait aussi sporadiquement dans toute la faille nord-finistérienne (cisaillement nord armoricain ou CNA ; Gouletquer et al. 1996 ; Marchand et Tsobgou Ahoupe 2007) à des distances de l'ordre d'une vingtaine de kilomètres de Kerbizien. Un examen à la binoculaire a été nécessaire pour distinguer certains silex et les variétés grises et noires de $\mathrm{FL}$, tellement cette dernière roche montre un grain fin. Notons que la variété grise est zonée, avec des bandes de 1 à $2 \mathrm{~mm}$ alternativement gris clair et gris foncé. Parmi les 28 fragments recueillis (8\%), on identifie trois lamelles tirées à la pierre, de 9 à $10 \mathrm{~mm}$ de large, dont l'une est le support d'une armature non identifiée et de huit petits éclats, le reste étant des esquilles.

Issues des failles du CNA au sud de Morlaix comme le microquartzite FL, la cataclasite de Mikaël (CM) et la calcédoine du Clos sont également présentes, avec respectivement 1,6 et $2,9 \%$ des pièces. Ces faibles nombres interdisent hélas de saisir la subtilité des chaînes opératoires. Pour la première, il y a deux esquilles, deux fragments d'éclat et un proximal de lame, que l'on imagine courte car cette roche ne favorise guère de telles productions. Pour la calcédoine du Clos, le bilan est identique. II s'agit d'une roche multicolore (jaune, blanche, rouge, rosée), toujours translucide avec de petites inclusions et souvent un fin litage. On connaît de grandes plaques épaisses d'environ $50 \mathrm{~mm}$ avec des longueurs atteignant les $120 \mathrm{~mm}$ dans les zones perturbées de Kerbizien, de même que dans la collection recueillie par J.J. Mazurier. Elle semble très sensible à la chaleur, d'autant que les craquelures internes sont très visibles car la roche est transparente. Les trois petits éclats irréguliers et les deux fragments de lamelles, tous tirés à la pierre, disent peu de chose de la production afférente. Un vaste sitecarrière est connu à $17 \mathrm{~km}$ au nord, au Clos (Plourin-lesMorlaix), par delà les Monts d'Arrée ; il a d'ailleurs livré en surface des pointes à dos courbe en silex, en calcédoine ou en microquartzite $\mathrm{FL}$, mélangées à des armatures du Premier Mésolithique (Gouletquer et al. 1994).

Le constat d'une production à l'Azilien est nettement mieux assuré pour le grès éocène, puisque parmi les neufs éléments $(2,9 \%)$, il y a une monopointe à dos courbe sur lamelle (fig. $28, n^{\circ} 13$ ). On note aussi un fragment proximal de lamelle à deux pans, au talon lisse et large, dont la corniche a subi une abrasion intense, ce qui a entraîné un doucis comme sur certaines lames en silex. Le cristal de roche a fait l'objet d'un débitage d'éclats anecdotique à l'échelle du site (cinq éléments sur 1313 ) ; seuls une esquille et un fragment distal de lamelle de très petites dimensions pourraient laisser penser à un travail au Tardiglaciaire.

L'assemblage lithique azilien recueilli à Kerbizien témoigne d'échanges ou de parcours à des distances d'une cinquantaine de kilomètres au nord vers les rivages de la Manche ; les niveaux jurassiques ou crétacés à l'est du Massif armoricain forment un autre pôle d'approvisionnement, qui invitent à imaginer de bien plus longs déplacements. L'analyse technologique est susceptible de nous instruire davantage sur leurs modalités.

\subsection{3 - Des chaînes opératoires incomplètes}

Les séquences opératoires décelables sur les roches originaires du Massif armoricain ont été rapidement évoquées précédemment ; elles concernent une production d'éclats de 15 à $30 \mathrm{~mm}$, peu standardisés et réalisés au percuteur dur (tabl. 7). Les talons sont en majorité punctiformes et portent une faible abrasion.

Les informations techniques les plus pertinentes proviennent plutôt des 247 pièces en silex recueillies en place. Les produits lamino-lamellaires y sont en fortes proportions avec $22,6 \%$ de l'ensemble des objets bruts et retouchés toutes roches confondues ou $24,3 \%$ pour les seuls silex. Si on affine ces considérations en ne prenant en compte que les pièces entières et les fragments proximaux en silex, lames et lamelles atteignent alors $38 \%$. II y a clairement une grande variété de standards de production, de la lamelle à la lame large, depuis des largeurs de $5 \mathrm{~mm}$ jusqu'à celles de 24, y compris au sein des armatures. D'ailleurs, la moyenne des largeurs de ces dernières est de $9,8 \mathrm{~mm}$ avec un écart-type de 3,4 et un simple coup d'œil sur la planche de dessins (fig. 28) suffit à prendre conscience de cette disparité de module. On juxtaposera ainsi aux deux extrêmes une petite monopointe du carré K4B (US4) et une bipointe du carré J5D (US8), avec beaucoup de cas intermédiaires. II convient cependant d'être circonspect quant à la présence en K3D (US5) d'un fragment d'armature à dos très étroite $(3,8 \mathrm{~mm})$, peut-être intruse depuis les niveaux mésolithiques où ces pièces sont davantage connues. Les différences de profil longitudinal sont également assez frappantes, les supports de certaines pointes étant franchement convexes, les plus fréquents étant cependant rectilignes. Les lames larges et plates sont destinées à être utilisées pour leur tranchant, avec parfois un ravivage ou un renforcement par des lignes de retouches directes semi-abruptes continues (fig. 29). Enfin, les cinq chutes de burin longues de 15 à $25 \mathrm{~mm}$ nous signalent de manière indirecte un troisième objectif de la production laminaire, la réalisation de supports allongés et épais destinés aux burins (mais sont-ce toujours des lames ou bien de grands éclats ?). 

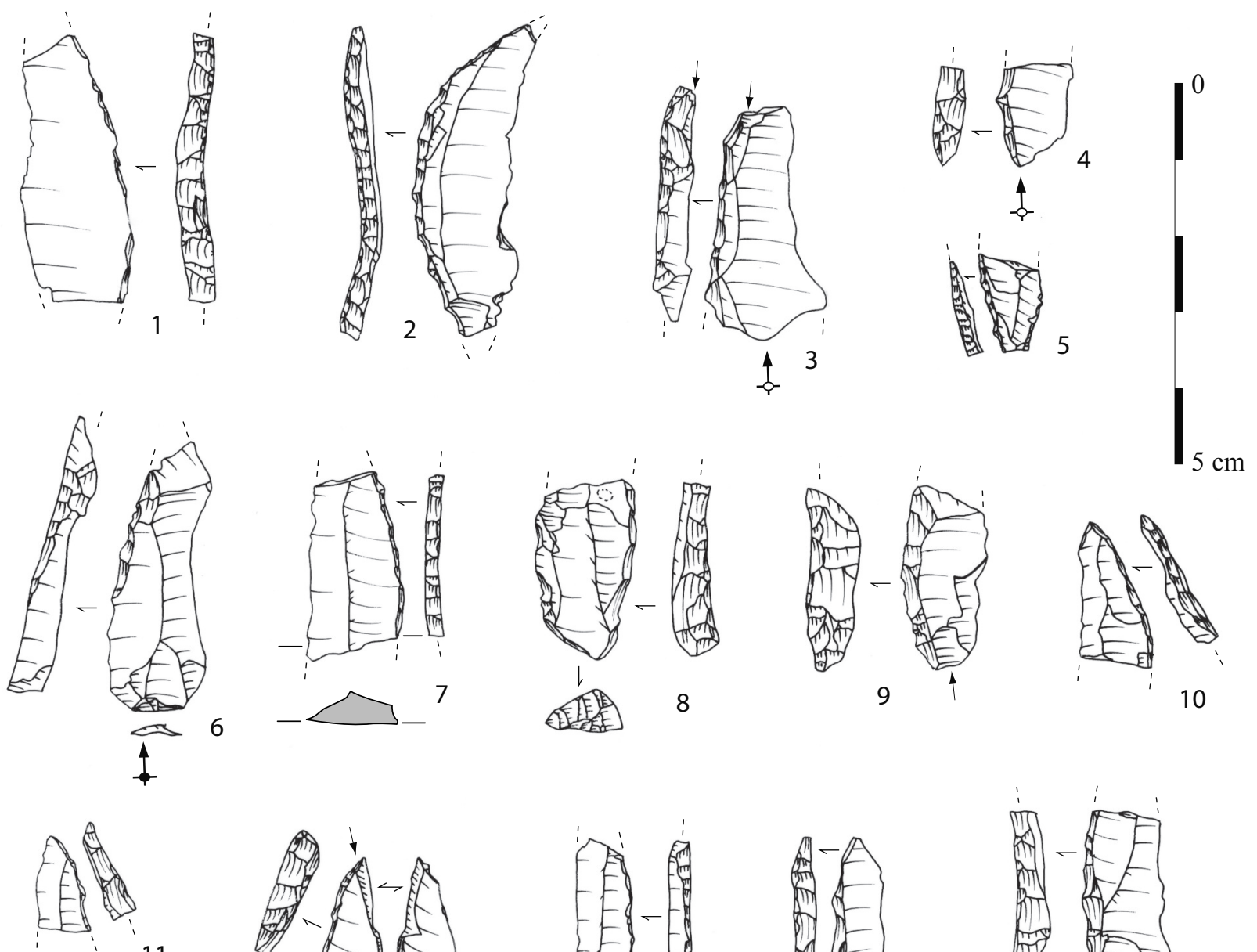

11
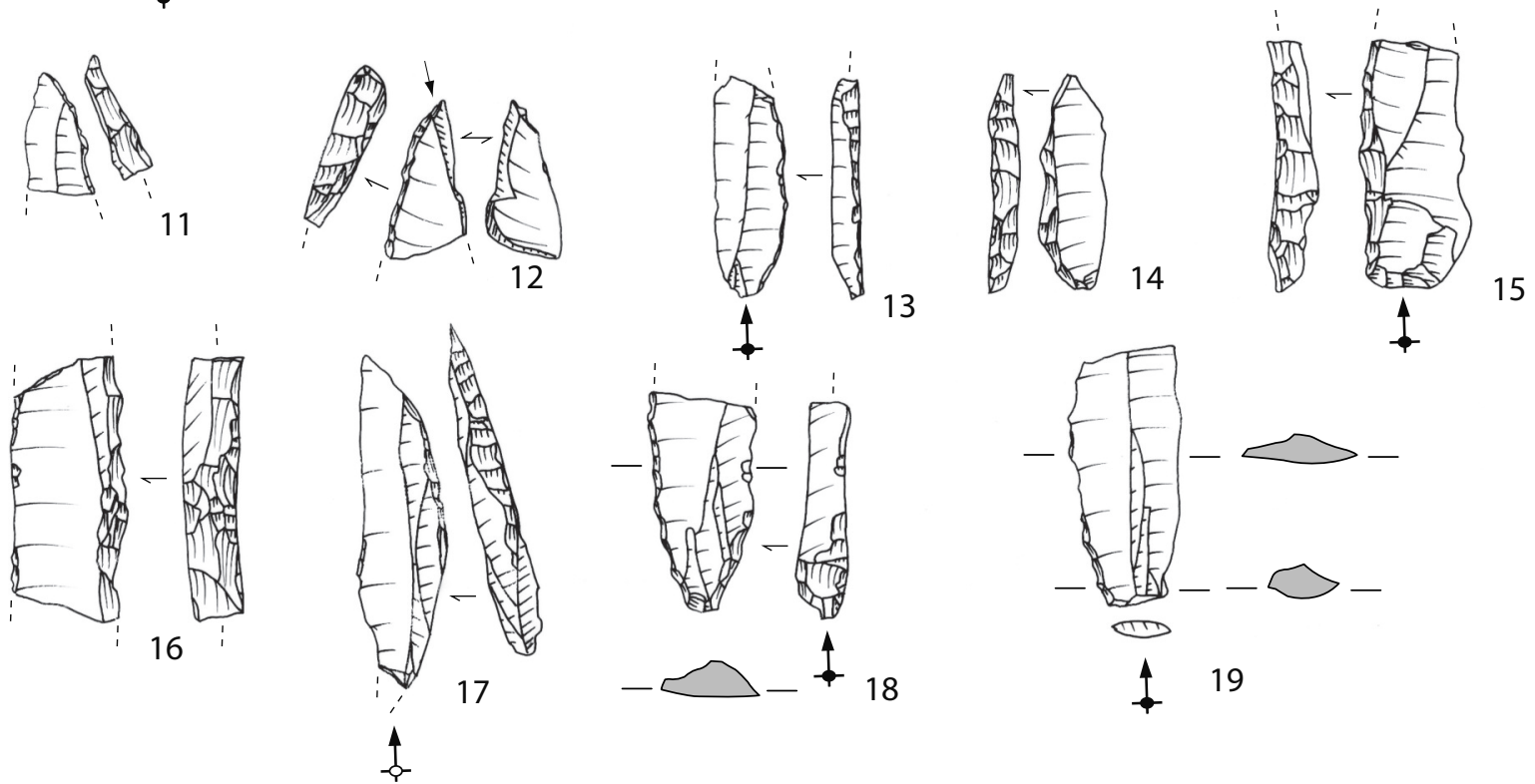

Figure 28 - Armatures à dos courbe recueillies dans les zones en place de l'intérieur de l'abri (Dessins : G. Marchand).

Figure 28 - Curved-backed points discovered in the azilian levels inside the rock shelter (drawings: G. Marchand). 


\begin{tabular}{|c|c|c|c|c|c|c|c|c|c|}
\hline & \multicolumn{3}{|c|}{ Totalité (N=314) } & \multicolumn{3}{c|}{ Éclat a-cortical et semi-cortical brut (N=62) } & \multicolumn{3}{c|}{ Lames et lamelles brutes $(\mathrm{N}=52)$} \\
\cline { 2 - 11 } & Longueur & Largeur & Épaisseur & Longueur & Largeur & Épaisseur & Longueur & Largeur & Épaisseur \\
\hline Moyenne & 23,6 & 12,1 & 3,5 & 17,4 & 14,5 & 3,8 & - & 9,6 & 2,5 \\
\hline $\begin{array}{c}\text { Écart- } \\
\text { type }\end{array}$ & 15,8 & 5,7 & 2,0 & 7,3 & 4,5 & 2,2 & - & 3,4 & 1,0 \\
\hline Maximum & 83,6 & 46,7 & 15,1 & 35,0 & 26,1 & 12,4 & - & 24,0 & 5,0 \\
\hline Minimum & 8,2 & 2,4 & 0,8 & 8,2 & 7,4 & 1,1 & - & 3,4 & 0,8 \\
\hline
\end{tabular}

Tableau 7 - Dimensions en mm de la totalité des pièces lithiques taillées, des éclats bruts non-corticaux et semi-corticaux et des lamelles et lames non corticaux. Ces pièces proviennent exclusivement des unités stratigraphiques aziliennes en place (US 4, 5, 6, 8 et 11), toutes roches confondues.

Table 7 - Size of all the lithic remains, of the unretouched flakes and of the uncortical blades and bladelets (all kind of raw materials). Pieces found exclusively in the homogeneous azilian levels (US 4, 5, 6, 8 et 11)..

La production laminaire semble en grande majorité unipolaire, mais il faut moduler ce constat car l'exploitation bipolaire d'une même table n'engendre pas forcément un recouvrement très étendu des différentes séquences, surtout lorsque leur croisement se fait en partie distale et que le fractionnement des objets en rend l'observation malaisée. Un grand fragment mésial de lame désigne une telle modalité ; cette pièce porte également un enlèvement antérieur au débitage bipolaire, peut-être lié à une crête latérale sur le nucléus. Elle a été retouchée sur les deux bords puis percutée - davantage que retouchée - dans un mouvement transversal qui a engendré des retouches inverses rasantes scalariformes (fig. 29, $\mathrm{n}^{\circ} 4$ ). On notera pour finir cette description une fracture en languette de la lame après la retouche. On mentionnera aussi un fragment distal de lame probablement inséré dans un débitage laminaire régulier, qui porte des négatifs opposés (fig. 29, $\mathrm{n}^{\circ} 5$ - M3D), en provenance hélas d'un niveau remanié (US7).

Les lames longues de plus de $80 \mathrm{~mm}$ et larges de 20 à $25 \mathrm{~mm}$ sont un des objectifs de débitage les plus marquants, d'autant que certains exemplaires ont été conservés entiers sous la forme de couteaux aux bords très retouchés ou ébréchés (fig. 30 et 31 ). La courbure longitudinale de ces lames plates est assez prononcée. Certaines (par exemple N3D US5, fig. 29, $n^{\circ} 1$ ) montrent un élargissement progressif depuis leur partie proximale. La moitié des pièces observables $(\mathrm{N}=16)$ arborent un doucissage des corniches extrêmement prononcé, associé à des talons punctiformes ou dans deux cas dièdres larges (c'est aussi le cas pour le grès éocène). Les stigmates de percussion sont peu diserts. La percussion directe à l'aide d'un percuteur de pierre tendre n'est pas l'hypothèse privilégiée à partir des stigmates disponibles, puisque l'on n'observe pas d'ondulations (ou de rides) légères de la face inférieure. La percussion directe tendre pourrait être présente sur certaines lames aux talons larges et doucis ; la percussion directe dure est en revanche fort probable sur d'autres talons de lame, de même que sur certains éclats.

Le débitage d'éclats montre une très faible standardisation et la rareté des outils aménagés empêche même de définir des objectifs clairs pour la production. Sur les 23 talons d'éclats a-corticaux diagnostics, 21 montrent les stigmates de la percussion directe dure, avec un entretien préalable des corniches similaires aux lames. Cet inventaire bref traduit bien la nature incomplète des chaînes opératoires, où manquent les prémices comme la mise en forme des volumes (probablement par des crêtes), mais aussi les nucléus. Le fractionnement des séquences dans l'espace est évident, mais à quelle échelle ? Sur la totalité du site ou bien seulement la partie résiduelle que nous avons pu fouiller? Impossible de répondre. Mais l'étude plus précise de l'outillage et de ses traces d'altération va nous permettre d'affiner nos conclusions.

\subsection{4 - Un spectre fonctionnel très particulier}

Le taux d'utilisation par support est plus important pour les lames $(66,7 \%)$, que pour les lamelles $(24,0 \%)$ ou les éclats a-corticaux $(17,7 \%)$. Le faible nombre des autres supports rend peu intéressant les considérations statistiques (tabl. 5 et 6). L'outillage aménagé est en directe continuité avec les supports utilisés sans aménagements préalables (dits aussi outils a posteriori), puisqu'il s'agit dans quatre cas de lames aux bords retouchées et dans deux cas de supports portant quelques retouches. L'inclinaison oblique des retouches et leur régularité plaident pour un ravivage en cours d'utilisation. II y a aussi un fragment d'éclat à bord abattu rectiligne, large de $12,3 \mathrm{~mm}$, trop court pour supporter une quelconque interprétation ou un fragment proximal de lamelle portant une coche par flexion. Si l'on excepte une pièce esquillée brûlée, ce sont les supports aux tranchants simplement utilisés qui dominent, éclats ou lames. Un grand fragment de lame porte des retouches semi-abruptes directes et continues des deux bords, avec un usage postérieur en percussion lancée sur un des bords, qui a entraîné des esquillements inverses (N3A).

A ce premier volet de l'outillage, lié à des actions de coupe pour la plupart, on doit adjoindre un second formé par les armatures (fig. 28). Plusieurs modules de supports laminaires existent pour les pointes à dos courbe, que l'on ne peut qu'estimer puisqu'ils sont évidemment bien 

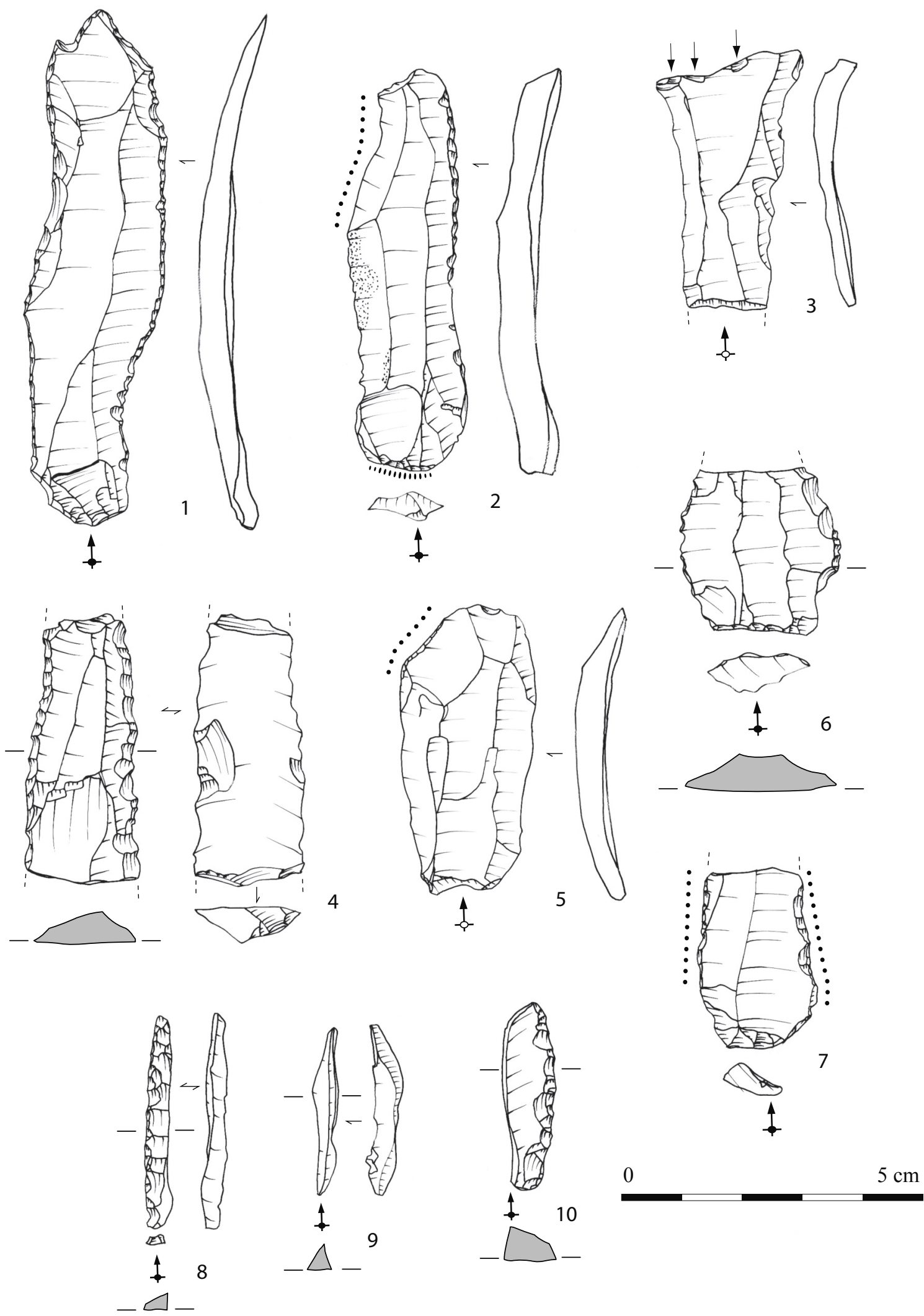

Figure 29 - Outils sur lames ( $n^{\circ} 1$ à 7$)$ et chutes de burins ( $n^{\circ} 8$ à 9) recueillies dans les zones en place de l'intérieur de l'abri (Dessins : G. Marchand).

Figure 29 - Tools on blade ( $n^{\circ} 1$ à 7$)$ and burin spalls ( $n^{\circ} 8$ à 9) from the homogeneous azilian levels (Drawings: G. Marchand). 


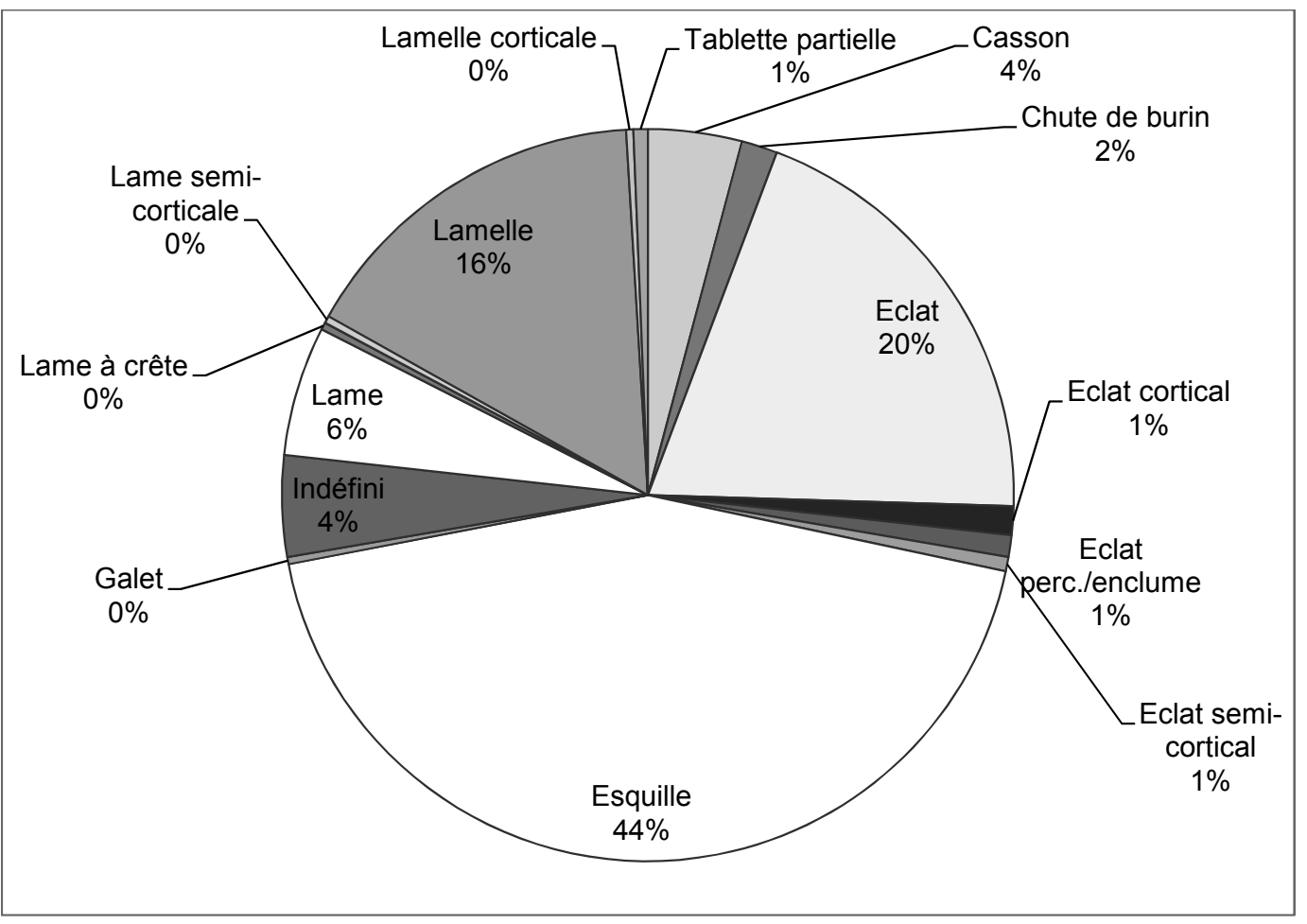

Figure 30 - Totalité des supports des couches aziliennes en place, bruts ou retouchés $(N=314)$.

Figure 30 - Blanks (retouched or not) from the homogeneous azilian levels $(N=314)$.

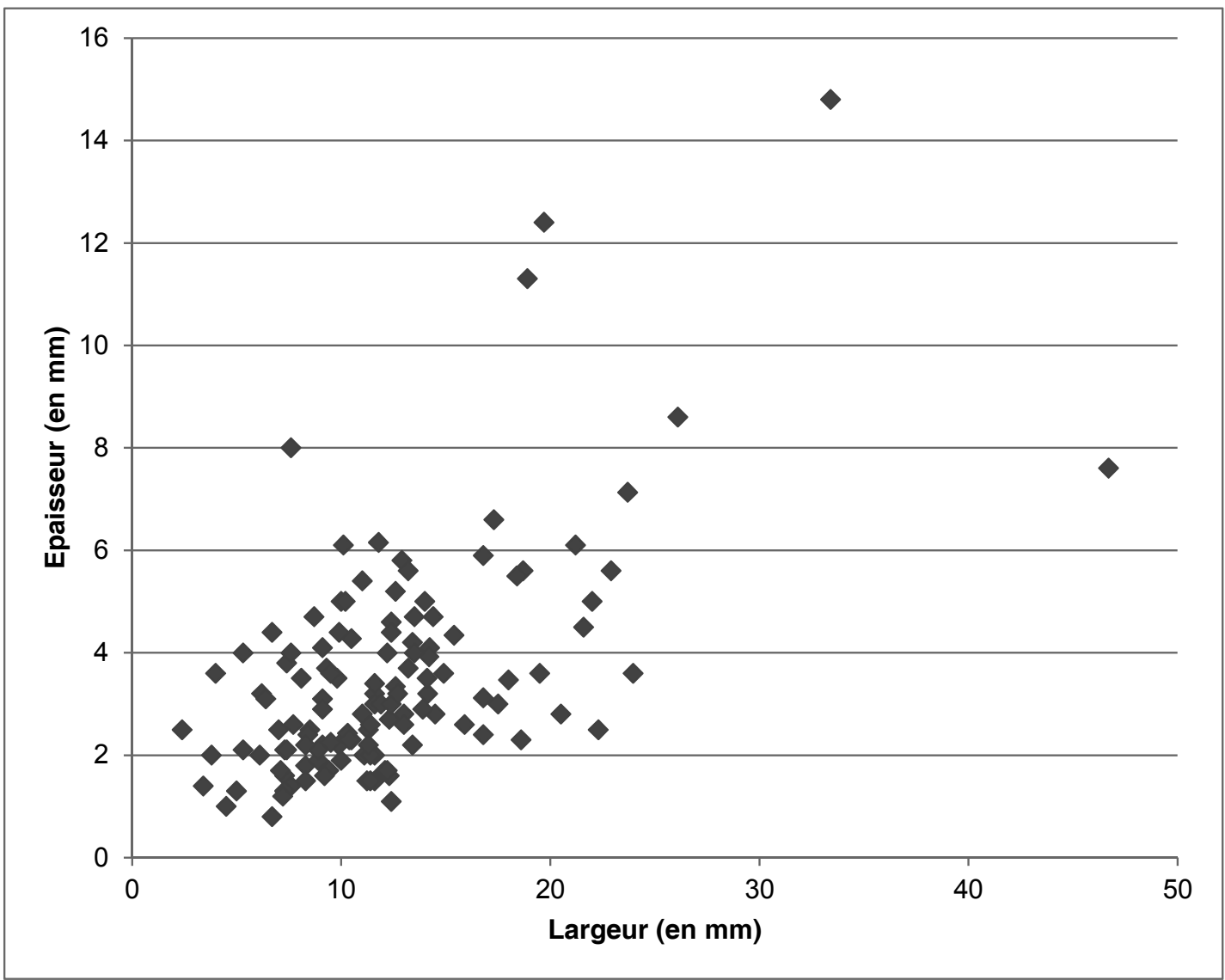

Figure 31 - Largeur et épaisseur des objets lithiques mesurés dans les couches aziliennes en place.

Figure 31 - Width and thickness of the lithic remains from the homogeneous azilian levels. 
modifiés par la retouche. II s'agit de lamelles et de lames relativement régulières, à profil rectiligne pour la plupart, ou bien étonnamment arquées pour certains grands exemplaires (J5B-US11 ou J5D-US8), ou bien encore torses (N3A-US5). Si l'on considère les 21 armatures à dos courbe entières ou fragmentées recueillies dans les niveaux aziliens en place en 2011, les largeurs sont comprises entre 6,2 et $15,4 \mathrm{~mm}$, avec une moyenne à 10,3 $\mathrm{mm}$ (écart-type : 3,0$)$. Les supports sont épais en moyenne de 3,3 mm (écart-type : 1,2). Les pièces entières témoignent aussi d'une disparité évidente des longueurs : 22 , 34 et $41,2 \mathrm{~mm}$ pour les niveaux en place et une pièce de $46 \mathrm{~mm}$ dans l'US 31. Avant d'interpréter cela comme une diversité fonctionnelle, il faut sûrement prendre en compte la durée de l'Azilien de presque un millénaire et donc les multiples incursions imaginables sur ce site, les objectifs des débitages et les disponibilités en matériaux changeant à chaque fois de manière subtile.

Parmi les 15 armatures aziliennes pour lesquelles ce type d'analyse est envisageable (monopointes, bipointes ou pièces à dos courbe, pièces à dos courbe ou rectiligne), les latéralisations s'équilibrent à gauche et à droite. Les retouches sont en général directes abruptes, dans un cas abruptes croisées lorsque la ligne de retouche croise une nervure sur un support épais (6 mm - K2D-US5 - fig. 28, $\left.\mathrm{n}^{\circ} 16\right)$. On note dans les niveaux en place deux bipointes et trois monopointes. Un fragment parmi les plus épais montre également une base convexe à retouches directes (J4AUS1G- fig. 28, $n^{\circ} 8$ ) ; d'autres bases correspondent à des talons encore bruts, l'extrémité apicale étant en partie distale en règle générale.

Beaucoup d'esquilles de retouches découvertes dans les niveaux de fond de l'abri témoignent de la fabrication de gros outils de quelques millimètres d'épaisseur, certains étant probablement des pointes aziliennes. Cette activité serait également dénoncée par trois pièces à dos courbe portant une fracture de type Krukowski, soit une cassure lors de la retouche d'un dos (J4D-US8 et N3A-US5). L'aspect usagé de ces pointes montre pourtant aussi un « retour de chasse »: il y a deux fragments d'armatures avec des impacts pseudo-burinant d'axe longitudinal (usage en pointe), tandis que nombre des cassures nettes pourrait aussi témoigner de tels impacts. Les extrémités apicales sont rares et en assemblant ces cassures à la fabrication, ces retouches et ces cassures à l'impact, l'hypothèse d'une réparation d'armes lors d'un démanchement / emmanchement gagne en crédibilité.

Le troisième volet d'activité est représenté par les burins, mais surtout de manière indirecte. En effet, un seul outil de ce type a été identifié, alors que cinq chutes de burins furent recueillies dans les niveaux aziliens en place, onze autres gisant dans d'autres unités stratigraphiques. II y a un double burin dièdre sur une lame à crête à un pan en silex gris, relativement court (longueur 27,3 mm, largeur 12,9 et épaisseur 5,8), avec un pan de chaque côté, repris plusieurs fois pour l'un d'eux (carré K3A-US6). Sur deux chutes de burin, le point d'impact, le talon et la corniche ont été totalement doucis avant l'enlèvement, probablement lors de l'usage en burin. Même sans analyse tracéologique, il est évident que toutes ces chutes montrent des usages antérieurs des tranchants et de longues lignes de retouches du bord. Dans un cas (M3B-US 7, fig. 29, n`8), la régularité de ces aménagement laissent plutôt penser au façonnage d'une néo-crête. Les burins étaient au moins dans deux cas sur troncature. Longues de 13 à $33,6 \mathrm{~mm}$, ces chutes proviennent plutôt d'outils sur grandes lames.

Outre les grands blocs de granite A, B et C dont il sera question plus bas, un galet allongé en micaschiste gris a été percuté longitudinalement puis cassé, ce qui a enlevé de grands éclats de part et d'autre. II mesure $33,4 \mathrm{~mm}$ de large pour 14,8 d'épaisseur. On distingue aussi sur cet outil un usage en pièce intermédiaire qui a entrainé un écrasement à une extrémité, peut-être dans une action d'abrasion. Un gros pavé en grès non taillé, non percuté et non poli est aussi à signaler (il mesure $96 \mathrm{~mm}$ de long).

Rarement dans une collection préhistorique de l'Ouest un spectre fonctionnel n'a été aussi singulier : de grandes lames usagées, des pointes aziliennes dans divers états et des nombreuses chutes de burin, mais avec un seul burin. Les unités stratigraphiques de Kerbizien plus hétérogènes fouillées en 2011 ne viennent pas transformer notablement ce spectre fonctionnel, pour autant que l'on puisse en juger. Les grands absents du tableau sont les grattoirs, sur bout de lame ou circulaires. Ces derniers étaient présents dans tous les locus du site azilien récent des Chaloignes à Mozésur-Louet (Maine-et-Loire ; Marchand 2008 ; Marchand et al. 2004, 2008, 2009, 2011a). Sur ce site, il y avait aussi des burins sur supports épais (lames ou éclats) et de grands couteaux à dos en continuité morphologique avec les pointes, un type d'outil absent ici aussi. Bien que les occupants du site angevin résidassent à une cinquantaine de kilomètres du seuil du Poitou et du Bassin parisien si riches en silex de bonne tenue, ils optèrent pour un débitage laminaire réalisé à la pierre. Les produits que nous étudiâmes étaient bien moins allongés et réguliers que ceux de Kerbizien. En d'autres termes, le caractère très laminaire de l'Azilien de l'abri finistérien est une donnée culturelle affirmée sans ambages, malgré l'éloignement des gîtes de silex. La préparation intense des corniches et l'usage probable de la percussion tendre (ou semi-tendre) tranchent également avec ce qui fut observé sur les différents locus des Chaloignes. Ce paramètre technique, de même que la présence de bipointes, nous orientent vers une attribution chronologique à une phase ancienne de l'Azilien, sur laquelle nous reviendrons plus loin.

\section{3 - Matériel lithique des unités stratigraphiques bouleversées}

L'ablation d'une bonne part des sédiments dans et devant la caverne a paradoxalement limité la présence d'unités stratigraphiques mélangées : tout a été nettoyé ! On pointera comme source principale d'informations le lit de limons et de débris végétaux partiellement décomposés qui nappait le site à notre arrivé (US 1), avec 239 pièces lithiques recueillies en son sein. Pointe azilienne, lamelle étroite à bord abattu du premier Mésolithique (L6D) et 

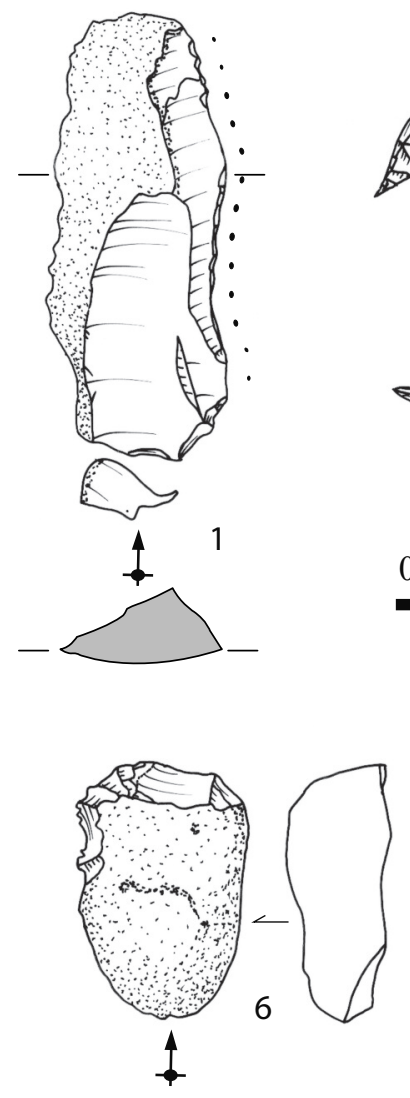
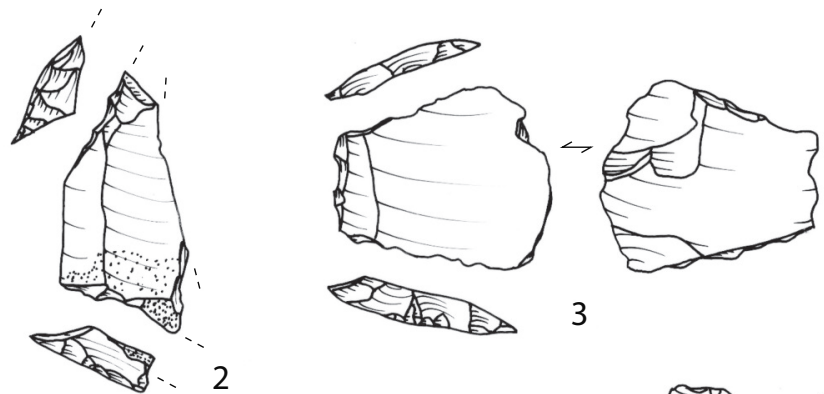
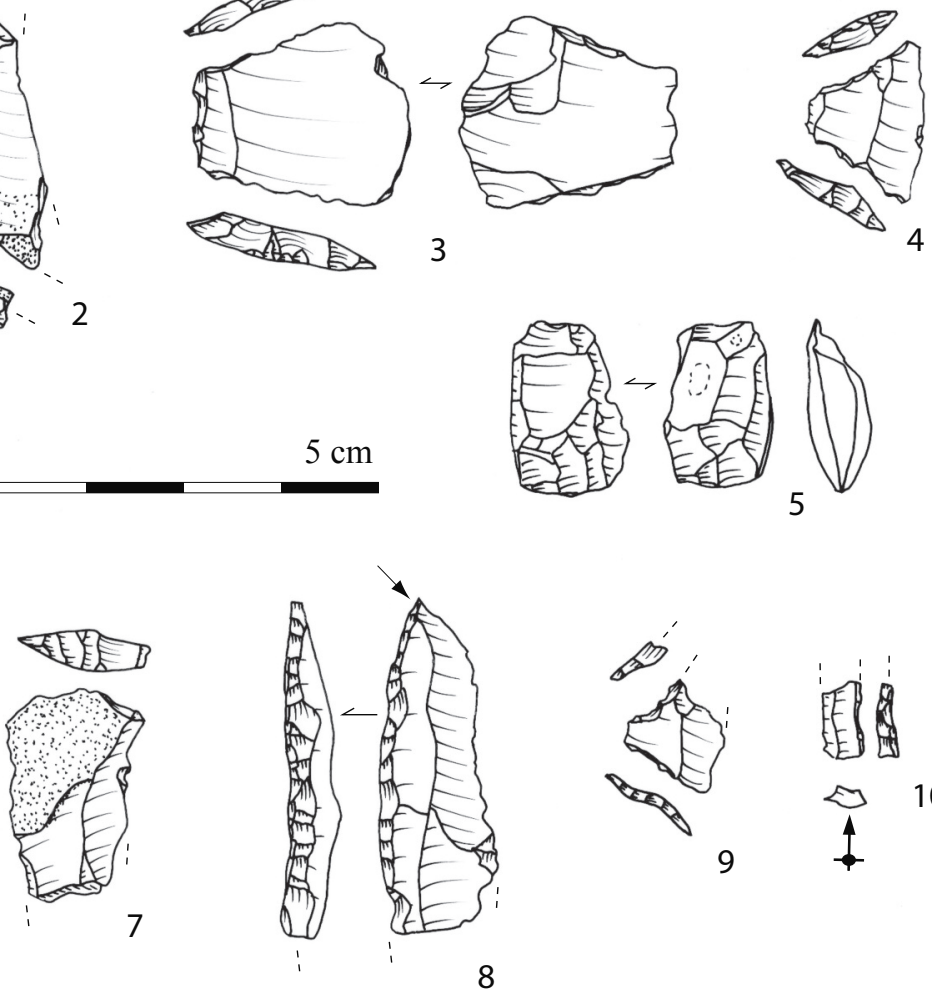
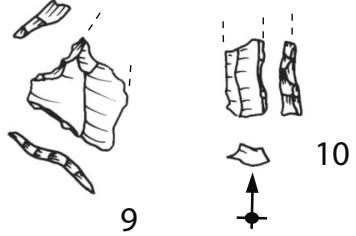

Figure 32 - Outils recueillis dans les US perturbées de Kerbizien (1-5: fond de la caverne ; 6-10: bande L). 1 : lame utilisée ; 2 : trapèze asymétrique ; 3 : bitroncature symétrique (flèche tranchante) ; 4 : trapèze symétrique ; $5:$ pièce esquillée ; $6:$ grattoir sur un éclat obtenu lors d'une percussion bipolaire sur enclume ; 7 : grattoir sur éclat ; 8 : pointe azilienne ; 9 : fragment de trapèze ; 10 : fragment de lamelle à dos (Dessins : G. Marchand).

Figure 32 - Tools from the mixed stratigraphic units (1-5: bottom of the cave ; $6-10$ : band L). 1 : used blade ; 2: symmetrical trapeze ; 3 : transverse arrowhead ; 4 : symmetrical trapeze ; 5 : splinted piece ; 6-7: scrapper ; 8 : azilian point ; $9:$ trapeze fragment ; 10 : backed bladelet fragment (drawings : $G$. Marchand).

trapèze symétrique du second Mésolithique (L7B) témoignent de la présence évidente d'occupations de la fin du Pléistocène et du début de l'Holocène dans cette cavité (fig. 32 - tabl. 8, 9 et 10).

Autre source d'information sur « ce qui fut », l'unité stratigraphique large de $20 \mathrm{~cm}$ tout le long de la paroi correspond à une perturbation qui est venue affecter tous les niveaux (US 13) et en condense l'information. Elle a livré 150 pièces. Outre une armature à dos courbe, on repère un trapèze asymétrique en silex $(\mathrm{K} 2 \mathrm{C})$, un trapèze symétrique en microquartzite $\mathrm{FL}$ (N2A), tous deux indubitablement attribuables au second Mésolithique, et une flèche tranchante du Néolithique moyen (fig. $32, n^{\circ} 3$ $\mathrm{K} 3 \mathrm{~A})$.

La tranchée $F$ est plus intéressante, même si nous ne sommes pas parvenus à distinguer strictement les assemblages aziliens des assemblages mésolithiques (fig. 33). Avec 166 pièces au mètre carré (avec tamisage à l'eau), il s'agit de carrés moyennement denses. Le même panel d'occupations que dans l'US 1 ou l'US 13 est représenté. On signalera en plus ici un grattoir double à retouches latérales sur éclat cortical qui présente un émoussé très marqué d'un des fronts, allant jusqu'à détruire l'angle d'attaque (fig. $33, n^{\circ} 6$ ). Selon J. Jacquier (Université de Rennes 1), de tels stigmates peuvent correspondre à des travaux d'assouplissement des peaux.

\section{5 - Autres éléments lithiques des niveaux tardiglaciaires}

\section{1 - Les plaquettes de schiste}

La présence de plaquettes de schiste dans un abri granitique ne va pas de soi de manière naturelle... Le tamisage à l'eau a permis de recueillir 166 éléments dans les carrés aziliens de la banquette du fond et à l'angle de l'abri, la plupart étant des esquilles : on compte en tout 5 éléments de plus de $51 \mathrm{~mm}, 51$ éléments d'une longueur comprise entre 11 et $50 \mathrm{~mm}$ (en moyenne longs de 20 à 


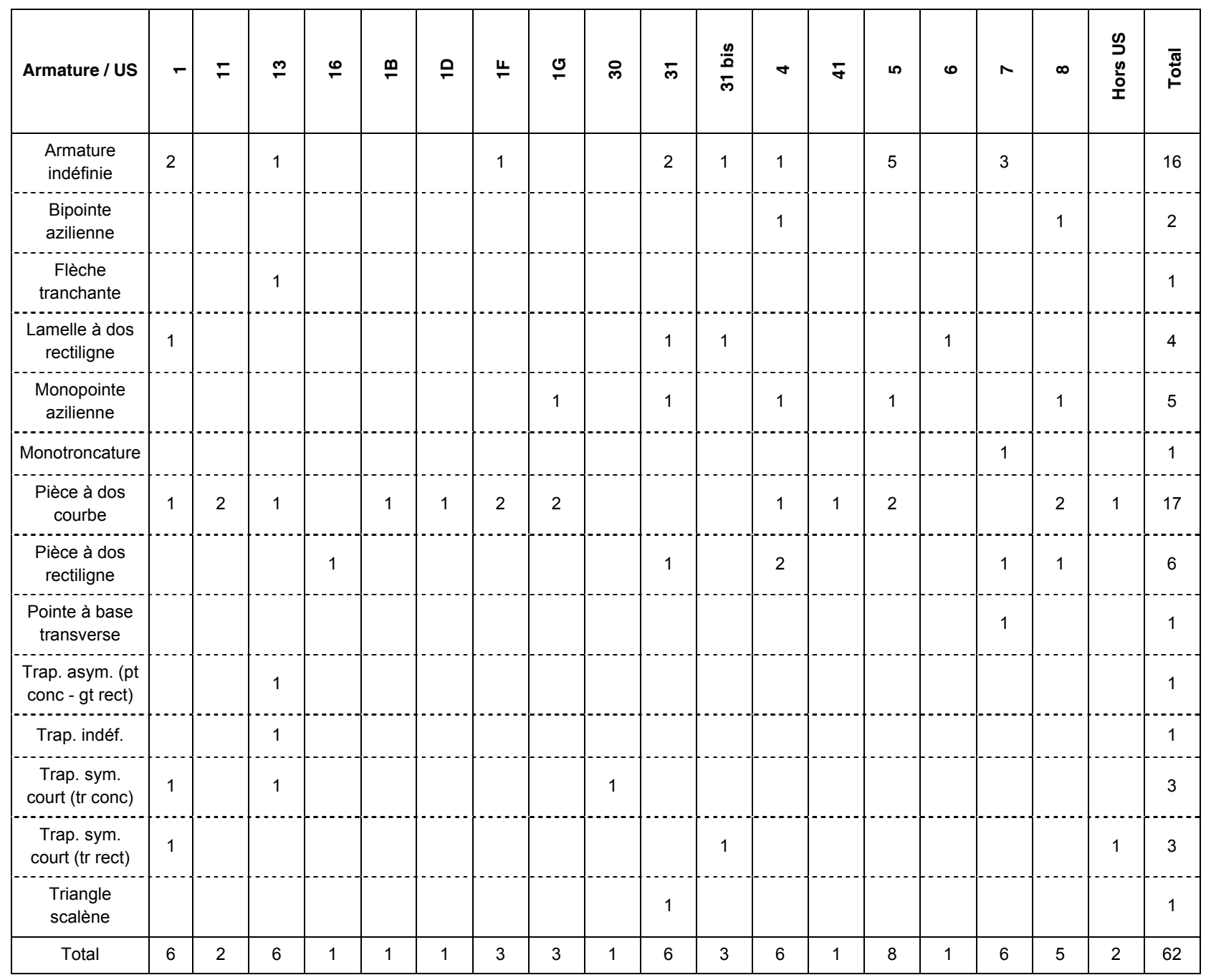

Tableau 8 - Répartition des types d'armatures par unités stratigraphiques.

Table 8 - Arrowheads types by stratigraphic units.

$30 \mathrm{~mm}$ ) et 110 fragments d'une taille inférieure à $10 \mathrm{~mm}$. Ils ont été trouvés dans un contexte stratigraphique assuré pour $71 \%$ d'entre eux, en particulier les grands éléments les plus significatifs (fig. 34). On distingue deux types de roche:

- un micaschiste satiné gris-vert qui se présente sous la forme de plaquettes très minces $(5 \mathrm{~mm})$, avec une nette opposition entre une face brillante grise et une face mate brun clair un peu grenue;

- un schiste gris sombre, plus dense et plus épais, à plan de clivage couleur rouille.

La première est largement dominante, avec notamment trois grands éléments mesurant entre 65 et $85 \mathrm{~mm}$ de long découverts dans le carré N2. Un autre gisait dans l'US 7 (terrier) du carré M3. II ne s'agit pas de galets mais de plaquettes ramassées autour des affleurements mêmes, sans plage roulée. Les fractures sont nettes et les fragments semblent pouvoir remonter entre eux, mais en définitive aucun raccord n'a été possible : les autres fragments étaient ailleurs dans le site ou pourquoi pas audelà. Plus trapu, le bloc de schiste gris sombre mesure 92 $\mathrm{mm}$ de long, pour $29 \mathrm{~mm}$ de large et $19 \mathrm{~mm}$ d'épaisseur. II est très altéré et aucune de ses surfaces originelles n'est désormais visible, contrairement à l'autre roche.

Pour en déterminer l'origine, nous avons pris conseil auprès de Mme M.-P. Dabard, géologue à l'université de Rennes 1. La présence de lamines silteuses et de trous de vers dans la variété satinée gris-vert, de même que leur allure générale, laissent penser à une origine dans l'Ordovicien moyen (symboles 0 2-3-4-5 de la carte géologique de Huelgoat - $n^{\circ} 276$ - 1988). Ces niveaux du Paléozoïque entourent le massif granitique de Huelgoat (Cabanis et al., 1981). On les rencontre au plus près à $4 \mathrm{~km}$ au nord-est du site (à l'est de Berrien), mais aussi sur les versants extérieurs des monts bordant la cuvette de Brennilis (fig. 2). 


\begin{tabular}{|c|c|c|c|c|c|c|c|c|c|c|c|c|c|c|}
\hline Armature / US & 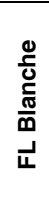 & $\begin{array}{l}\frac{\omega}{2} \\
\vec{山}\end{array}$ & 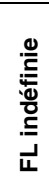 & 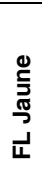 & 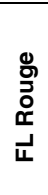 & 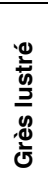 & 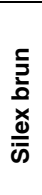 & $\begin{array}{l}\frac{n}{\vdots} \\
\times \\
\frac{x}{\sigma}\end{array}$ & 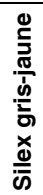 & 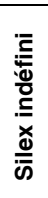 & 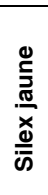 & 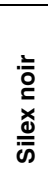 & 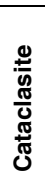 & 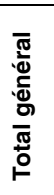 \\
\hline Armature indéfinie & 2 & & & 1 & & & 2 & 4 & & 6 & 1 & & & 16 \\
\hline Bipointe azilienne & & & & & & & & 1 & 1 & & & & & 2 \\
\hline Flèche tranchante & & & & & & & & & & & 1 & & & 1 \\
\hline Lamelle à dos rectiligne & & & 1 & & & 2 & & & & & 1 & & & 4 \\
\hline Monopointe azilienne & & & & & & 1 & & 2 & 1 & 1 & & & & 5 \\
\hline Monotroncature & & & & & & & & & & & 1 & & & 1 \\
\hline Pièce à dos courbe & & 1 & & & & & 2 & 10 & 2 & 1 & 1 & & & 17 \\
\hline Pièce à dos rectiligne & & & & & & & 1 & 5 & & & & & & 6 \\
\hline Pointe à base transverse & & & & & & & & & & 1 & & & & 1 \\
\hline $\begin{array}{l}\text { Trap. asym. (pt conc - gt } \\
\text { rect) }\end{array}$ & & & & & & & & 1 & & & & & & 1 \\
\hline Trap. indéf. & & & & & & & & 1 & & & & & & 1 \\
\hline Trap. sym. court (tr conc) & & & & & 1 & & & & & 1 & & & 1 & 3 \\
\hline Trap. sym. court (tr rect) & & & & & & & & 1 & & 1 & & & 1 & 3 \\
\hline Triangle scalène & & & & & & & & & & & & 1 & & 1 \\
\hline Total général & 2 & 1 & 1 & 1 & 1 & 3 & 5 & 25 & 4 & 11 & 5 & 1 & 2 & 62 \\
\hline
\end{tabular}

Tableau 9 - Répartition des types d'armatures par matières (toutes US).

Table 9 - Arrowheads types by raw materials (all stratigraphic units).

Trois galets de schiste gravés de lignes parallèles avaient été trouvés en 1999 dans le locus 11 des Chaloignes, vaste site de l'Azilien récent au sud d'Angers (Marchand et al. 2009). Plus près de Kerbizien, mais sans contexte stratigraphique, on connaît également des schistes gravés à l'embouchure de la Loire au Croisic ou à Lann Gazel (Trémaouézan). Ce dernier site découvert par M. Le Goffic se trouve à $40 \mathrm{~km}$ au nord-ouest de Kerbizien et a livré une industrie de l'Azilien lors de ramassages de surface (Le Goffic 2001). En toute logique, nous avons donc scruté à la loupe binoculaire toutes les surfaces, sans aucun résultat. Lors de leur recueil sur le site, elles n'ont pas été lavées à grande eau, mais observées avec précaution auparavant et nettoyées très progressivement. Si peinture il y eut, il n'en est rien resté. Que les motivations fussent symboliques ou fonctionnelles, l'usage de ces roches entre bel et bien dans l'éventail des comportements aziliens connus ailleurs.

\section{2 - Les blocs de granite taillés}

Plus originaux dans ces contextes culturels, trois gros blocs de granite à gros grain, d'origine locale, ont été découverts au milieu de l'US 5, dans les carrés L2, L3, K2 et K3 (fig. 13 et 15). Aussi étonnant que cela puisse paraitre, ils ont manifestement été taillés, comme le montre un raccord :

- Le bloc A est un gros éclat de granit de $17 \mathrm{~cm}$ de long sur $11 \mathrm{~cm}$ de large, pour une épaisseur de $7 \mathrm{~cm}$ et un poids de $1,2 \mathrm{~kg}$. II porte un talon et un point d'impact conséquent. II remonte sur le bloc $B$ qui se trouvait à $6 \mathrm{~cm}$ à l'ouest ;

- Le bloc B mesure $43 \mathrm{~cm}$ de long pour $21 \mathrm{~cm}$ de large et $13 \mathrm{~cm}$ d'épaisseur ; il pèse $15,5 \mathrm{~kg}$ (fig. 35 et 36). Outre l'éclat $A$ tiré dans le sens de la longueur, il y a d'évidentes traces de régularisation tout autour.

- Le bloc $C$ gisait à $10 \mathrm{~cm}$ au nord du bloc $\mathrm{B}$ (fig. 37 et 38 ). S'il ne remonte pas sur les autres, il faut noter les négatifs de six éclats sur la face supérieure, frappés depuis la face d'arrachement. Les enlèvements sont courts $(7 \mathrm{~cm})$ et larges. II est de forme très grossièrement quadrangulaire, avec une longueur de $26 \mathrm{~cm}$ pour $21 \mathrm{~cm}$ de large et $8 \mathrm{~cm}$ d'épaisseur. II pèse 7 kg.

II existait peut-être des petits éclats de granite alentours, mais ils ont pu se désagréger ou être confondus par les fouilleurs avec les quelques petits fragments de granite dispersés dans l'arène. N'oublions pas que ces blocs 


\begin{tabular}{|c|c|c|c|c|c|c|c|c|c|c|c|c|}
\hline Support & Outil aménagé & $\stackrel{\circ}{0}$ & $\begin{array}{l}\text { 里 } \\
\text { J } \\
\text { L }\end{array}$ & 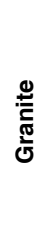 & 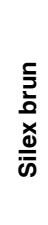 & 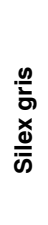 & 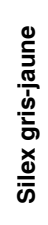 & 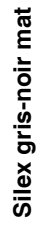 & 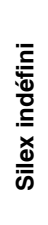 & 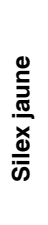 & $\begin{array}{l}\frac{ \pm}{0} \\
\frac{\pi}{0} \\
\frac{\pi}{0} \\
\frac{\mathbb{\pi}}{\pi} \\
0\end{array}$ & 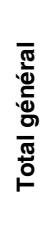 \\
\hline \multirow[t]{4}{*}{ Éclat } & Bord abattu total rectiligne & & & & & & & & & 1 & & 1 \\
\hline & Coche & & 1 & & & & & & & & & 1 \\
\hline & Grattoir & & & & 1 & & & & & & & 1 \\
\hline & Retouche diverse & & & & 1 & & & 1 & & & & 2 \\
\hline \multirow[t]{2}{*}{ Éclat cortical } & Denticulé transversal & & & & & 1 & & & & & & 1 \\
\hline & Grattoir & & & & & 2 & & & & & & 2 \\
\hline Éclat cortical perc./encl. & Grattoir & & & & & 1 & & & & & & 1 \\
\hline \multirow[t]{3}{*}{ Éclat semi-cortical } & Denticulé & & & & & 1 & & & & & & 1 \\
\hline & Denticulé latéral & 1 & & & & & & & & & & 1 \\
\hline & Grattoir & & & & & 1 & & & & & & 1 \\
\hline \multirow[t]{3}{*}{ Indéfini } & Bord abattu total rectiligne & & & & & 1 & & & & & & 1 \\
\hline & Meule & & & 1 & & & & & & & & 1 \\
\hline & Retouche diverse & & & & 1 & 2 & & & 1 & & & 4 \\
\hline \multirow[t]{3}{*}{ Lame } & Burin & & & & & 1 & & & & & & 1 \\
\hline & Retouche diverse & & & & & 3 & 2 & & & & & 5 \\
\hline & Troncature oblique concave & & & & & 1 & & & & & & 1 \\
\hline Lame à crête & Burin dièdre & & & & & 1 & & & & & & 1 \\
\hline \multirow[t]{2}{*}{ Lamelle } & Coche & & & & & 1 & & & & & & 1 \\
\hline & Troncature oblique concave & & & & & & & & & & 1 & 1 \\
\hline \multicolumn{2}{|l|}{ Total général } & 1 & 1 & 1 & 3 & 16 & 2 & 1 & 1 & 1 & 1 & 28 \\
\hline
\end{tabular}

Tableau 10 - Répartition des types d'outils aménagés par matières (toutes US).

Table 10 - Tools types by raw materials (all stratigraphic units).

proviennent directement de la paroi, puisqu'ils procèdent de l'érosion en pelure d'oignon. La destination de ces débitages massifs, aux stigmates indubitables, laisse perplexe... II ne faut peut-être pas y chercher autre chose qu'une activité anecdotique des occupants aziliens.

\section{6 - Originalité de l'Azilien de Kerbizien}

\section{1 - Un maillage des connaissances encore bien fragile dans l'ouest de la France}

La remarquable cavité dans le bloc monolithique de Kerbizien a été le siège d'occupations humaines de l'Azilien et de plusieurs phases mésolithiques agencées en stratigraphie sur environ un mètre d'épaisseur. Une des scories a été datée du Haut Moyen-Âge, autre période pendant laquelle l'abri-sous-roche a représenté un intérêt particulier. La destruction d'une telle séquence est évidemment à déplorer. Notre opération de 2011 aura néanmoins permis d'identifier et de fouiller en totalité un reste d'occupation azilienne particulièrement rare à l'échelle régionale. Si l'analyse radiométrique d'un charbon n'a permis que de détecter une intrusion du Néolithique, un affinage chronologique reste possible par analogies typologiques.

Débitage laminaire, burins et pointes à dos courbe désignent évidemment l'Azilien, entité technique dont le meilleur point de comparaison dans l'Ouest est le site des Chaloignes, sur la commune de Mozé-sur-Louet dans le Maine-et-Loire (Marchand et al. 2008, 2009). Hélas, en Pays-de-la-Loire comme en Bretagne, aucune datation 

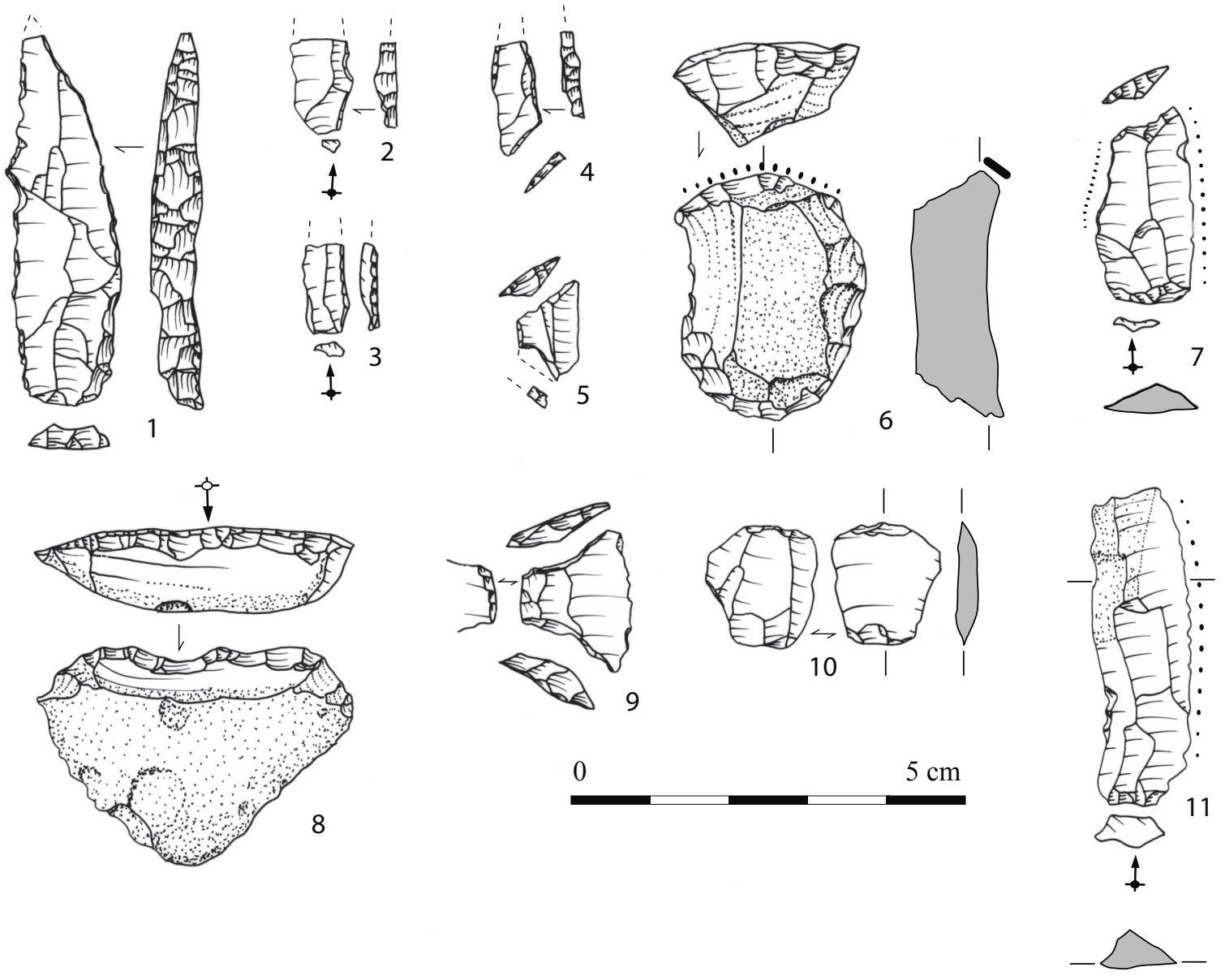

Figure 33 - Outils recueillis dans les US 30 et 31 du sondage F. 1 : monopointe à dos courbe et à base retouchée (pointe de Malaurie); 2-3: fragment de lamelles à dos ; 4 : triangle scalène ; $5:$ trapèze ; 6 : grattoir double montrant un front extrêmement émoussé ; 7 : lamelle tronquée et utilisée ; 8 : éclat denticulé ; 9 : trapèze symétrique ; 10 : pièce esquillée ; 11 : lame utilisée (Dessins : G. Marchand).

Figure 33 - Tools from the stratigraphic units 30 and 31 of the trench F. 1: curve backed point (Malaurie point) ; 2-3: backed bladelets fragments ; $4:$ scalene triangle; $5:$ trapeze ; $6:$ scrapper ; $7:$ truncation on bladelet ; $8:$ denticulate flake ; $9:$ symmetrical trapeze ; $0:$ splinted piece ; 11 : used blad (Drawings : G. Marchand).

correcte par le radiocarbone n'a été pour l'instant obtenue sur ces ensembles et il faut s'en remettre aux comparaisons avec d'autres régions pour établir un semblant de cadre chronologique. Dans l'Ouest, les analyses récentes autour de la stratigraphie de référence du Bois-Ragot (Gouex, Vienne) ont remis en question l'assertion d'une apparition des pointes à dos courbe dans le Magdalénien de la couche 5 daté de l'intervalle 13500 12400 avant J.-C. (Chollet et Dujardin 2005). Ces pointes si emblématiques qualifient en revanche sans conteste l'Azilien au sud de la Loire et le Federmesser autour de la Seine, entre 12000 et 11000 avant J.-C. (11 800 10800 BP), durant tout l'interstade d'Alleröd, et peut-être au-delà. À l'échelle de la Bretagne, nous avons recensé 48 assemblages du Paléolithique final, la plupart mélangés à d'autres composantes (Marchand et al. 2004).
Trois autres sites fouillés dans le Finistère témoignent de la présence azilienne : la grotte de Roc'h Toul à Guiclan, Enez Guennoc à Landéda et l'abri du Rocher de l'Impératrice à Plougastel-Daoulas (fig. 39). La première est une caverne qui s'enfonce dans un massif de grès armoricain sur un versant abrupt. Elle a été explorée en 1868 et 1869 par le Docteur Le Hir, puis par C. Bénard dit le Pontois et enfin par E. Morel ; le matériel a été étudié par G. Laplace (LaplaceJauretche 1957), par J.-L. Monnier (Giot et al. 1977 ; Monnier 1980) et enfin par N. Naudinot (2010), le nombre de pièces examinés diminuant au gré des pertes, des emprunts ou des vols... On note sur ce site la présence de bipointes à dos courbe, de grattoirs sur lame ou sur éclat et de nombreux éclats denticulés. Les burins semblent rares, contrairement à ce qui fut affirmé un temps. Le débitage a été fait au percuteur tendre, à partir de deux plans de frappe opposés (Naudinot 2010). Le mobilier conservé 


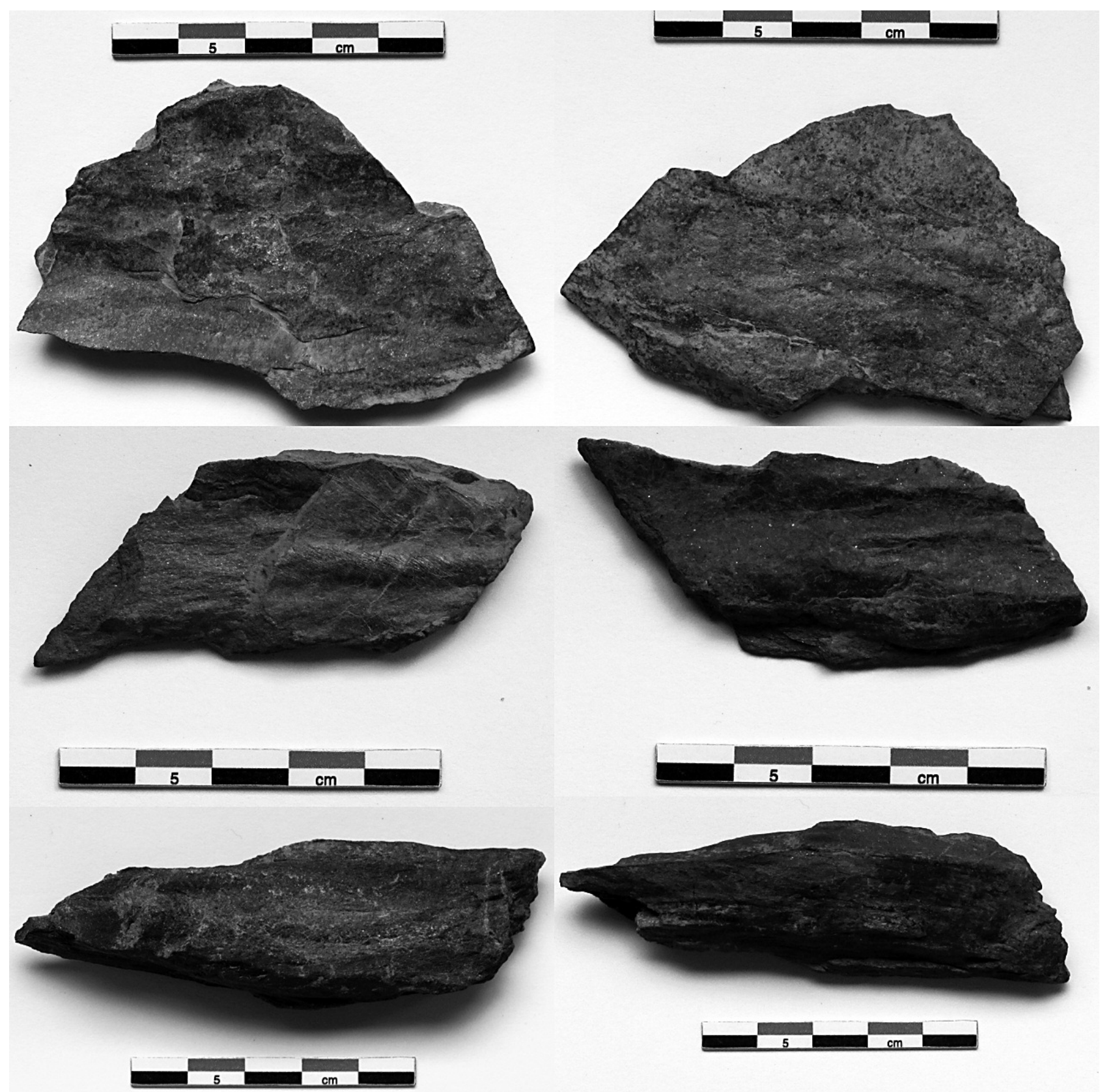

Figure 34 - Photographies recto-verso des grandes plaquettes de schiste (de haut en bas : N2A US 5, M3D US 7, J5D US 8) (clichés : G. Marchand).

Figure 34 - Pictures of the schist plates (from top to bottom: N2A US 5, M3D US 7, J5D US 8) (pictures : G. Marchand).

aujourd'hui est en silex, la plupart provenant de glanes de galets marins sur les estrans. Quelques cortex natifs montrent pourtant une importation à longues distances, peut-être depuis les marges jurassiques du Massif armoricain (au moins $300 \mathrm{~km}$ à l'est). Des éléments en grès éocène - dont une pointe azilienne - témoignent à l'inverse d'un approvisionnement à partir des ressources de ce massif. Les bipointes, le fort taux de burins ou les grattoirs sur lames nous orientent vers une phase assez ancienne de l'Azilien (pour autant qu'une fouille aussi ancienne nous permette ce type de réflexion), et donc un évident rapprochement avec Kerbizien.

Le second site fouillé, Enez Guennoc, a été découvert sur une île actuelle lors des fouilles de P.R. Giot. Les épandages de mobilier lithique étaient dans deux zones de fouille principales, dans un niveau sous-jacent à des cairns néolithiques (Monnier 1980). II était de tradition depuis les recherches de J.-L. Monnier de décrire Enez Guennoc 


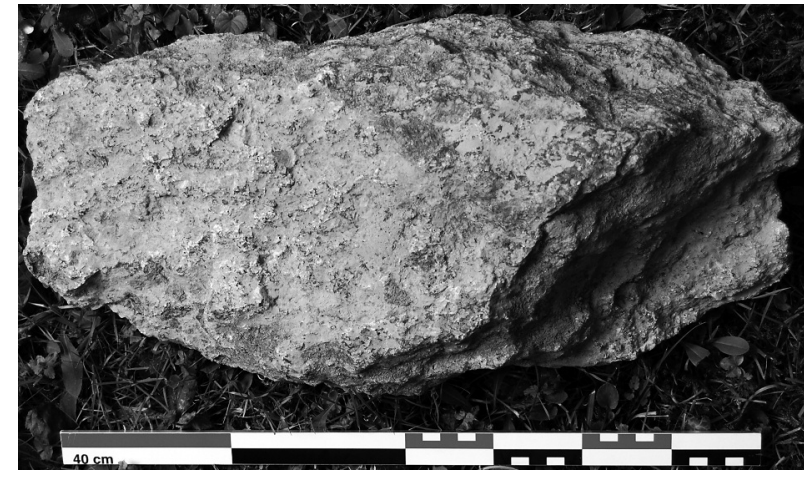

Figure 35 - Le bloc B. A droite de la photo, le négatif de l'éclat $A$, qui raccorde sur le $B$, apparait nettement. Les encoches autour du bloc correspondent à d'autres enlèvements de régularisation (cliché G. Marchand).

Figure 35 - Block $B$. The notches around the block are made to regularize the shape (picture: $G$. Marchand).

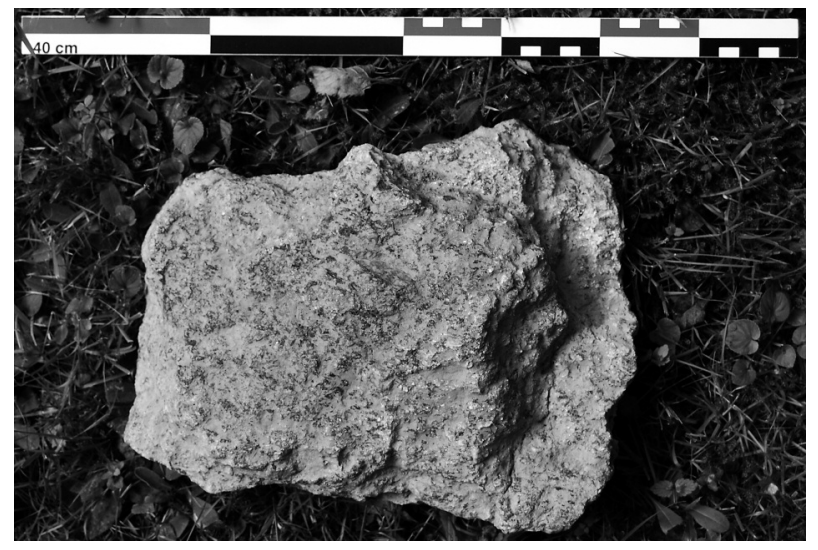

Figure 37 - Le bloc C, avec ses enlèvements de débitage périphériques (cliché : G. Marchand).

Figure 37 - The block $C$ with its peripheral flakes (picture: G. Marchand).

comme un site " de transition », des microlithes nongéométriques se mêlant à des pointes à dos. Une nouvelle étude de $\mathrm{S}$. Michel et $\mathrm{N}$. Naudinot a bien montré qu'il s'agissait d'un mélange dans un paléosol trop peu épais (Michel et Naudinot 2009).

Le troisième site, l'abri du Rocher de l'Impératrice, est au pied d'une grande falaise de grès-quartzite qui borde au sud la vallée de l'Elorn, à proximité de Brest. L'occupation préhistorique a été découverte en 1991 par M. Le Goffic dans les déblais de l'aménagement sauvage d'un mur d'escalade. Le mobilier exhumé durant le tamisage de déblais par l'inventeur comprenait principalement des outils (burins, lames esquillées et bipointes), avec une très forte composante laminaire. Le site a fait l'objet de sondages en juillet 2013 suivis de fouilles à partir de 2014 sous la direction de $\mathrm{N}$. Naudinot, qui ont permis d'identifier un niveau de l'Azilien ancien.

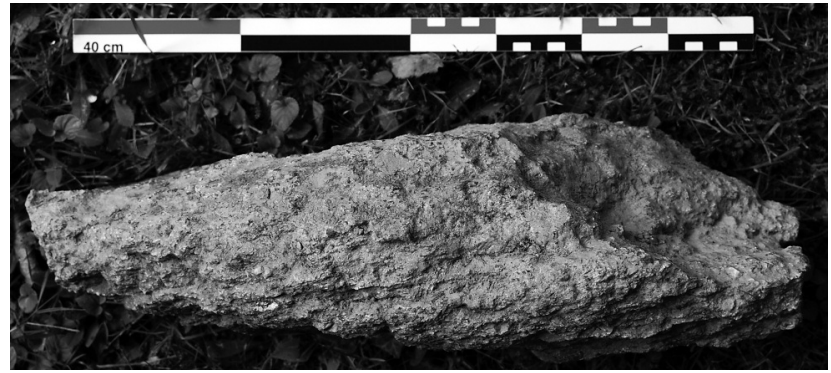

Figure 36 - Le bloc B vu de profil (cliché G. Marchand). Figure 36 - Profile of the block B (picture: G. Marchand).

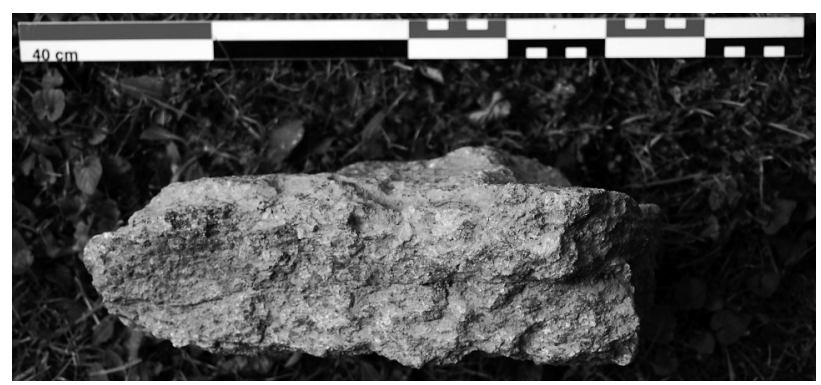

Figure 38 - Le bloc C vu de profil (cliché : G. Marchand). Figure 38 - Profile of the block C (picture: G. Marchand).

Par les ramassages de surface, d'autres sites ou indices de site sont d'ores et déjà connus en Bretagne, dont plusieurs sont des ensembles majeurs :

- Lann Gazel (Trémaouézan, Finistère ; Le Goffic 2001),

- Quillien (Le Cloître Saint-Thégonnec, Finistère ; Gouletquer et Léopold, 1991),

- Runigou/Notenno (Trébeurden ; Chevalier 1999),

- Roc'h Glas (Penvenan, Côte-d'Armor ; Chevalier 1999),

- Le Perzo (Neuillac, Morbihan ; Marchand et al. 2004),

- L'anse de Landroannec (Mûr-de-Bretagne, inédit O. Kayser et G. Tournay).

Dans l'évolution des formes d'armatures à l'échelle du territoire français, l'ancienneté des industries à bipointes sur celles à monopointes est un fait qui semble acquis et sur lequel nous nous sommes déjà appuyés pour proposer 


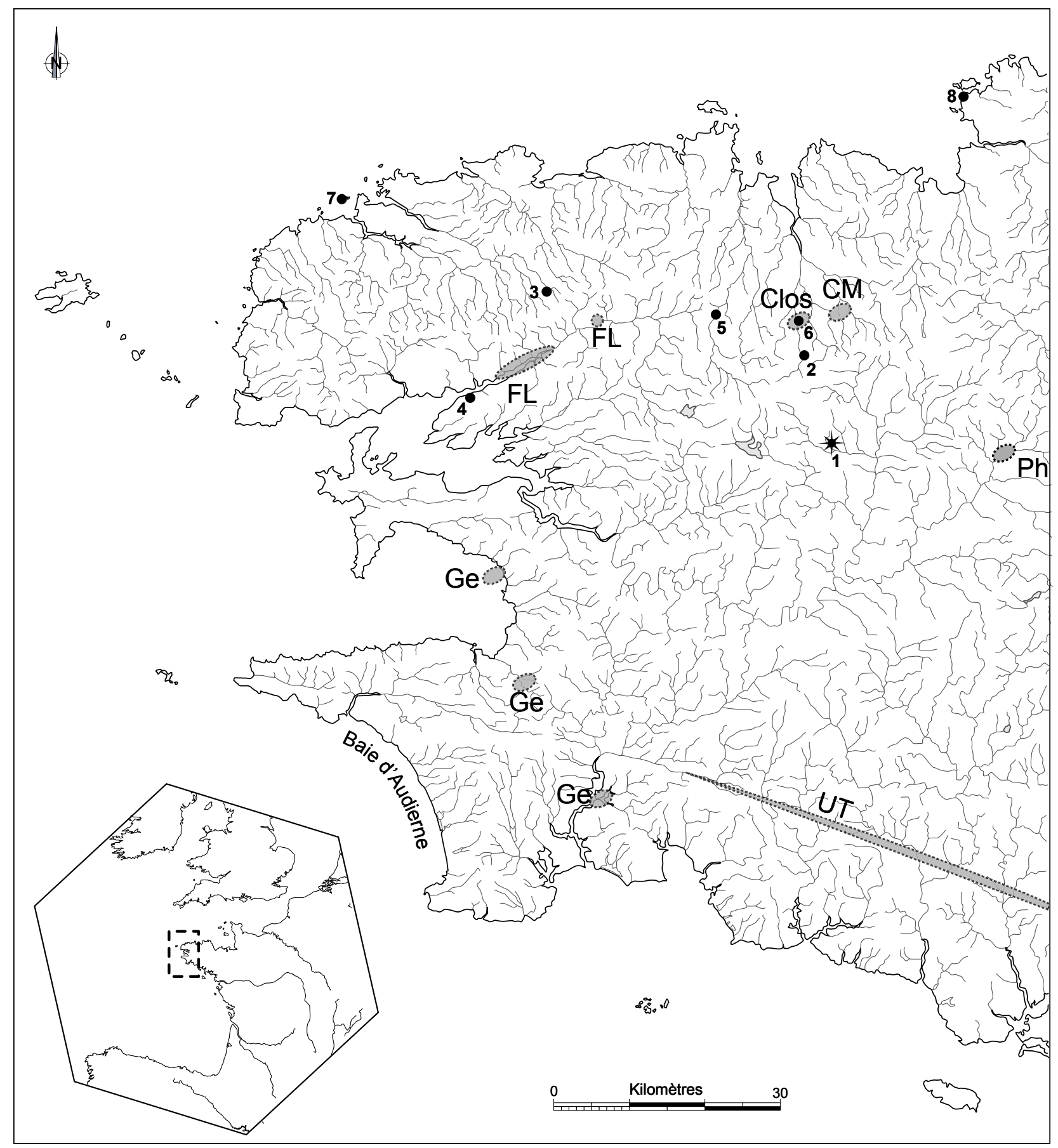

Figure 39 - Position de l'abri-sous-roche de Kerbizien (étoile noire) au sein des principaux sites aziliens et post-aziliens du Finistère, et des gisements de roche taillables (Ge : grès éocène ; UT : ultramylonite de Tréméven ; CM : cataclasite de Mikaël ; Clos : calcédoine du Clos ; FL : microquartzite de la Forest-Landerneau). Nom des sites : 1 : Kerbizien (Huelgoat) ; 2 : Quillien (Le Cloitre-Saint-Thégonnec) ; 3 : Lann-Gazel (Trémaouézan) ; 4 : le Rocher de l'Impératrice (Plougastel-Daoulas) ; 5 : Roc'h Toul (Guiclan) ; 6 : le Clos (Plourin-lèsMorlaix) ; 7 : Enez Guennoc (Landéda) ; 8 : Runigou/Notenno (Trébeurden) (DAO : Philippe Forré et Grégor Marchand).

Figure 39 - Location of the Kerbizien rock shelter (black star) with the main azilian and post-azilian sites in Finistère and the main regional raw materials used for knapping (Ge : Eocene sandstone ; UT : Tréméven ultramylonite; CM : Mikaël cataclasite; Clos : Clos chalcedony ; FL : Forest-Landerneau microquartzite). Name of the archaeological sites : 1 : Kerbizien (Huelgoat) ; 2 : Quillien (Le Cloitre-Saint-Thégonnec) ; 3 : Lann-Gazel (Trémaouézan) ; 4 : le Rocher de l'Impératrice (Plougastel-Daoulas) ; 5 : Roc'h Toul (Guiclan) ; 6 : le Clos (Plourin-lès-Morlaix) ; 7 : Enez Guennoc (Landéda) ; 8 : Runigou/Notenno (Trébeurden) (CAD : Philippe Forré and Grégor Marchand). 
une datation de l'Azilien régional (Marchand et al. 2004 ; Marchand 2008). II est par exemple observé dans la stratigraphie du Bois-Ragot (Gouex, Vienne ; Chollet et Dujardin 2005), comme dans celle du Pont d'Ambon (Bourdeilles, Dordogne ; Célérier 1994, 1998). Plus récemment, cette clé de datation décidément robuste a été confirmée par un collectif de chercheurs travaillant sur le quart sud-ouest de la France, tant dans le Bassin aquitain que dans les Pyrénées (Fat Cheung et al. 2014).

L'essentiel des sites armoricains mentionnés ci-dessus ressortent clairement de la phase à monopointes, soit la seconde partie de l'Alleröd. En revanche Roc'h Toul et le Rocher de l'Impératrice témoigneraient de la phase à bipointes, plus ancienne. Il en irait de même pour Kerbizien. Les grandes lames retouchées et utilisées de multiples fois sont une des originalités de cette série. De tels outils sont particulièrement bien représentés dans le niveau inférieur du Closeau (Rueil-Malmaison, Hauts-de-Seine), qui reste la principale référence de cette entité technique au Nord de la France (Bodu 1995, 2000 ; Bodu et Valentin 1997). Ce niveau a été placé à la fin du XIVe et le début du XIII millénaire avant notre ère, soit la fin du Bölling, à la fois par une dizaine de datations par le radiocarbone sur des ossements animaux, mais aussi par les données stratigraphiques. Les locus 4 et 46 sont les principales zones d'habitat du niveau inférieur, avec des agencements de gros blocs de calcaire autour d'un espace central occupé par un foyer (Bodu 2000). Parmi l'outillage abondant, $\mathrm{P}$. Bodu et $\mathrm{L}$. Mével ont isolé de grandes lames à retouches intentionnelles qui se retrouvent à l'intérieur même des espaces structurés de ce site et non dans des ateliers périphériques, de même d'ailleurs que les lames utilisées brutes (Bodu et Mével 2008). Ces grands supports dont le tranchant est plusieurs fois repris seraient affectés au raclage de la peau. Les bipointes aziliennes dominent nettement dans ce niveau inférieur du Closeau et on en trouve quelques-unes aussi à Kerbizien. Le débitage laminaire ou les burins sur lame sont également des éléments convergents avec Kerbizien. II y a en revanche un fort taux de grattoirs au Closeau alors que ces outils sont absents de notre échantillonnage.

Mentionnons à l'échelle de la région, la présence durant l'Azilien de quelques pointes à dos anguleux dans le nord du Finistère, par exemple sur le site de Lann Gazel (Le Goffic 2001), en accompagnement de monopointes et de bipointes aziliennes. Cette association rappelle les assemblages à « penknife points » (dites aussi pointe de Grundy) présents dans le sud de l'Angleterre. Ils sont postérieurs au Creswellien et contemporains de l'Alleröd (Barton, Roberts 1997). Ces rapprochements incitent à considérer autrement la géographie humaine autour de l'embouchure du vaste estuaire de la paléo-Manche, avec peut-être un fonctionnement territorial différent du reste de la région. $M$. Le Goffic a d'ailleurs bien montré que le silex utilisé à Lann Gazel provenait directement d'affleurements datés du Crétacé, rendus aujourd'hui inaccessibles par la transgression flandrienne.
Grandes lames retouchées et bipointes nous inclineraient à attribuer l'assemblage de Kerbizien à une phase ancienne de l'Azilien, seulement représentée à Roc'h Toul et au Rocher de l'Impératrice pour le cadre régional. II faut évidemment émettre bien des réserves. La diversité des supports de pointes à dos courbe incite à croire en de multiples passages au cours de l'Azilien. Une grande pointe à dos courbe et à base retouchée trouvée en F5 (fig. 33, $n^{\circ}$ 1) peut être qualifiée de pointe de Malaurie, signalant une occupation ou à tout le moins un passage à la fin de l'Azilien. Nous avons donc fouillé une accrétion d'occupations aziliennes dans un reste de niveau peu dilaté, avec des caractères fonctionnels relativement homogènes entre eux.

Que sait-on des paysages parcourus par ces êtres humains ? La connaissance des environnements du Tardiglaciaire a progressé depuis la fin des années 1990 en Bretagne et en Pays-de-la-Loire (Barbier 1999 ; Barbier et Visset 1999 ; Marguerie 2000 ; Gaudin 2004). L'amélioration climatique du Bölling/Alleröd apparaît dans trois tourbières du nord-est de la Mayenne : Saint-Ursin (Lignières-Orgères), (Lignières-Orgères) et le Fourneau (Pré-en-Pail) (Barbier 1999). Elle a été détectée également en Ille-et-Vilaine, dans le paléo-chenal de la vallée de la Vilaine, à Rennes et à la Minette (Saint-Sauveur-desLandes). A l'encontre de la situation en domaine continental, les analyses polliniques montrent l'existence d'une steppe à Poacées, soit un milieu très ouvert où le pin tient un rôle très faible à l'ouest, tandis que l'est du Massif est marqué davantage par le bouleau. Durant le refroidissement du Dryas récent, le caractère steppique reste également très accentué et le couvert forestier ne s'installera que très progressivement au Préboréal (Gaudin 2004 - p. 277-282).

\section{2 - Des paramètres fonctionnels très particuliers}

II y a assurément beaucoup trop de lacunes nées des conditions de gisement dans l'assemblage azilien de Kerbizien pour que l'on puisse comprendre la nature des occupations successives. L'abandon de grandes lames en silex alors que la matière est si rare en Centre-Bretagne doit attirer notre attention. Dans un tel contexte de pénurie géologique, leur non-reconversion pourrait signaler une certaine mobilité humaine, les gens ne s'embarrassant pas d'outils usés avant de repartir et n'ayant pas l'occasion de les réutiliser. L'absence de burin est probablement liée à la nature partielle de l'échantillon, puisqu'il y a 16 chutes, certaines montrant plusieurs ravivages et un très grand soin dans leur réalisation. Les lacunes archéologiques pourraient aussi expliquer l'absence de grattoirs. Au chapitre des interventions sur la matière minérale, il faut aussi signaler, d'une part l'import de plaquettes minces de schistes depuis quelques kilomètres pour un usage inconnu, d'autre part le débitage de grosses plaques de granite local à des fins également mystérieuses. Cet assemblage présente en l'état une structure fonctionnelle très originale, qui évoque immanquablement une station logistique de groupes très mobiles. II est alors permis 
d'imaginer des expéditions de chasse dans cette zone collinaire du centre de la péninsule bretonne. L'usage des roches locales (microquartzite de la Forest-Landerneau, ultramylonite de Mikaël et calcédoine du Clos), même en faibles proportions, est une information également essentielle, qui incite à croire en un bon arpentage des alentours par ces gens de la Préhistoire. En d'autres termes, il ne s'agit pas d'expéditions de chasseurs depuis les grandes plaines de l'est du Massif armoricain, mais de modèles économiques plus complexes qui s'appuient sur une connaissance approfondie de cette zone collinaire. Quels en seraient les relais ? Occupée aussi au début de l'Azilien, la grotte de Roc'h Toul est à $21 \mathrm{~km}$ au nord-ouest de l'abri-sous-roche de Kerbizien et offre davantage d'espace pour une longue occupation : la destruction de son remplissage par les fouilles anciennes ne permet guère de réfléchir aux statuts fonctionnels réels de ces occupations du Tardiglaciaire. L'abri du Rocher de l'Impératrice à Plougastel-Daoulas (Finistère), découvert par M. Le Goffic et fouillé actuellement par N. Naudinot, est un autre relais possible, à $45 \mathrm{~km}$ à l'ouest de Kerbizien. On peut ajouter évidemment le site de plein-air de Lann-Gazel à Trémaouézan dans cette ambiance chrono-culturelle (Le Goffic 2001). Quelques points existent donc, essentiellement cavernicoles, qui jalonnent maigrement ces paysages tardiglaciaires que la palynologie nous décrit comme très ouverts. Mais à petites touches le tableau se révèle...

\section{Remerciements}

II nous est particulièrement agréable de remercier Madame Anne-Marie Mazurier (propriétaire de la parcelle) et JeanMichel Moullec pour ses précieuses indications concernant ses travaux. Nous sommes reconnaissant envers le Service régional d'archéologie (Jean-Yves Tinévez et Emile Bernard) et le Conseil général du Finistère (Michel Le Goffic et Sophie Casadebaig) pour le financement du projet. Notre gratitude va également aux fouilleurs: Nicolas Audier, Bernard Bodinier, Alex Brie de Vernet, Jean-Marc Cardeilhac, Aude Chevallier, Laurence Dorvault, Annette Flageul, Sophie Hérisson, Nadège Jouanet-Aldous, André Lenormand, Georges Leprince, Carole Vigouroux, JeanPierre Toularastel.

\section{Références bibliographiques}

BARBIER D. 1999 - Histoire de la végétation du nordmayennais de la fin du Weichsélien à l'aube du XXle siècle. Mise en évidence d'un Tardiglaciaire armoricain. Interactions Homme-Milieu. GEMINA, 2 vol.

BARBIER D., VISSET L.1999 - Les spécificités d'un Tardiglaciaire armoricain : étude pollinique synthétique à partir de trois tourbières du nord-est mayennais (France). Quaternaire, 11 (2), p. 99-106.

BARTON R.N.E., ROBERTS A.J. 1997 - Systèmes économiques et modalités techniques dans l'ouest de la Grande- Bretagne au Tardiglaciaire. In : Fagnart J.-P. et Thévenin A. Le Tardiglaciaire en Europe du Nord- Ouest.
Actes du $119^{\circ}$ Congrès national des Sociétés historiques et scientifiques. Amiens, 1994, p. 198-207.

BODU P. 1995 - Un gisement à Ferdermesser sur les bords de la Seine : le « Closeau » à Rueil-Malmaison (Hauts-deSeine), Bulletin de la Société Préhistorique française, T. 92, $\mathrm{n}^{\circ} 4$, p. 451-456.

BODU P. 2000 - Les faciès tardiglaciaires à grandes lames rectilignes et les ensembles à pointes de Malaurie dans le sud du Bassin parisien : quelques réflexions à partir de l'exemple du gisement du Closeau (Hauts-de-Seine), In : Crotti P. dir., Meso'97. Table-ronde sur l'Epipaléolithique et le Mésolithique, Lausanne, novembre 1997, p. 9-28.

BODU P., MEVEL L. 2008 - Enquête autour des lames tranchantes de l'Azilien ancien. Le cas du niveau inférieur du Closeau (Rueil-Malmaison, Hauts-de-Seine, France). L'anthropologie, 112, 4, p. 509-543.

BODU P., VALENTIN B. 1997 - Groupes à Federmesser ou aziliens dans le sud et l'ouest du Bassin parisien. Propositions pour un modèle d'évolution, Bulletin de la Société Préhistorique française, 94, 3, p. 341-347.

BRIARD J., MONNIER J.L. 1976 - Tumulus armoricains de l'Age du Bronze et couverture loessique weichsélienne. Bull. Soc. géol. minéral. Bretagne, 1976, VIII, 75-88 .

CABANIS B. et al. 1981 - Carte et notice explicative de la feuille Morlaix à 1/50 000. BRGM, 48 p. (et carte).

CÉLÉRIER G. 1994 - L'abri-sous-roche de Pont-d'Ambon à Bourdeilles (Dordogne), Gallia-Préhistoire, 36, p. 65-144.

CÉLÉRIER G. 1998 - L'abri sous-roche de Pont d'Ambon à Bourdeilles (Dordogne, France). Perspective synthétique, Paleo, 10, p. 233-264.

CHEVALIER G. 1999 - De nouveaux indices du Paléolithique supérieur sur le littoral trégorrois (Côtes d'Armor). Bulletin de l'AMARAl, 12, p. 29-49.

CHOLLET A., DUJARDIN V. dir. 2005 - La grotte du BoisRagot à Gouex (Vienne). Magdalénien et Azilien. Essais sur les hommes et leur environnement, Société Préhistorique Française, Mémoire 38, 427 p.

FAT CHEUNG C., CHEVALLIER A., BONNETJACQUEMENT P., LANGLAIS M., FERRIÉ J.-G., COSTAMAGNO S., KUNTZ D., LAROULANDIE V., MALLYE J.-B., VALDEYRON N., BALLISTA S. 2014 Comparaison des séquences aziliennes entre Dordogne et Pyrénées: état des travaux en cours, In : Langlais $\mathrm{M}$. ; Naudinot N. ; Peresani M. (dir.), Les sociétés de l'Allerød et du Dryas récent entre Atlantique et Méditerranée, Actes de la séance de la Société préhistorique française de Bordeaux, 24-25 mai 2012, Mémoire de la Société Préhistorique Française, 3, p. 17-44. 
GAUDIN L. 2004 - Les transformations spatio-temporelles de la végétation du nord-ouest de la France depuis la fin de la dernière glaciation. Reconstitutions paléo-paysagères. Thèse de doctorat de l'Université de Rennes 1, 2 volumes, $763 \mathrm{p}$.

GIOT, P.-R., HALLEGOUET, B., MONNIER, J.-L. 1977 - Le Paléolithique supérieur du Pays de Léon (Finistère). Les gisements de Roc'h Toul, Parc ar Plenen (Guiclan), Enez Guennoc (Landéda) et la Forest-Landerneau, L'anthropologie, 81, 2, p. 201-234.

GOULETQUER P., LÉOPOLD P. 1991 - État provisoire d'une prospection de longue durée : le site mésolithique de Quillien (Le Cloître de Saint-Thégonnec, Finistère), Revue Archéologique de l'Ouest, n`8, p. 61-83.

GOULETQUER P., LEOPOLD P., avec la collaboration de E. BAUDOUIN, P. JEZEQUEL ET M.-F. DIETSCH 1994 Autopsie d'un site mésolithique, Le Clos (Plourin-lesMorlaix, Finistère). Revue Archéologique de l'Ouest, 11, p. 31-52.

GOULETQUER P., KAYSER O., LE GOFFIC M., MARCHAND G. 1997 - Approche géographique du Mésolithique de la Bretagne, In : Fagnard J.-P., Thévenin A. dir., Le Tardiglaciaire en Europe du nord-ouest, Actes du $119^{\circ}$ congrès national des Sociétés historiques et scientifiques, Amiens 1994. Editions du Comité des travaux historiques et scientifiques, p. 279-292.

GOULETQUER P., KAYSER O., LE GOFFIC M., LÉOPOLD P., MARCHAND G., MOULLEC J.-M. 1996 - Où sont passés les Mésolithiques côtiers bretons ? Bilan 19851995 des prospections de surface dans le Finistère, Revue Archéologique de l'Ouest, 13, p. 5-30.

KELLY R. 2007 - The foraging spectrum. Diversity in Hunter-Gatherer lifeways. New York , Percheron Press, $446 \mathrm{p}$.

LAPLACE-JAURETCHE G. 1957 - Les industries de Roc'h Toul et Par-ar-Plenen en Guiclan (Finistère), Bulletin de la Société Préhistorique Française, LIV, 7-8, p. 422-438.

LE GOFFIC M. 1990 - L'abri-sous-roche de Pont-Glas en Plounéour-Ménez. Bulletin de la Société archéologique du Finistère, 119, p. 61-69.

LE GOFFIC M. 2001 - Trémaouézan, Lann-Gazel. In : Notice d'archéologie finistérienne, Bulletin de la Société Archéologique du Finistère, tome CXXX, p. 98-100.

LEFORT J.-P., MONNIER J.-L., DANUKALOVA G., à paraître - Deflation and Transportation of the upper Pleistocene loess particles by Katabatic winds during the low stands of the English Channel: their control on the Neandertalians and Homo Sapiens dwelling. Quaternary International.
MARCHAND G. 2008 - Dynamique des changements techniques sur les marges du Massif armoricain de l'Azilien au Premier Mésolithique, In : J-P. Fagnart, A. Thévenin, Th. Ducrocq, B. Souffi et P. Coudret dir., Le début du Mésolithique en Europe du Nord-Ouest. Actes de la table ronde d'Amiens (9 et 10 octobre 2004), p 52-64.

MARCHAND G. 2012 - Différences de potentiels géologiques entre Massifs cristallins et Bassins sédimentaires, In : Marchand G. et Querré G. (dir), Roches et sociétés de la Préhistoire entre Massifs cristallins et Bassins sédimentaires. Rennes : Presses Universitaires de Rennes, Collection Archéologie et Cultures, p. 9-28.

MARCHAND G. 2014 - Préhistoire atlantique. Fonctionnement et évolution des sociétés. Arles : Éditions Errance, 520 p.

MARCHAND G., LE GOFFIC M. 2009 - Give us some small sites please! Report on the first year of excavations in the rock shelter of Pont-Glas (Plouneour-Menez, Finistère, France), Mesolithic Miscellany, 19, 2, p. 12-16.

MARCHAND G., TSOBGOU AHOUPE R. 2007 Comprendre la diffusion des roches au Mésolithique en Bretagne : analyse structurale des matériaux et variabilité technique, Archéosciences, 31, p. 113-126.

MARCHAND G., LE GOFFIC M., MARCOUX N. 2011 b Occupations mésolithiques fugaces dans l'abri-sous-roche de Pont-Glas : une analyse de la segmentation des chaînes opératoires dans l'espace pour évoquer la mobilité des groupes préhistoriques en Bretagne, In : Bon Fr., Costamagno S., Valdeyron N. (dir.), Haltes de chasse en Préhistoire. Quelles réalités archéologiques ?, actes du colloque international du 13 au 15 mai 2009, université Toulouse II - Le Mirail, p@lethnologie, 3, p. 313-333.

MARCHAND G., NAUDINOT N., PHILIBERT S., SICARD S. 2011 a- Chasse aux haltes sur un site azilien de l'Ouest de la France, In : Bon Fr., Costamagno S., Valdeyron N. (dir.), Haltes de chasse en Préhistoire. Quelles réalités archéologiques ?, Actes du colloque international du 13 au 15 mai 2009, université Toulouse II - Le Mirail, P@lethnologie, 3, p. 271-294.

MARCHAND G., SICARD S., FORRÉ P. et NAULEAU J.F. 2008 - De la pelle mécanique aux remontages lithiques : espace habité et techniques au Tardiglaciaire sur l'habitat des Chaloignes (Mozé-sur-Louet, Maine-et-Loire), Revue archéologique de l'Ouest, 25, p. 7-52.

MARCHAND G., ARTHUIS R., PHILIBERT S., SELLAMI F., SICARD S., avec la collaboration de FORRÉ P., LANOË S., NAULEAU J.-F., QUESNEL L., QUERRÉ G. 2009 - Un habitat azilien en Anjou : les Chaloignes à Mozé-sur-Louet (Maine-et-Loire), Gallia-Préhistoire, 51, p. 1-113.

MARCHAND G., BLANCHET S., CHEVALIER G., GALLAIS J.-Y., LE GOFFIC M., NAUDINOT N., YVEN E. 2004 - La fin du Tardiglaciaire sur le Massif armoricain : territoires et cultures matérielles, Paleo, 16, p. 137-170. 
MARGUERIE D. 2000 - Végétation néolithique sous impact anthropique en Morbihan et dans le reste de la Bretagne. In : Cassen S. (Dir.), Eléments d'architecture (Exploration d'un tertre funéraire à Lannec er Gadouer, Erdeven, Morbihan. Constructions et reconstructions dans le Néolithique morbihannais. Propositions pour une lecture symbolique. Chauvigny : APC, Editions chauvinoises, 2000, $815 \mathrm{p}$.

MICHEL S., NAUDINOT N. 2009 - De retour à Guennoc, Revue Archéologique de l'Ouest, 26, p. 23-36.

MONNIER J.-L. 1980 - Le Paléolithique de la Bretagne dans son cadre géologique, Travaux du Laboratoire d'Anthropologie, Rennes.

MOULLEC J-M. 1984 - Rapport de sondage archéologique, abri sous roche de Kerbizien (Huelgoat, 29). Rapport d'opération, SRA Bretagne, Rennes, 6 p., planches.
MOULLEC J-M. 1985 - Rapport de sondage archéologique. Abri sous roche de Kerbizien. Site $n^{\circ}$ 29.02.16.081.002. SRA Bretagne, Rennes, 8p., planches.

NAUDINOT N. 2010 - Dynamiques techno-économiques et de peuplement au Tardiglaciaire dans l'Ouest de la France, Thèse de doctorat de l'Université de Rennes 1, 731 p.

NAUDINOT N. 2013 - La fin du Tardiglaciaire dans le NordOuest de la France, Bulletin de la Société Préhistorique Française, t. 110, 2, p. 233-255.

YESNER D. 1980 - Maritime Hunter-Gatherers: Ecology and Prehistory, Current Anthropology, 21, 6, p. 727-750. 